Florida International University FIU Digital Commons

$11-2-2011$

\title{
The Influence of Body Size on the Ecology of Coastal Fish Predators in The Bahamas
}

Caroline M. Hammerschlag-Peyer

Florida International University, cpeye001@fiu.edu

DOI: $10.25148 /$ etd.FI1 1120608

Follow this and additional works at: https://digitalcommons.fiu.edu/etd

\section{Recommended Citation}

Hammerschlag-Peyer, Caroline M., "The Influence of Body Size on the Ecology of Coastal Fish Predators in The Bahamas" (2011). FIU Electronic Theses and Dissertations. 502.

https://digitalcommons.fiu.edu/etd/502 


\section{FLORIDA INTERNATIONAL UNIVERSITY}

Miami, Florida

THE INFLUENCE OF BODY SIZE ON THE ECOLOGY OF

COASTAL FISH PREDATORS IN THE BAHAMAS

A dissertation submitted in partial fulfillment of the

requirements for the degree of

DOCTOR OF PHILOSOPHY

in

BIOLOGY

by

Caroline M. Hammerschlag-Peyer

2011 
To: Dean Kenneth G. Furton

College of Arts and Sciences

This dissertation, written by Caroline M. Hammerschlag-Peyer, and entitled The Influence of Body Size on the Ecology of Coastal Fish Predators in The Bahamas, having been approved in respect to style and intellectual content, is referred to you for judgment.

We have read this dissertation and recommend that it be approved.

$\begin{array}{r}\hline \text { William T. Anderson } \\ \hline \text { James W. Fourqurean } \\ \hline \text { Michael R. Heithaus } \\ \hline \text { Joseph E. Serafy } \\ \hline \text { Craig A. Layman, Major Professor }\end{array}$

Date of Defense: November 2, 2011

The dissertation of Caroline M. Hammerschlag-Peyer is approved.

\begin{tabular}{r} 
Dean Kenneth G. Furton \\
College of Arts and Sciences \\
\hline Dean Lakshmi N. Reddi \\
University Graduate School
\end{tabular}

Florida International University, 2011 


\section{ACKNOWLEDGMENTS}

The work presented in this dissertation could not have been accomplished without the help, time, and support of numerous individuals.

I first would like to thank my advisor, Dr. Craig Layman, for taking me on as his first graduate student, and for his continuous guidance, assistance and mentorship. Never in my life have I met somebody so committed to his work and graduate students, as Craig. While I have heard many students complaining about their advisors taking too long to get back to them with their comments on their work, I received my comments mostly within one day, and have felt extremely fortunate about it.

I also thank my committee members, Dr. Bill Anderson, Dr. Jim Fourqurean, Dr. Mike Heithaus and Dr. Joe Serafy for their time, help, effort and support throughout my graduate studies. All of them provided valuable expertise and advice to my dissertation research. I would also like to take this opportunity to specially thank Dr. Joe Serafy. If he would have not become my advisor for my diploma research project in 2005, my career path and life might have taken a completely different turn.

My dissertation research required many hours collecting data in the field on Abaco, The Bahamas, and many more hours sorting through the samples in the lab. I could have not done all this work without the help of many people, especially Megan Seese, Suzanne Hurley, Carlos Villegas, Jenny Peterson, Patricia Gonzales, Sean Giery, Lauren Yeager, Elizabeth Stoner, Olivia Patterson, Samantha Whitcraft, Greg Mineau, Kevin Bernhardt, Megan Ioli, Jake Allgeier, Amelia Mercado, and Angel Yoc-Kim. For logistical support on Abaco, Bahamas, I thank Kaye Rennirt and Friends of the Environment. I also highly appreciate all the help I received with data analysis and 
editing, especially from Dr. Marcio Araujo, Dr. Joel Trexler, Lauren Yeager, Sean Giery, Jeremy Vaudo, Zack Jud, Elizabeth Stoner, Phil Matich, and Dr. Neil Hammerschlag. Funding was provided by Dissertation Year Fellowship, Biscayne Bay Research Scholarship, Judith Evans Parker Travel Scholarship to C. Hammerschlag-Peyer, as well as National Science Foundation grants OCE \#0746164 and DEB \# 0842196 to C. Layman. Permission to use Chapter II was provided by Inter-Research.

Sampling of my study species was conducted with the required authorization from the review boards of the Brazilian Institute of Environment and Renewable Natural Resources (IBAMA; Permit Numbers: 0121586BR, 0123253BR), the Bahamas Department of Marine Resources and the FIU Institutional Animal Care and Use Committee (IACUC; Permit Numbers: 09-009, 08-008).

I also would like to take this opportunity to thank my friends for their continuous support and encouragement during the course of this journey. A group of strong South Florida-bound ladies made my life easier especially during my graduate studies, namely Elizabeth Stoner, Lauren Yeager, Megan Seese and Roxaneh Khorsand Rosa. Thanks for all the great lunches, beach walks/runs, ladies nights, yoga/water 'robic sessions and gettogethers. Furthermore, my two best friends from home, Eveline Wicki and Charlotte Bütler, thank you both so very much for always being there and supporting me when I needed you. Despite the long distance between us, you both are the best friends one can hope for.

I am deeply indebted to my wonderful family. Thank you, Mark and Corinne, for all your continued support, encouragement and love. I am truly fortunate to be part of your family. I also owe many thanks to my fantastic brothers, Rolf, Robert and Urban, for 
supporting and motivating me, as well as putting my life into perspective, over and over again. You all are the best brothers I could ever have asked for. No words can express my gratitude and appreciation to my beautiful mam. She taught me to work hard and realize my dreams. I would have not gotten this far in my life if not for her amazing inspiration, motivation, encouragement and love. Last, but certainly not least, I would like to thank my wonderful husband and best friend Neil for inspiring, supporting, helping and motivating me from the first moment we've met. You kept me sane and I could have not done this journey without you. 


\section{ABSTRACT OF THE DISSERTATION \\ INFLUENCE OF BODY SIZE ON THE ECOLOGY OF COASTAL FISH \\ PREDATORS IN THE BAHMAS}

by

Caroline M. Hammerschlag-Peyer

Florida International University, 2011

Miami, Florida

\section{Professor Craig A. Layman, Major Professor}

Body size is a fundamental structural characteristic of organisms, determining critical life history and physiological traits, and influencing population dynamics, community structure, and ecosystem function. For my dissertation, I focused on effects of body size on habitat use and diet of important coastal fish predators, as well as their influence on faunal communities in Bahamian wetlands. First, using acoustic telemetry and stable isotope analysis, I identified high variability in movement patterns and habitat use among individuals within a gray snapper (Lutjanus griseus) and schoolmaster snapper (L. apodus) population. This intrapopulation variation was not explained by body size, but by individual behavior in habitat use. Isotope values differed between individuals that moved further distances and individuals that stayed close to their home sites, suggesting movement differences were related to specific patterns of foraging behavior. Subsequently, while investigating diet of schoolmaster snapper over a two-year period using stomach content and stable isotope analyses, I also found intrapopulation diet variation, mostly explained by differences in size class, individual behavior and temporal variability. I then developed a hypothesis-testing framework examining 
intrapopulation niche variation between size classes using stable isotopes. This framework can serve as baseline to categorize taxonomic or functional groupings into specific niche shift scenarios, as well as to help elucidate underlying mechanisms causing niche shifts in certain size classes. Finally, I examined the effect of different-sized fish predators on epifaunal community structure in shallow seagrass beds using exclusion experiments at two spatial scales. Overall, I found that predator effects were rather weak, with predator size and spatial scale having no impact on the community. Yet, I also found some evidence of strong interactions on particular common snapper prey. As Bahamian wetlands are increasingly threatened by human activities (e.g., overexploitation, habitat degradation), an enhanced knowledge of the ecology of organisms inhabiting these systems is crucial for developing appropriate conservation and management strategies. My dissertation research contributed to this effort by providing critical information about the resource use of important Bahamian fish predators, as well as their effect on faunal seagrass communities. 


\section{TABLE OF CONTENTS}

CHAPTER

PAGE

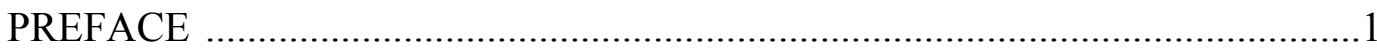

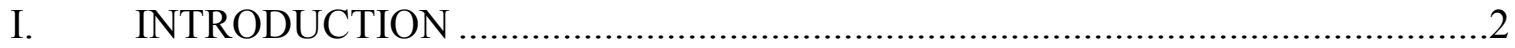

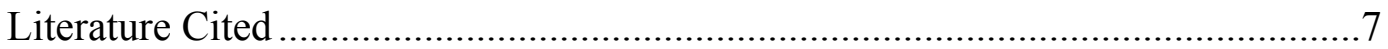

II. INTRAPOPULATION VARIATION IN HABITAT USE

BY TWO ABUNDANT COASTAL FISH SPECIES..........................................10

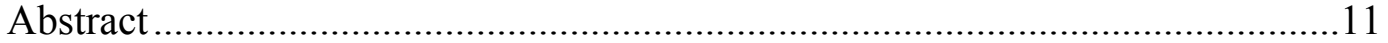

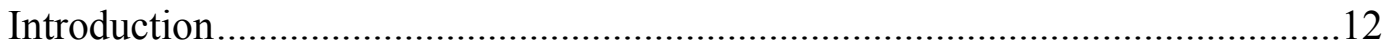

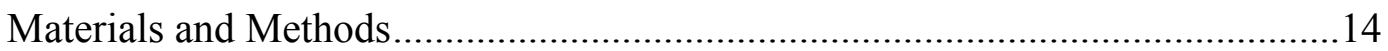

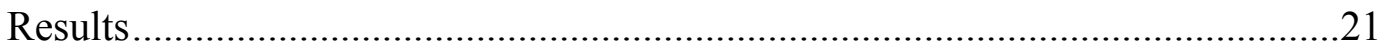

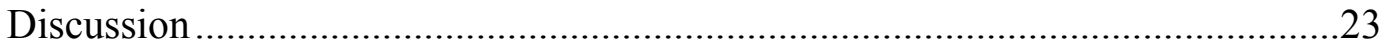

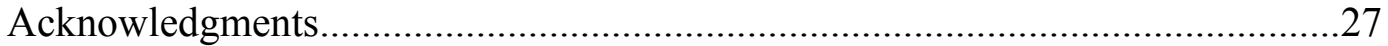

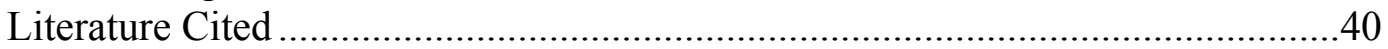

III. FACTORS AFFECTING RESOURCE USE VARIATION

FOR AN ABUNDANT COASTAL FISH PREDATOR, LUTJANUS APODUS, IN A BAHAMIAN WETLAND SYSTEM .....................48

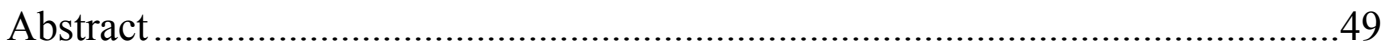

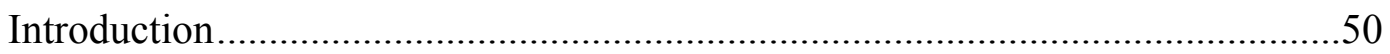

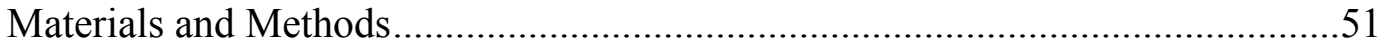

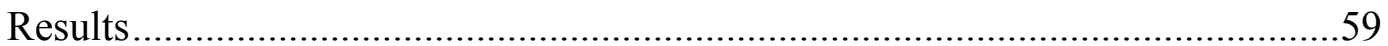

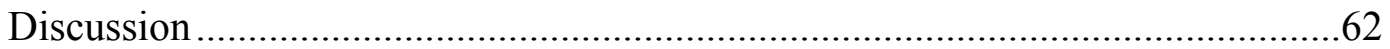

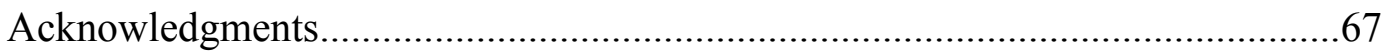

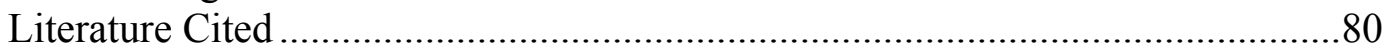

IV. A HYPOTHESIS-TESTING FRAMEWORK FOR STUDIES

INVESTIGATING ONTOGENETIC NICHE SHIFTS USING

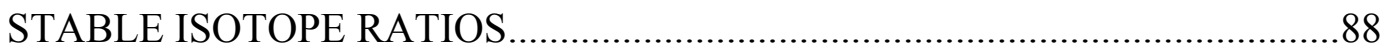

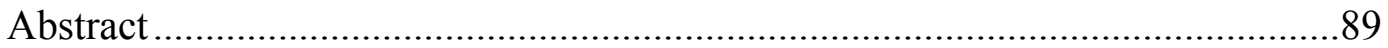

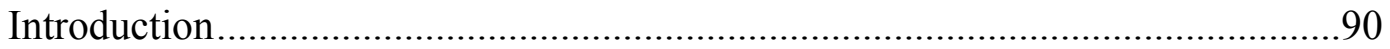

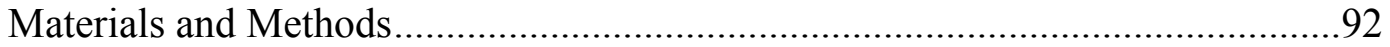

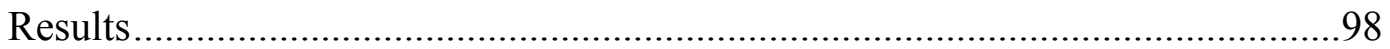

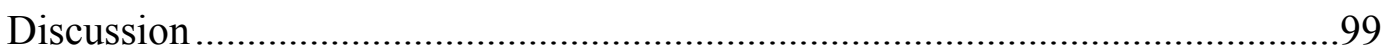

Acknowledgments....................................................................................103

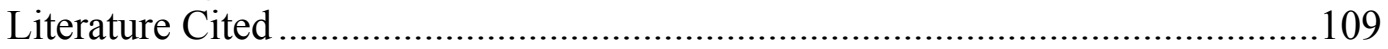

V. PREDATOR EFFECTS ON FAUNAL COMMUNITY COMPOSITION

IN SHALLOW SEAGRASS BEDS OF THE BAHAMAS ….............................114

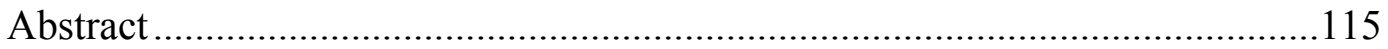

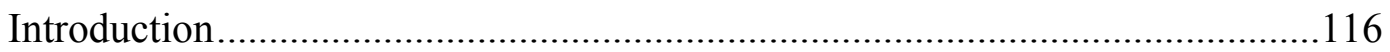




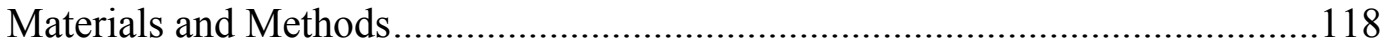

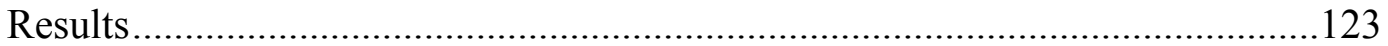

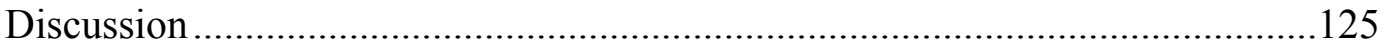

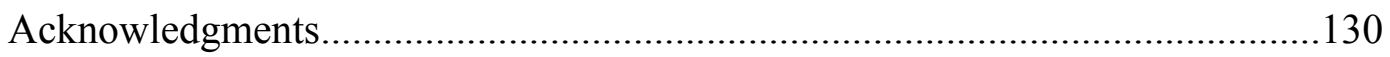

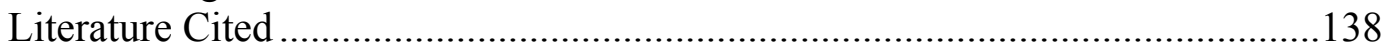

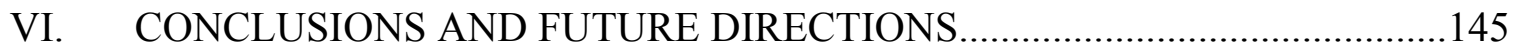

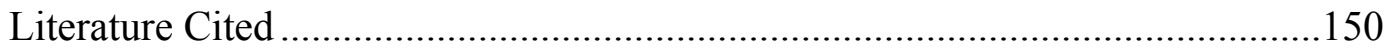

VITA 


\section{LIST OF TABLES}

TABLE

PAGE

\section{CHAPTER II}

2.1 Characteristics of 20 gray snapper (GS) and 20 schoolmaster snapper (SM) implanted with acoustic tags in April 2009. Individuals that were tagged at the south-west margin (SW mar) were not included in the analysis since these individuals had $<10$ observation points (see text for details). Number of detections from mobile receiver (MR) and stationary receiver (SR) and number of total distance moved per tidal cycle (D) are included (see text for details)

2.2 Influence of body size on habitat use measures for Lutjanus griseus (gray snapper) and L. apodus (schoolmaster snapper), based on linear regressions........31

2.3 Total number of days that Lutjanus griseus (gray snapper) and L. apodus (schoolmaster snapper) moved outside the home sites and the proportion of trips that each individual visited the different creek zones

\section{CHAPTER III}

3.1 Sample size of stable isotope analysis of fin tissue of individual schoolmaster snapper (Lutjanus apodus)

3.2 Results of stepwise one-way ANOVA on $\delta^{13} \mathrm{C}$. Bold $P$-values indicate statistically significant findings $(P<0.05)$. For each test, $\mathrm{df}=1$

3.3 Results of stepwise one-way Kruskal-Wallis analysis on $\delta^{15} \mathrm{~N}$. Bold $P$-values indicate statistically significant findings $(P<0.05)$. For each test, $\mathrm{df}=1 \ldots \ldots \ldots \ldots . . .70$

3.4 Sample size of gut contents in schoolmaster snapper (Lutjanus apodus).............71

3.5 Results of stepwise one-way $\chi^{2}$ analysis on gut content data. Bold $P$-values indicate statistically significant findings $(P<0.05)$. For each test, $\mathrm{df}=6$ .72

3.6 $\delta^{13} \mathrm{C}$ values, $\delta^{15} \mathrm{~N}$ values and sample size (n) for prey items used in the individual specialization model

\section{CHAPTER V}

5.1 Taxa that contributed $\geq 3 \%$ to the overall biomass and density were included in the community analysis (relative biomass and density for the small-scale 
and medium-scale exclusion experiment). Taxa are organized in

phylogenetic order

5.2 Results of analysis of variance (ANOVA) for the small- and medium-scale exclusion experiment. Treatments consisted of small- and large-predator exclusion, manipulated and unmanipulated control, and in each experiment, four blocks were used. Bold $P$-values indicate statistically significant findings $(P<0.05)$, and italic $P$-values represent marginally significant results $(0.05<P \leq 0.1)$ 


\section{LIST OF FIGURES}

FIGURE

PAGE

\section{CHAPTER II}

2.1 Broad Creek system coded by land/seascape type. $(\Delta, \square)$ Furthest distance away from home sites by gray snapper, Lutjanus griseus and schoolmaster snapper, $L$. apodus, respectively, during the study period. Size of triangles and squares reflects size of the fish (small: 110-150 mm standard length (SL), medium: 151$200 \mathrm{~mm}$ SL, big: > $200 \mathrm{~mm}$ SL). The open star represents home site A (HS A) and the closed home site B (HS B). Panels on the left are maps of The Bahamas (top left) and Abaco Island (bottom left) with the rectangle representing the location of Broad Creek.

2.2 Proportion of habitat types in each zone. HS: home site; SG: seagrass; Silt: mangrove-derived, rich sediment.

2.3 Lutjanus griseus (left panels) and L. apodus (right panels). Frequency histograms of: 1) mean distance moved (average of daily movement distances, April $26-$ May 24 2009) (A-B); 2) maximum distance moved (C-D); 3) furthest distance away from home sites (HS; E-F); 4) activity space based on minimum convex polygon (MCP) estimates $(\mathrm{G}-\mathrm{H})$

2.4 Examples of the activity space for 5 individuals (gray snapper: A-C; schoolmaster snapper: D and E) in the study area (dark gray: land, light gray: aquatic habitat) from April 26 to May 24 2009. The black frame in A corresponds to the area represented in the smaller maps $(\mathrm{C}-\mathrm{E})$

2.5 Linear regression between $\delta^{13} \mathrm{C}$ and activity space (minimum convex polygon, MCP) for A) gray snapper and B) schoolmaster snapper. (•) Data for an individual snapper, while each triangle represents a mean $\delta^{13} \mathrm{C}$ value for an individual taxa known to be snapper prey (error bars: SD). The $\delta^{13} \mathrm{C}$ values of prey items vary between creek mouth $(\boldsymbol{\Lambda})$ and upstream $(\Delta)$ areas. PDB: PeeDee belemnite, global standard of $\delta^{13} \mathrm{C}$. The $\delta^{13} \mathrm{C}$ values of prey items were corrected for trophic discrimination $(1 \%$, according to Post 2002).....

\section{CHAPTER III}

3.1 Significant linear regression between body size (i.e., standard length) and A) $\delta^{13} \mathrm{C}$ $\left(\mathrm{R}^{2}=0.16, P<0.0001, \mathrm{n}=150\right)$ and $\left.\mathrm{B}\right) \delta^{15} \mathrm{~N}$ values. In panel $\mathrm{B}$, open circles represent $\delta^{15} \mathrm{~N}$ of individual schoolmaster snapper for 2007-08 $\left(\mathrm{R}^{2}=0.22, P<\right.$ $0.0001, \mathrm{n}=90$; dashed trendline), and closed circles indicate snapper in the year 2008-09 $\left(\mathrm{R}^{2}=0.32, P<0.0001, \mathrm{n}=60\right.$; solid trendline). PDB (PeeDee 
belemnite) and AIR (atmospheric nitrogen) are the global standards of $\delta^{13} \mathrm{C}$ and $\delta^{15} \mathrm{~N}$, respectively

3.2 Niche width (estimated using minimum convex polygon, MCP) of juveniles (white) and sub-adults (gray) of schoolmaster snapper Lutjanus apodus represented in a $\delta^{13} \mathrm{C}-\delta^{15} \mathrm{~N}$ niche space. Triangles represent isotope data of individual juveniles and circles individual sub-adults. A) includes all individuals from both sampling years, B) from 2007-08, and C) from 2008-09. The $\delta^{13} \mathrm{C}$ ranges of primary producers are represented by gray bars below the $\mathrm{x}$-axis in Panel $\mathrm{C}$ and are based on stable isotope data from Bahamian primary producers in similar study systems (Kieckbusch et al. 2004). PDB (PeeDee belemnite) and AIR (atmospheric nitrogen) are the global standards of $\delta^{13} \mathrm{C}$ and $\delta^{15} \mathrm{~N}$, respectively

3.3 Percent of diet by volume in individual stomachs of A) all schoolmaster snapper (pooled across years), B) schoolmaster snapper in 2007-08, and C) in 2008-09. White bars represent stomach contents of juveniles and gray bars of sub-adults. Panopeus and Aratus are a crab genera, Xanthidoidae a crab superfamily, while Alpheus, Palaemonetes and Farfantepenaeus are shrimp genera

3.4 Stable isotope data of prey taxa (mean value; gray squares), as well as individual juvenile (triangles) and sub-adult (circles) schoolmaster snapper sampled during the sampling year of 2007-08 (white symbols) and of 2008-09 (black symbols) represented in a $\delta^{13} \mathrm{C}-\delta^{15} \mathrm{~N}$ niche space. For the teleost group, I used frillfin goby $(\mathrm{n}=8)$, crested goby $(\mathrm{n}=3)$, banded goby $(\mathrm{n}=1)$, and rosy blenny $(\mathrm{n}=1)$. Error bars represent standard deviation of prey taxa stable isotope values. The $\delta^{13} \mathrm{C}$ ranges of primary producers are represented by gray bars below the $\mathrm{x}$-axis are based on stable isotope data from Bahamian primary producers (Kieckbusch et al. 2004). PDB (PeeDee belemnite) and AIR (atmospheric nitrogen) are the global standards of $\delta^{13} \mathrm{C}$ and $\delta^{15} \mathrm{~N}$, respectively

\section{CHAPTER IV}

4.1 Representation of three possible ontogenetic niche shift scenarios using stable isotope ratios. Horizontally adjacent panels represent the same ontogenetic niche shift scenario. (A-C) Multivariate illustration of potential differences in niche width (represented by convex hull polygons), niche position and niche overlap (see text for more details) between two size groups in $\delta^{13} \mathrm{C}-\delta^{15} \mathrm{~N}$ niche space. (D-F) Univariate representation of niche width (variance of isotope values) and niche position (mean isotopic value) of either $\delta^{13} \mathrm{C}$ or $\delta^{15} \mathrm{~N}$ between size groups. Closed circles represent isotope data of small individuals and open circles of large individuals. Solid line $=$ constant niche width, dotted line $=$ niche reduction, dashed line $=$ niche expansion; $\mathrm{S}=$ small size group, $\mathrm{L}=$ large size group. In panel $\mathrm{F}$, solid line = constant variance, dotted line $=$ reduced variance, dashed line $=$ increased variance 
4.2 Flow chart of the hypothesis-testing framework. Niche aspects (i.e., niche width, niche position, and niche overlap) are shown in rectangles, test types in diamonds, and possible test results in circles; n.s. = non-significant. The three possible scenarios are represented in ovals, with "No Niche Shift" = first scenario, "Niche Expansion" = second scenario, and "Discrete Niche Shift" = third scenario. Low = low niche overlap for both size groups; High/Low $=$ asymmetric niche overlap between two size groups .

4.3 Isotopic niche use of two ontogenetically distinct groups. Differences in niche width (for illustration purposes represented by convex hull polygons) of a small (solid line) and large (dashed line) size group of A) Eupemphix nattereri, B) Lutjanus griseus, and C) Atherinomorus stipes represented in a $\delta^{13} \mathrm{C}-\delta^{15} \mathrm{~N}$ niche space. Closed circles represent isotope data of individual juveniles and open circles individual adults (or sub-adults in case of L. griseus). PDB (PeeDee belemnite) and AIR (atmospheric nitrogen) are the global standards of $\delta^{13} \mathrm{C}$ and $\delta^{15} \mathrm{~N}$, respectively

\section{CHAPTER V}

5.1 Size-frequency distribution of A) schoolmaster snapper (Lutjanus apodus) and B) gray snapper (L. griseus) observed in the four different treatments: $\mathrm{SPE}=$ small-predator exclusion, $\mathrm{LPE}=$ large-predator exclusion, $\mathrm{MC}=$ manipulated control, and $\mathrm{UC}=$ unmanipulated control. Bins included $2 \mathrm{~cm}$ total length (TL) starting at $3 \mathrm{~cm}$ TL

5.2 Species Richness (A and D), Total Biomass (B and E), and Total Density (C and F) of the small-scale (A-C) and medium-scale (D-F) experiments. LPE = largepredator exclusion, $\mathrm{SPE}=$ small-predator exclusion, $\mathrm{MC}=$ manipulated control, $\mathrm{UC}=$ unmanipulated control (see text for more details). Error bars represent standard error. Standard error for total biomass (small-scale exclusion) was low in the unmanipulated control and thus not visible in panel B. $(a, b)$ indicate statistically significant $(\mathrm{P}<0.05)$ differences between treatments (on the basis of Least Significant Difference comparisons) and are not present for Total Density $(\mathrm{C}$ and $\mathrm{F})$ because all pairwise comparisons were $\mathrm{P} \geq 0.05$

5.3 Total Biomass of A) Panopeus sp. (mud crab), B) Pitho sp. (urn crab), C)

Panopeus sp. and D) Portunidae (family of swimming crabs) in the small-scale $(\mathrm{A}-\mathrm{B})$ and medium-scale $(\mathrm{C}-\mathrm{D})$ exclusion. $\mathrm{LPE}=$ large-predator exclusion, $\mathrm{SPE}=$ small-predator exclusion, $\mathrm{MC}=$ manipulated control, $\mathrm{UC}=$ unmanipulated control (see text for more details). Error bars represent standard error. Standard error of Pitho sp. (small-scale exclusion) was low in the large-predator exclusion and thus not visible in panel B. $(\mathrm{a}, \mathrm{b})$ indicate statistically significant $(\mathrm{P}<0.05)$ differences between treatments (on the basis of Least Significant Difference comparisons), and are not present for Portunidae 
(D) because all pairwise comparisons were $\mathrm{P} \geq 0.05$ (i.e., SPE-LPE:

$\mathrm{P}=0.08$, SPE-MC: $\mathrm{P}=0.06$, SPE-UC: $\mathrm{P}=0.06)$

5.4 Linear regression between total density and sponge biomass in the A) small-scale and B) medium-scale exclusion experiment. Block $1=$ squares, block $2=$ triangles, block $3=$ diamonds, block $4=$ circles. Linear regression across the four blocks result in a $\mathrm{R}^{2}=0.09$ and $P=0.25$ in the small-scale exclusion (A), and $\mathrm{R}^{2}=0.09$ and $P=0.008$ in the medium-scale exclusion (B). Dashed regression line represents non-significant trend $(P>0.05)$, and solid line statistically significant relationship $(P<0.05)$ 


\section{PREFACE}

The following chapters have been published.

\section{CHAPTER II}

Hammerschlag-Peyer CM, Layman, CA (2010) Intrapopulation variation in habitat use by two abundant coastal fish species. Marine Ecology Progress Series 415: 211-220, doi: 10.3354/meps08714 www.int-res.com/abstracts/meps/v415/p211-220/

\section{CHAPTER IV}

Hammerschlag-Peyer CM, Yeager LA, Araújo MS, Layman, CA (2011) A hypothesis-testing framework for studies investigating ontogenetic niche shifts using stable isotope ratios. PLoS ONE 6(11): e27104, doi:10.1371/journal.pone.0027104 www.plosone.org/article/info\%3Adoi\%2F10.1371\%2Fjournal.pone.0027104 


\section{CHAPTER I}

INTRODUCTION 
In his classic book, Elton (1927) proposed that body size has a fundamental effect on the organization of animal communities. His observation has been widely supported, with body size emerging as a primary structuring mechanism within and across many levels of biological organization (Peters 1983, Kerr \& Dickie 2001, Brown et al. 2004, Yvon-Durocher et al. 2011). At the individual level, for instance, body size determines many key life history processes and physiological characteristics, such as growth rate, metabolic rate, consumption rate, predation risk, energetic requirements and resource utilization ability (Peters 1983, Werner \& Gilliam 1984, Persson 1988, Brown et al. 2004). Likewise, body size also mediates the occurrence and consequences of the interactions among organisms (Brooks \& Dodson 1965, Rudolf 2006), and thus affects population density (Blackburn et al. 1993, Dalerum \& Angerbjorn 2005), species distributions (Brown et al. 1993, Greenwood et al. 1996), secondary production (Jennings et al. 2002), food web structure and dynamics (Cohen et al. 2003, Akin \& Winemiller 2008), and structure and function of communities and ecosystems (Marquet et al. 1990, Hildrew et al. 2007).

Ecological studies that examine how body size affects resource use have focused on variation among species and the resulting implications (Blackburn et al. 1996, Robertson 1998, Cromsigt \& Olff 2006, Bumrungsri et al. 2007, Langkilde \& Shine 2007, Storms et al. 2008). Yet, effects of body size on resource use variation within species can also influence important aspects of population dynamics and community structure (Werner \& Gilliam 1984). For instance, populations with large body size ranges are often characterized by strong ontogenetic shifts in resource use, leading to distinct functional size classes within a population that, for instance, can cause interactions with 
other species to shift between competition and predation (Wilbur 1988, Jennings et al. 2001, Woodward \& Hildrew 2002, De Roos et al. 2003, Rudolf 2006).

As resource use can change during ontogeny, driving differences in resource use among ontogenetic stages (i.e., size or age classes), variation in resource use among individuals can also exist within a single ontogenetic stage (Bolnick et al. 2003, Araujo et al. 2011). Changing resource use within an ontogenetic stage has been called "individual specialization" and specifically is defined as the feeding behavior of an individual that causes its dietary niche to be significantly smaller than the population niche for reasons not attributable to its sex, body size, or age classes (Bolnick et al. 2003). Individual specialization has been identified in a number of diverse taxa (Ringler 1983, Magurran 1986, Schindler et al. 1997, Bolnick et al. 2003, Araujo et al. 2011), and can have important evolutionary, ecological and conservation implications (Bolnick et al. 2003).

The primary focus of my dissertation is to examine how resource use (i.e., diet and habitat use) can change during ontogeny within a predator population, as well as to investigate how resource variation among individuals may differ within size classes. In addition, my dissertation research examines the community level effects of predator body size variation, by exploring how different-sized predators can affect faunal community structure in seagrass beds. The central organizing principle of my dissertation research is the role of body size in driving ecological variation within shallow Bahamian coastal ecosystems, using abundant meso-predators as model organisms. The outline of my dissertation is as follows:

Chapter II examines whether movement patterns and habitat use of two abundant coastal predators (schoolmaster snapper, Lutjanus apodus, and gray snapper, L. griseus) 
change with body size, and if there is evidence of specialization in habitat use among conspecifics in a Bahamian wetland system. To do so, I used acoustic telemetry and stable isotope analysis. With this chapter, I attempt to provide a framework for future research to examine the variation in habitat use within marine populations, as well as to recognize its ecological importance. This study has been published in Marine Ecology Progress Series.

Chapter III focuses on how diet varies within and between size classes of schoolmaster snapper (L.apodus) in a Bahamian wetland system, as well as examines whether sampling period (i.e., year and season) influences their feeding behavior. I employ stable isotope ratios, direct diet information and simulation modeling as suite of complementary tools to examine underlying resource use variation. The findings of this research may add evidence that marine populations do not use their resources homogeneously, contrary to what is often tacitly assumed.

In Chapter IV, I generate a hypothesis-testing framework to examine ontogenetic niche shifts using stable isotope analysis. The majority of research that has applied stable isotope ratios to examine ontogenetic niche shifts used qualitative methods, or quantitative approaches that analyzed isotope elements separately. Yet, multivariate analyses are useful in depicting the characteristics of dietary changes through ontogeny because they can offer an enhanced understanding of shifts in niche width, niche position and niche overlap, which are critical factors in examining changes in resource use. Specifically, in this study, I (1) generate specific criteria to identify three main ontogenetic niche shift scenarios, and (2) provide an empirical example for illustration purposes. This study can be a baseline for future studies on ontogenetic niche shifts and 
can also be applied to investigate variation in resource use among other groupings (e.g., sex, phenotype). This study has been published in PLoS ONE.

Chapter V focuses on how different-sized fish predators affect the species composition and structure of seagrass epifauna in a shallow Bahamian system. To do so, I perform a small- and medium-scale exclusion experiment, utilizing mesh sizes that exclude different-sized predator individuals. This study is one of the first to investigate predator effects in subtidal seagrass systems when predator access is restricted to relatively small time windows during the daily tidal cycle.

Overall, each chapter of this dissertation concentrates on a different aspect related to body size in coastal fish predators. My dissertation provides valuable information on intrapopulation variation in diet and habitat use driven by differences in body size and/or individual feeding behavior, as well as offers a better understanding of the effect of different-sized fish predators on their faunal communities in important seagrass systems. Generally, my findings suggest the importance of incorporating resource variation based on differences in body size and individual behavior into the study of coastal fish populations, since this kind of variation is typically overlooked in traditional conservation and management strategies. 


\section{LITERATURE CITED}

Akin S, Winemiller KO (2008) Body size and trophic position in a temperature estuarine food web. Acta Oecol-Int J Ecol 33:144-153

Araujo MS, Bolnick DI, Layman CA (2011) The ecological causes of individual specialization. Ecol Lett 14:948-958

Blackburn TM, Brown VK, Doube BM, Greenwood JJD, Lawton JH, Stork NE (1993) The relationship between abundance and body-size in natural animal assemblages. J Anim Ecol 62:519-528

Blackburn TM, Lawton JH, Gregory RD (1996) Relationships between abundances and life histories of British birds. J Anim Ecol 65:52-62

Bolnick DI, Svanback R, Fordyce JA, Yang LH, Davis JM, Hulsey CD, Forister ML (2003) The ecology of individuals: Incidence and implications of individual specialization. Am Nat 161:1-28

Brooks JL, Dodson SI (1965) Predation body size and composition of plankton. Science $150: 28-35$

Brown JH, Gillooly JF, Allen AP, Savage VM, West GB (2004) Toward a metabolic theory of ecology. Ecology 85:1771-1789

Brown JH, Marquet PA, Taper ML (1993) Evolution of body size - Consequences of an energetic definition of fitness. Am Nat 142:573-584

Bumrungsri S, Leelapaibul W, Racey PA (2007) Resource partitioning in sympatric Cynopterus bats in lowland tropical rain forest, Thailand. Biotropica 39:241-248

Cohen JE, Jonsson T, Carpenter SR (2003) Ecological community description using the food web, species abundance, and body size. Proc Natl Acad Sci U S A 100:17811786

Cromsigt J, Olff H (2006) Resource partitioning among savanna grazers mediated by local heterogeneity: An experimental approach. Ecology 87:1532-1541

Dalerum F, Angerbjorn A (2005) Resolving temporal variation in vertebrate diets using naturally occurring stable isotopes. Oecologia 144:647-658 
De Roos AM, Persson L, McCauley E (2003) The influence of size-dependent lifehistory traits on the structure and dynamics of populations and communities. Ecol Lett 6:473-487

Elton CS (1927) Animal Ecology, Vol. Sidgewick and Jackson, London

Greenwood JJD, Gregory RD, Harris S, Morris PA, Yalden DW (1996) Relations between abundance, body size and species number in British birds and mammals. Philos Trans R Soc Lond B 351:265-278

Hildrew AG, Raffaeli DG, Edmonds-Brown R (2007) Body Size: The structure and function of aquatic ecosystems, Vol. Cambridge University Press, Cambridge

Jennings S, Greenstreet SPR, Hill L, Piet GJ, Pinnegar JK, Warr KJ (2002) Long-term trends in the trophic structure of the North Sea fish community: evidence from stable-isotope analysis, size-spectra and community metrics. Mar Biol 141:10851097

Jennings S, Pinnegar JK, Polunin NVC, Boon TW (2001) Weak cross-species relationships between body size and trophic level belie powerful size-based trophic structuring in fish communities. J Anim Ecol 70:934-944

Kerr SR, Dickie LM (2001) The biomass spectrum: a predator-prey theory of aquatic production, Vol. Columbia University Press

Langkilde T, Shine R (2007) Interspecific conflict in lizards: Social dominance depends upon an individual's species not its body size. Austral Ecol 32:869-877

Magurran AE (1986) Individual differences in fish behaviour. In: Pitcher TJ (ed) The behaviour of teleost fishes. Croom Helm, London

Marquet PA, Navarrete SA, Castilla JC (1990) Scaling population-density to body size in rocky intertidal communities. Science 250:1125-1127

Persson L (1988) Asymmetries in competitive and predatory interactions in fish populations. In: Ebenman B, Persson L (eds) Size-structured populations: ecology and evolution. Springer-Verlag, Berlin, Germany

Peters RH (1983) The ecological implications of body size, Vol. Cambridge University Press, Cambridge 
Ringler NH (1983) Variation in foraging tactics in fishes. In: Noakes DLG, Lindquist DG, Helfman GS, Ward JA (eds) Predation and Prey in Fishes. Junk, The Hague

Robertson DR (1998) Implications of body size for interspecific interactions and assemblage organization among coral-reef fishes. Aust J Ecol 23:252-257

Rudolf VHW (2006) The influence of size-specific indirect interactions in predator-prey systems. Ecology 87:362-371

Schindler DE, Hodgson JR, Kitchell JF (1997) Density-dependent changes in individual foraging specialization of largemouth bass. Oecologia 110:592-600

Storms D, Aubry P, Hamann JL, Said S, Fritz H, Saint-Andrieux C, Klein F (2008) Seasonal variation in diet composition and similarity of sympatric red deer Cervus elaphus and roe deer Capreolus capreolus. Wildl Biol 14:237-250

Werner EE, Gilliam JF (1984) The ontogenetic niche and species interactions in size structured populations. Annu Rev Ecol Syst 15:393-425

Wilbur HM (1988) Interactions between growing predators and growing prey. In: Ebenman B, Persson L (eds) Size-structured populations. Springer, Berlin

Woodward G, Hildrew AG (2002) Body-size determinants of niche overlap and intraguild predation within a complex food web. J Anim Ecol 71:1063-1074

Yvon-Durocher G, Reiss J, Blanchard J, Ebenman B, Perkins DM, Reuman DC, Thierry A, Woodward G, Petchey OL (2011) Across ecosystem comparisons of size structure: methods, approaches and prospects. Oikos 120:550-563 
CHAPTER II

INTRAPOPULATION VARIATION IN HABITAT USE BY TWO ABUNDANT COASTAL FISH SPECIES 


\begin{abstract}
Decline of marine fisheries has become one of the most severe global environmental crises. In typical fishery management efforts, fish populations are often treated as homogeneous units, thereby tacitly ignoring potential intrapopulation variation within taxonomic groupings. I used acoustic telemetry and stable isotope analysis to examine movement patterns of 20 gray snapper (Lutjanus griseus) and 20 schoolmaster snapper (L.apodus) in a Bahamian tidal creek and wetland. In particular, I examined 1) if intrapopulation variation existed in fish habitat use and movement patterns, 2) whether that variation was a function of body size, and 3) if there was evidence of specialization in habitat use among individuals. I found that movement varied substantially among individuals, but was independent of body size. Some individuals exhibited frequent, repeated, movements to certain areas of the study site. The $\delta^{13} \mathrm{C}$ values of individual snapper were significantly related to movement metrics, suggesting that movement differences were related to specific patterns of foraging behavior. My findings suggest the importance of incorporating intrapopulation niche variation into the study of coastal fish populations, a source of variation that is often overlooked in traditional conservation and management strategies.
\end{abstract}




\section{Introduction}

Overexploitation of marine fishes is considered one of the most critical global environmental crises (Jackson et al. 2001, Worm et al. 2006). Stocks of economically and ecologically important species have been drastically reduced through commercial and recreational fisheries (Coleman et al. 2004, Lotze \& Worm 2009). Although large pelagic predators are especially susceptible to declines (Pauly et al. 1998, Heithaus et al. 2008), populations of coastal mesopredators such as groupers (Serranidae) and snappers (Lutjanidae) are also threatened by overexploitation (Willis et al. 2001, Nieland et al. 2007, Graham et al. 2008). For example, populations of Nassau Grouper, Epinephelus striatus, have declined by up to $60 \%$ over the last three decades and the species has been added to the IUCN Red List (Baillie \& Groombridge 1996, Sadovy 1997).

To provide a template for developing conservation and management strategies, scientists usually seek to identify broad generalities that define the "typical" individual of a particular population. Individuals are assumed to possess generally the same behavioral or feeding traits during certain life stages or size classes, and thus a population is treated as a homogeneous unit from a management perspective. One well-known example are juvenile grunts (Haemulidae) in Teague Bay, U.S. Virgin Islands, which rest over coral heads during the day and move to seagrass beds at night as a group (Meyer et al. 1983). Similarly, gray snapper, Lutjanus griseus, in Biscayne Bay, Florida have been observed to move in groups from mangroves during the day to seagrass beds at night (Luo et al. 2009). With respect to ontogeny, individuals of many reef fishes are assumed to go through predictable sequences of habitat utilization (Nagelkerken et al. 2000). For instance, larval French grunts, Haemulon flavolineatum, in Piscadera Bay, Curaçao settle 
in sand/rubble habitat at the mouth of bays, move further into the bay to utilize mangroves and seagrass beds as juveniles, and then shift to coral reefs as adults (Huijbers et al. 2008).

Despite the common perspective that individuals of a population are homogeneous units, substantial intrapopulation variation in behavior has been shown to occur across diverse taxonomic groups and may have important evolutionary, ecological and conservation implications (Van Valen 1965, Roughgarden 1972, 1974, Schindler et al. 1997, Bolnick et al. 2003). From a management perspective, focusing only on the core habitats for a population may ignore those individuals that utilize alternative habitats or food sources. Ignoring intrapopulation variation in habitat use can be especially problematic when variation among individuals is a function of body size or age, so that a demographically important subset of the population is not considered (Durell 2000, Bolnick et al. 2003). Recognizing intrapopulation variation in fishery management plans may facilitate preserving species' ecological, phenotypic and genetic diversity (Moritz 1994, Coates 2000, Smith et al. 2001, Bolnick et al. 2003).

The aim of this study was to examine potential variation in habitat use and movement patterns among individuals of two ecologically and economically important nearshore snapper populations. Specifically, I investigated 1) if variation in habitat use and movement patterns occurred among individuals of gray snapper (Lutjanus griseus) and/or schoolmaster snapper (L.apodus), 2) whether that variation was a function of body size (a well-acknowledged mechanism of intrapopulation variation), and 3) if there was evidence of specialization in habitat use for either focal population. I used acoustic telemetry to directly explore the movements of fishes at an individual level, as well as 
stable isotope ratios to provide indirect information as to potential feeding patterns. I endeavored to provide a framework for future research that acknowledges variation in behavioral attributes and foraging within marine populations.

\section{Materials and Methods}

\section{Study System and Species}

Broad Creek $\left(26^{\circ} 29^{\prime} 35^{\prime \prime} \mathrm{N}, 77^{\circ} 02^{\prime} 34^{\prime \prime} \mathrm{W}\right)$ is an estuarine tidal creek located on the east side of Abaco Island, The Bahamas (Fig. 1). Tidal creeks in The Bahamas range in size from several hectares with maximum low tide depths of $1 \mathrm{~m}$, to thousands of hectares with maximum depths $>10$ m (Layman et al. 2007, Rypel et al. 2007, ValentineRose et al. 2007b); Broad Creek falls at the lower end of this range. The system has a semi-diurnal tidal regime and a mean daily tidal amplitude of $\sim 0.8 \mathrm{~m}$. There is little freshwater input to this system and thus it is marine-dominated throughout its extent (Valentine-Rose et al. 2007a).

Broad Creek consists of extensive, shallow, intertidal, flats. These flats primarily are composed of a silt substrate with interspersed mangroves (mainly Rhizophora mangle). The most prevalent benthic habitat types are seagrass beds (primarily Thalassia testudinum), submerged mangrove prop roots (mostly $R$. mangle), hard bottom with soft corals (mostly Gorgonia spp.) and sand. At low tide, water depths $>\sim 0.3 \mathrm{~m}$ are only found in two pools ( $\sim 10 \mathrm{~m}$ in diameter) in the northwest corner of Broad Creek (Fig. 1). The tidal pools are depressions in the karst substrate that stay inundated even at the lowest tides, thereby providing habitat for fishes at all tidal phases (Rypel et al. 2007, Valentine-Rose et al. 2007b). The majority of the creek area ( $>99 \%)$ is $<0.3 \mathrm{~m}$ at low 
tide, depths that are generally too shallow for adult and sub-adult snapper to traverse (Rypel et al. 2007).

Gray snapper, Lutjanus griseus (Linnaeus 1758), and schoolmaster snapper, Lutjanus apodus (Walbaum 1972), are abundant generalist fish predators that coexist in many nearshore ecosystems in the tropics and subtropics of the Atlantic (Starck \& Schroeder 1971, Allen 1985). In Broad Creek, as is common in shallow creeks of The Bahamas, these fishes typically inhabit deeper pools or deep mangrove-lined shorelines, herein referred to as "home sites" (e.g., A and B in Fig. 1). Individual fish may leave these home sites with rising water during flood tides, likely to feed, and they typically return to the home sites as water levels fall with the ebbing tide (Rypel et al. 2007). These repeated daily movements to and from the home sites in Broad Creek provide a unique opportunity to quantitatively evaluate individual level variation in local scale movement patterns.

\section{Tagging and Tracking}

Twenty gray snapper and 20 schoolmaster snapper were caught in home site A and B at low tide between April 20-28 2009 using baited hooks and fish traps. Sizes were representative of those fishes found in these systems (Layman et al. 2007, Luo et al. 2009). Small acoustic transmitters (V7, Vemco Ltd., Nova Scotia, Canada; 19mm x $7 \mathrm{~mm}, 1.6 \mathrm{~g}$ in air, 77-day battery life), which pinged every 15-45 seconds, were surgically implanted into each fish. Each transmitter had a unique code to identify individual fish. Individual fish were anesthetized in a mixture of fresh sea water and clove oil (active ingredient: eugenol), a commonly used fish anesthetic (Sladky et al. 2001, Hiscock et al. 
2002, Parsons et al. 2003, Cotter \& Rodruck 2006), and measured for standard length (SL). The transmitter was inserted into the body cavity through a $10-\mathrm{mm}$ incision made between the pelvic and anal fins following a procedure similar to Nowak and Quinn (2002). The incision was closed with two stitches using a C-curved needle with attached suture. A small sample of the dorsal fin tissue $\left(\sim 1 \mathrm{~cm}^{2}\right)$ was removed from each fish for stable isotope analysis (see below) before the fish was transferred to a cooler with fresh sea water for recovery. After $\sim 1$ hour the fish were released at the capture location. Fin clips were transported on ice to a field station, stored in a freezer and later processed at Florida International University.

To quantify presence/absence patterns at the two home sites, one stationary omnidirectional hydrophone (VR2, Vemco Ltd., Nova Scotia, Canada) was placed at each location. The receivers were secured to cinder blocks and placed on the substrate in the middle of both home sites at $\sim 1.5 \mathrm{~m}$ low tide depth. Since both home sites were surrounded by dense mangroves, detection ranges did not extend beyond the edges of the pools (C. Hammerschlag-Peyer, unpublished data).

To estimate movement outside the home sites, tagged fish were located from an inflatable Zodiac boat using a hand-held receiver and hydrophone (VR100, Vemco Ltd., Nova Scotia, Canada). The hydrophone was situated in the water column about halfway between the substrate and water surface to avoid acoustic disturbances. Once a fish was detected, the coordinates of its position and time of detection was recorded by the manual receiver. Mobile tracking was conducted every day at high tide for an entire lunar cycle, from April 26 to May 24 2009. Because most parts of the creek are largely intertidal (and thus very shallow at low tide with no fish movement) manual tracking was conducted two 
hours before until two hours after high tide. Tracking paths were chosen haphazardly each session.

\section{Data Analysis}

The continuous data from stationary receivers was categorized into "time in" and "time out" of the home site for each individual fish. If an individual was not detected by a stationary receiver for more than $60 \mathrm{~min}$, the fish was considered to have left the tidal pool. For each fish, the home site, date, time in and time out were identified. Tracking with the manual receiver was used to identify the location of fish outside the home sites during each daily high tide. If more than one location fix (outside of the home sites) was obtained for an individual per tidal cycle, I used the fix with the highest detection strength $(\mathrm{dB})$ as an estimate of its most precise location during that given detection period. This procedure eliminated the problem of autocorrelation of successive detections (Van den Avyle \& Evans 1990, Sackett et al. 2007).

To determine mean distance moved, maximum distance moved and furthest distance away from the home sites for each individual, the stationary and mobile tracking data were combined. Euclidean distance between two successive locations (typically between a home site and the strongest detection from the manual receiver) was estimated using ArcMap GIS version 9.3.1 (ESRI 2008). The mean distance moved of an individual was calculated by dividing its total distance moved during the study period by the total number of tidal cycles in which a movement of that individual occurred (e.g., Roth \& Greene 2006, Carfagno \& Weatherhead 2008). The maximum distance moved of an individual was the longest distance it moved during a single tidal cycle. This measure 
usually included a movement from one of the tidal pools to some location in the tidal creek and then back to a tidal pool during the same tidal cycle. The furthest distance away from the home sites was the greatest distance that a fish was ever detected away from the home sites during the study period.

Activity space was defined as the area a fish utilized during daytime tracking for the duration of the entire study period. It was estimated using minimum convex polygon (MCP), i.e., the area of the smallest convex polygon that contains all observed positions of an individual fish (Anderson 1982). The MCP estimations were obtained using Animal Movements extension (Hooge \& Eichenlaub 1997) for ArcView GIS version 3.2 (ESRI 1999). Areas of MCP that extended onto land were clipped using ArcMap Geoprocessing tools. The total activity space of each population was calculated by combining movement data for all 20 individuals of each species.

Fin tissues were analyzed for their $\delta^{13} \mathrm{C}$ values as $\delta^{13} \mathrm{C}$ reflects long term diet and thus may be used to indicate foraging areas (Layman 2007). In Bahamas tidal creek systems, prey $\delta^{13} \mathrm{C}$ values vary predictably from upper reaches of creeks systems to creek mouths (C. Layman and C. Hammerschlag-Peyer, unpublished data). Snapper prey are relatively enriched in $\delta^{13} \mathrm{C}$ at the creek mouth relative to prey typically found in the upper reaches of creeks (see Fig 4), and thus $\delta^{13} \mathrm{C}$ values of snapper fin tissue may reflect longterm feeding in particular parts of the creek system. Analysis followed Post et al. (2007) and was conducted at the Yale Earth System Center for Stable Isotopic Studies (ESCSIS). All stable-isotope values are reported in the $\delta$ notation where $\delta^{13} \mathrm{C}=\left[\left(R_{\text {sample }} / R_{\text {standard }}\right)-\right.$ 1] $\mathrm{x} 1000$, and where $R$ is ${ }^{13} \mathrm{C} /{ }^{12} \mathrm{C}$. 


\section{Statistical Analysis}

For some individuals, I had a small number of observations because a fish may have died or left the study area. Linear regression revealed that all of my response measures were not significantly related to sample size when individuals with less than nine observation points were excluded from each analysis ( $p>0.05)$, so each of these individuals was excluded. Additionally, it is also important to note that the number of individuals for a given analysis sometimes differed because of the way the individual observation points were used. For example, while two data points of each fish were used in the analysis of activity space and individual specialization, the same two points resulted in only one distance estimate for that fish. Hence, 14 gray and 15 schoolmaster snapper were used for the activity space and individual specialization analysis (see below), and nine gray and nine schoolmaster snapper for distance analysis.

Movement distances and activity space were examined as a function of body size using linear regression in SigmaPlot 10.0. When necessary to meet model assumptions, data were $\ln (x+0.5)$ transformed. Frequency histograms of movement distances and activity space were performed in $\mathrm{R}$ version 2.9.2. I examined a potential relationship between activity space and $\delta^{13} \mathrm{C}$ using linear regression.

\section{Individual Specialization}

Recent studies have shown that intrapopulation variation in resource use can exist at a single ontogenetic life history stage (Bolnick et al. 2003). Individual specialization, defined as an individual whose (dietary) niche is significantly smaller than the niche of its population for reasons not attributable to its sex, body size, or discrete morphology, has 
been identified in a number of diverse taxa (Ringler 1983, Magurran 1986, Schindler et al. 1997, Bolnick et al. 2003). One way to infer the occurrence of individual specialists in a population is by examining components of niche variation following Roughgarden $(1972,1974,1979)$. In this approach, the population's total niche width (TNW) in terms of resource use is subdivided into a within-individual component (WIC) and a betweenindividual component (BIC). Individual specialists occur in a population when the TNW consists mostly of the BIC, such that WIC/TNW is small (Roughgarden 1972, 1974, 1979). Most studies on individual specialization have focused on differences in diet and morphology (Bolnick et al. 2003, Araujo et al. 2007, Svanbäck \& Bolnick 2007, Svanbäck et al. 2008, Quevedo et al. 2009). Herein, I extend this framework to examine movement data.

In this analysis, the tidal creek was divided into seven zones (the equivalent of individual diet items in traditional specialization studies) according to their habitat composition (Fig. 2), water depth, and distance from home site A and B (Fig. 1). To calculate WIC/TNW, I used the number of detections of an individual fish in each zone during the entire study period. Individual specialization is likely to be present if the WIC/TNW value differs significantly from a null expectation. To this end, the movement-based WIC/TNW value for each population was tested against a null-model using a non-parametric Bootstrap Monte Carlo simulation. Calculations were performed in IndSpec1 (Bolnick et al. 2002). 


\section{Results}

The 20 gray snapper implanted with a transmitter had a mean SL of $168.5 \pm 43.4$ $\mathrm{mm}$ (mean $\pm \mathrm{SD}$; range 111-276 mm; Table 1) and schoolmaster snapper had a mean SL of $148.3 \pm 33.7 \mathrm{~mm}$ (range: $110-272 \mathrm{~mm}$ ). On the basis of otolith readings, the body size range in this study included fish of age 1 to 7 for gray snapper (Rypel \& Layman 2008) and 2 to 8 for schoolmaster snapper (A. Rypel, University of Alabama, unpublished data), including sexually mature individuals (>185-195 mm SL for gray snapper, Starck \& Schroeder 1971, and >250 mm FL for schoolmaster snapper, Munro 1983). According to length-weight regressions from tidal creeks on Abaco Island (C. Hammerschlag-Peyer, unpublished data), the SL range corresponded to body weights 39-533 g for gray snapper and 37-571 $\mathrm{g}$ for schoolmaster snapper. A total of 295,621 individual detections were recorded for these 40 fishes by stationary and manual receivers. All individuals were detected at least once by the stationary receivers at the home sites, and 17 gray and 18 schoolmaster snapper were detected using the manual receiver outside the home sites. Body size had no significant effect on any habitat use measure in both gray and schoolmaster snapper (Table 2). Most schoolmaster snapper stayed in the vicinity of the home sites throughout the study period. Only three of the 20 schoolmaster snapper and seven of the 20 gray snapper were detected outside the zones immediately adjacent to the home sites (Fig. 1).

A few individuals in both populations utilized large areas, whereas most individuals were characterized by small activity spaces (Fig. 3, G-H). The MCP estimates of the total activity space were $145,837 \mathrm{~m}^{2}$ for 14 gray snapper and $46,565 \mathrm{~m}^{2}$ for 15 schoolmaster snapper. Eleven gray and 12 schoolmaster snapper used less than $10 \%$ of 
the total activity space for each population, while three gray and three schoolmaster snapper used between $40-60 \%$ and $20-35 \%$, respectively. Importantly, activity spaces differed among individuals by their spatial orientation and location in the creek (e.g., Fig. 4). These data suggest that movements and habitat use among individuals varied substantially.

The WIC/TNW of gray snapper and schoolmaster snapper equaled 0.34 and 0.47 , respectively, with BIC larger than WIC in both cases. The WIC/TNW index for both populations was significantly different from the null model $(p<0.001)$, which provides evidence for individual specialization in habitat use (Bolnick et al. 2002). Specialization is evident when looking more closely at the differential habitat use of individual fish. For instance, four gray snapper and five schoolmaster snapper only utilized one home site area during the entire study period and were never observed outside the home site areas. The seven gray snapper and three schoolmaster snapper that utilized other zones of the creek tended to move to the same areas repeatedly, with areas differing among individuals (Table 3). Four gray snapper and two schoolmaster snapper moved to only one zone in addition to the home sites.

The $\delta^{13} \mathrm{C}$ values of schoolmaster snapper were significantly related to size of activity space $\left(\mathrm{R}^{2}=0.31, p=0.03\right)$ with individuals with small activity spaces having more depleted $\delta^{13} \mathrm{C}$ values (Fig. 5B). The $\delta^{13} \mathrm{C}$ values of gray snapper became more enriched with increased activity space utilization, but this positive relationship was not statistically significant $\left(\mathrm{R}^{2}=0.15, p=0.19\right.$; Fig. $\left.5 \mathrm{~A}\right)$. These patterns are consistent with the $\delta^{13} \mathrm{C}$ values of prey in upper and lower portions of the creek. Individual snapper that moved further (i.e., had large activity spaces extending toward the ocean) tended to have 
enriched $\delta^{13} \mathrm{C}$ values similar to prey collected at the mouths of creeks (i.e., marine influences). This finding likely reflects that individuals that moved further were feeding at a food web module originating from seagrass or seagrass epiphytes (that tend to be relatively enriched in $\delta^{13} \mathrm{C}$ ). Snapper individuals that moved less had more depleted $\delta^{13} \mathrm{C}$ values. These values were similar to prey collected in portions of creeks adjacent to the home sites, likely reflecting feeding pathways originating from micro- and macroalgae that are abundant in these areas (Kieckbusch et al. 2004).

\section{Discussion}

Populations usually are considered to be homogeneous entities with variation among individuals often not incorporated into ecological studies. My data suggest that there may be substantial small-scale intrapopulation variability in movement patterns in gray and schoolmaster snapper. In both populations, some individuals moved repeatedly outside of the home sites, while others remained in or near the deep pools for the entire study period. The activity space of individual fish also differed by spatial orientation and location. Such intrapopulation variation has been shown to be important in several freshwater fish taxa (Bourke et al. 1997, Morbey et al. 2006, Kobler et al. 2009), and I provide one of the first extensions of this research framework to marine fishes (see also Egli \& Babcock 2004).

Intrapopulation variation in movement patterns and habitat use was generally not explained by body size even though the body size range in this study included juvenile and adult individuals. While body size is widely accepted as driver of intrapopulation variation in fish habitat utilization (e.g., Minns 1995), my results support recent research 
findings that body size had no effect on intraspecific patterns of home range/activity space (Lowry \& Suthers 1998, Weller \& Winter 2001, Sakaris et al. 2003, Morbey et al. 2006) and movement patterns (Bourke et al. 1997, Egli \& Babcock 2004, Ng et al. 2007, Childs et al. 2008, Koster \& Crook 2008). Only the mean and maximum distances moved in schoolmaster snapper were marginally significant $(0.1>p>0.05$; Table 2$)$ likely because three of the larger individuals moved outside the home site zones (Fig. 1). These findings could be affected by the inherently small sample size that is common in telemetry studies as a result of costs associated with tagging technology (Luo et al. 2009). Yet, despite this limitation, I demonstrated that intrapopulation differences in movement patterns of marine fishes may be greater than has previously been recognized and that factors other than body size may drive much of this variation.

In back reef systems, seascape attributes have been shown to be a primary determinant of habitat use of fishes (Pittman et al. 2007). Many coastal fishes, including snapper, generally prefer mangroves surrounded by dense seagrass (Pittman et al. 2007) since mangrove prop roots provide shelter (Hammerschlag et al. 2010) and seagrass beds contain high densities of prey items for coastal fishes (Orth et al. 1984). In the present study system, potential resource pools, such as seagrass, were patchily distributed across the creek system. Such a heterogeneous matrix of resources provides a large scope for individuals to develop specialized movement patterns. Such systems contrast with places where resources are concentrated in a single location. For example, schoolmaster snapper in Spanish Water Bay, Curaçao, typically move less than 5m during the day (Verweij et al. 2007), perhaps because dense seagrass beds are found immediately adjacent to fringing mangroves. In this context, distinct movement patterns among individuals may 
be less likely to develop because of the concentration of food resources. Alternatively, the relatively short movement distances of schoolmaster snapper in Spanish Water Bay could also be because they feed and seek shelter in mangroves during the day, while feeding in adjacent seagrass beds at night (Nagelkerken \& van der Velde 2004, Verweij et al. 2006), probably to minimize predation risk (e.g., Laedsgaard \& Johnson 1995). Predation pressure could be higher in Spanish Water Bay than in my study system (I did not quantify this variable), and is another factor that must be considered when analyzing movement distances of individual fish.

Several contexts could be used to elucidate the intrapopulation variation in habitat use. The simplest explanation is that individuals moved randomly, thereby creating habitat use variation among individuals. However, repeated use of certain zones by the same individuals does not seem to support this explanation. Alternatively, movement patterns of individuals may relate to optimal foraging at an individual level (MacArthur \& Pianka 1966) in conjunction with differential learning among individuals (Brown \& Laland 2003). In this context, it could be more beneficial for certain individuals to forage in proximity of the home sites, while others maximize their intake by foraging in other areas of the creek. Differential habitat use patterns among individuals also are consistent with the "boldness versus shyness" dichotomy of behavioral traits (Gosling \& John 1999, Gosling 2001), a pattern found in many fish species (Sih et al. 2004a, Sih et al. 2004b). Bold individuals would be those that frequently explore other habitats or zones, while shy individuals largely remain in the proximity of their home sites (Russell 1983, Wilson et al. 1993). 
An underlying driver for the above-mentioned contexts of intrapopulation habitat variation could be differential responses of individuals to competition. Specialization in movement patterns and habitat use is most likely when intraspecific competition is high (Svanbäck et al. 2008), and my empirical data may provide such an example in a marine system. Because all individuals are forced into the home sites at low tide, competition for food resources is likely high (Whitham 1978). Fishes that move further may be able to access underutilized food resources in patchily distributed seagrass beds outside the home site zones, with a trade-off of increased risk of predation (i.e., less shelter away from home sites) and energy expenditure (MacArthur \& Pianka 1966).

Snapper $\delta^{13} \mathrm{C}$ values tended to be more enriched in individuals that had large activity spaces (Fig. 5). For both species, individuals that used large activity spaces (i.e., moved further toward the ocean) had similar $\delta^{13} \mathrm{C}$ values to prey collected from creek mouths, while individuals with small activity spaces tended to have more depleted $\delta^{13} \mathrm{C}$ values. These findings suggest that individuals with large activity spaces were feeding from a marine-derived food web module, likely originating in seagrass beds $\left(\delta^{13} \mathrm{C}=-10.5\right.$ \pm 2.5 ; Kieckbusch et al. 2004). In contrast, individuals with small activity spaces seem to feed on prey in the upstream portion of the creek (in and around the home sites), likely on the basis of diverse macro- and microalgae assemblages $\left(\delta^{13} \mathrm{C}=-18.0 \pm 5.4\right.$, Kieckbusch et al. 2004). Patterns in tissue $\delta^{13} \mathrm{C}$ provides strong evidence that the movement patterns observed over the course of the four-week study period were reflective of longer term feeding trends (Hesslein et al. 1993, Suring \& Wing 2009).

Fisheries management strategies often have ignored intrapopulation variation in marine systems. Simply concentrating on the "typical" habitats of a fish population may 
inherently ignore those individuals that use alternative habitats or food sources (Durell 2000, Bolnick et al. 2003). For instance, in a New Zealand marine protected area $\sim 50 \%$ of New Zealand Snapper, Pagrus auratus, remained within the area during the research period. However, the remaining individuals spent most of their time outside the reserve (Egli \& Babcock 2004). This marine protected area would only provide protection for those individuals that moved less through time. Such cases and the present study suggest that a shift in perspective - from a population to an individual level - may be warranted in the management of some marine fisheries. Such an approach may help preserve species' ecological, phenotypic and genetic diversity, and thus their ability to adapt to environmental change and to human impacts in marine ecosystems (Moritz 1994, Coates 2000, Smith et al. 2001, Bolnick et al. 2003).

\section{Acknowledgements}

This project was conducted as part of a broad educational outreach program funded by NSF OCE \#0746164, MacTaggart Third Fund, Friends of the Environment, the Bahamas Reef Environmental Education Foundation. Dozens of Bahamian students were involved with catching their "own" fish and tracking the fishes' movements through time. I thank Friends of the Environment for their logistical support and all people that helped with field work, data analysis, and manuscript editing, including S. Whitcraft, S. Hurley, G. Mineau., K. Bernhardt, M. Ioli, J. Allgeier, M. Araujo, N. Hammerschlag, L. Yeager, S. Giery, E. Stoner, Z. Jud, and P. Matich. Sampling of Lutjanus griseus and L. apodus was permitted by the Bahamas Department of Marine Resources and the FIU 
Institutional Animal Care and Use Committee (IACUC; Permit Numbers: 09-009, 08008). 
Table 1 Characteristics of 20 gray snapper (GS) and 20 schoolmaster snapper (SM) implanted with acoustic tags in April 2009. Individuals that were tagged at the south-west margin (SW mar) were not included in the analysis since these individuals had $<10$ observation points (see text for details). Number of detections from mobile receiver (MR) and stationary receiver (SR) and number of total distance moved per tidal cycle (D) are included (see text for details)

\begin{tabular}{|c|c|c|c|c|c|c|c|c|}
\hline$\#$ & ID & Species & SL (mm) & $\begin{array}{l}\text { Tagging } \\
\text { Date }\end{array}$ & $\begin{array}{c}\text { Caught } \\
\text { at }\end{array}$ & MR & SR & D \\
\hline 1 & 57223 & GS & 161 & $4 / 22 / 2009$ & HS B & 12 & 49 & 10 \\
\hline 2 & 57224 & GS & 184 & $4 / 22 / 2009$ & HS B & 8 & 56 & 4 \\
\hline 3 & 57225 & GS & 126 & $4 / 23 / 2009$ & HS B & 15 & 26 & 15 \\
\hline 4 & 57228 & GS & 147 & $4 / 28 / 2009$ & HS B & 0 & 7 & 0 \\
\hline 5 & 57229 & GS & 143 & $4 / 23 / 2009$ & HS B & 11 & 53 & 10 \\
\hline 6 & 57230 & GS & 111 & $4 / 23 / 2009$ & HS B & 11 & 46 & 14 \\
\hline 7 & 57237 & GS & 185 & $4 / 26 / 2009$ & SW Mar & 1 & 0 & 1 \\
\hline 8 & 57238 & GS & 134 & $4 / 23 / 2009$ & HS B & 26 & 36 & 30 \\
\hline 9 & 57241 & GS & 150 & $4 / 23 / 2009$ & HS B & 4 & 14 & 9 \\
\hline 10 & 57242 & GS & 139 & $4 / 28 / 2009$ & SW Mar & 3 & 4 & 0 \\
\hline 11 & 57245 & GS & 158 & $4 / 22 / 2009$ & HS A & 19 & 45 & 23 \\
\hline 12 & 57249 & GS & 153 & $4 / 28 / 2009$ & SW Mar & 1 & 0 & 0 \\
\hline 13 & 57250 & GS & 276 & $4 / 28 / 2009$ & SW Mar & 7 & 0 & 0 \\
\hline 14 & 58468 & GS & 162 & $4 / 22 / 2009$ & HS A & 25 & 42 & 28 \\
\hline 15 & 58470 & GS & 187 & $4 / 21 / 2009$ & HS A & 5 & 91 & 4 \\
\hline 16 & 58471 & GS & 194 & $4 / 21 / 2009$ & HS A & 2 & 62 & 1 \\
\hline 17 & 58472 & GS & 166 & $4 / 21 / 2009$ & HS A & 0 & 18 & 0 \\
\hline 18 & 58473 & GS & 118 & $4 / 20 / 2009$ & HS A & 0 & 0 & 0 \\
\hline 19 & 58474 & GS & 212 & $4 / 20 / 2009$ & HS A & 22 & 26 & 28 \\
\hline 20 & 58475 & GS & 264 & $4 / 20 / 2009$ & HS A & 3 & 80 & 10 \\
\hline 1 & 57221 & SM & 162 & $4 / 23 / 2009$ & HS B & 12 & 48 & 11 \\
\hline 2 & 57222 & SM & 160 & $4 / 23 / 2009$ & HS B & 7 & 48 & 9 \\
\hline 3 & 57226 & SM & 131 & $4 / 22 / 2009$ & HS A & 4 & 102 & 17 \\
\hline 4 & 57227 & SM & 126 & $4 / 22 / 2009$ & HS A & 4 & 110 & 7 \\
\hline 5 & 57231 & SM & 140 & $4 / 23 / 2009$ & HS B & 2 & 53 & 0 \\
\hline 6 & 57232 & SM & 110 & $4 / 26 / 2009$ & HS B & 0 & 0 & 0 \\
\hline
\end{tabular}


Table 1 continued

\begin{tabular}{ccccccccc}
\hline \# & ID & Species & SL $(\mathbf{m m})$ & $\begin{array}{c}\text { Tagging } \\
\text { Date }\end{array}$ & $\begin{array}{c}\text { Caught } \\
\text { at }\end{array}$ & MR & SR & D \\
\hline 7 & 57233 & SM & 129 & $4 / 23 / 2009$ & HS B & 2 & 52 & 0 \\
8 & 57234 & SM & 141 & $4 / 23 / 2009$ & HS B & 10 & 11 & 10 \\
9 & 57235 & SM & 139 & $4 / 28 / 2009$ & HS B & 22 & 0 & 0 \\
10 & 57236 & SM & 158 & $4 / 28 / 2009$ & HS B & 2 & 15 & 3 \\
11 & 57239 & SM & 134 & $4 / 23 / 2009$ & HS B & 30 & 9 & 31 \\
12 & 57240 & SM & 128 & $4 / 23 / 2009$ & HS B & 0 & 0 & 0 \\
13 & 57243 & SM & 136 & $4 / 28 / 2009$ & HS B & 2 & 0 & 0 \\
14 & 57244 & SM & 120 & $4 / 26 / 2009$ & SW Mar & 2 & 2 & 0 \\
15 & 57246 & SM & 146 & $4 / 22 / 2009$ & HS A & 5 & 29 & 1 \\
16 & 57247 & SM & 140 & $4 / 22 / 2009$ & HS A & 9 & 64 & 23 \\
17 & 57248 & SM & 166 & $4 / 22 / 2009$ & HS A & 3 & 27 & 9 \\
18 & 58466 & SM & 147 & $4 / 22 / 2009$ & HS A & 8 & 100 & 9 \\
19 & 58467 & SM & 180 & $4 / 22 / 2009$ & HS A & 2 & 32 & 5 \\
20 & 58469 & SM & 272 & $4 / 22 / 2009$ & HS B & 8 & 161 & 46 \\
\hline
\end{tabular}


Table 2 Influence of body size on habitat use measures for Lutjanus griseus (gray snapper, GS) and L. apodus (schoolmaster snapper, SM), on the basis of linear regressions

\begin{tabular}{ccccc}
\hline Meas ure & Species & $\mathbf{R}^{2}$ & Slope & p-value \\
\hline \multirow{2}{*}{ Mean distance moved } & GS & 0.03 & -0.25 & 0.64 \\
& SM & 0.4 & 1.03 & 0.07 \\
Max distance moved & GS & 0.03 & -0.67 & 0.68 \\
& SM & 0.36 & 2.17 & 0.09 \\
Furthest distance from HS & GS & 0.06 & -0.84 & 0.55 \\
& SM & 0.07 & 0.48 & 0.49 \\
Minimum convex polygon & GS & 0.04 & -0.01 & 0.5 \\
& SM & 0.15 & 0.02 & 0.15 \\
\hline
\end{tabular}


Table 3 Total number of days that Lutjanus griseus (gray snapper, GS) and L. apodus (schoolmaster snapper, SM) moved outside the home sites and the proportion of trips that each individual visited the different creek zones (see text and Fig. 1 for more details).

Total number of days is smaller than the actual number of observation points per individual because observations in home site areas are excluded here (see Table 1 for more details)

\begin{tabular}{cccccccc}
\hline ID & Species & $\begin{array}{c}\text { Total \# } \\
\text { of days }\end{array}$ & $\begin{array}{c}\text { South } \\
\text { West } \\
\text { Margin }\end{array}$ & $\begin{array}{c}\text { West } \\
\text { Margin }\end{array}$ & $\begin{array}{c}\text { South } \\
\text { Margin }\end{array}$ & Middle & Mouth \\
\hline 57223 & GS & 9 & 0 & 100 & 0 & 0 & 0 \\
57224 & GS & 1 & 0 & 100 & 0 & 0 & 0 \\
57229 & GS & 10 & 0 & 100 & 0 & 0 & 0 \\
57230 & GS & 3 & 0 & 0 & 33 & 67 & 0 \\
57245 & GS & 3 & 0 & 0 & 0 & 100 & 0 \\
58468 & GS & 7 & 29 & 0 & 0 & 57 & 14 \\
58474 & GS & 17 & 88 & 0 & 0 & 12 & 0 \\
57221 & SM & 9 & 0 & 100 & 0 & 0 & 0 \\
57222 & SM & 2 & 0 & 50 & 0 & 50 & 0 \\
58469 & SM & 1 & 0 & 0 & 0 & 100 & 0 \\
\hline
\end{tabular}




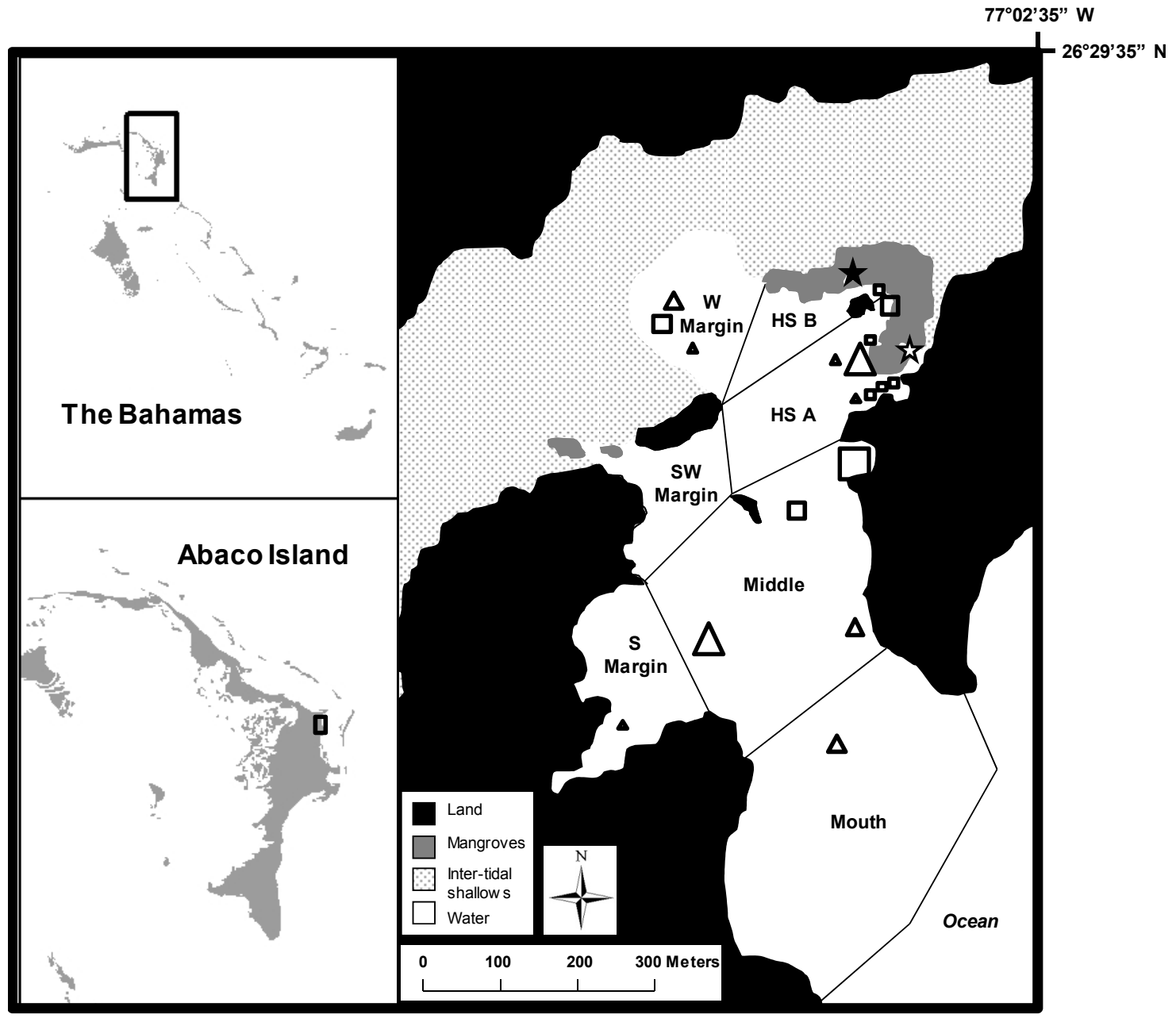

Fig. 1 Broad Creek system coded by land/seascape type. $(\Delta, \square)$ Furthest distance away from home sites by gray snapper, Lutjanus griseus and schoolmaster snapper, L. apodus, respectively, during the study period. Size of triangles and squares reflects size of the fish (small: 110-150 mm standard length (SL), medium: 151-200 mm SL, big: > $200 \mathrm{~mm}$ SL). The open star represents home site A (HS A) and the closed home site B (HS B). Panels on the left are maps of The Bahamas (top left) and Abaco Island (bottom left) with the rectangle representing the location of Broad Creek 

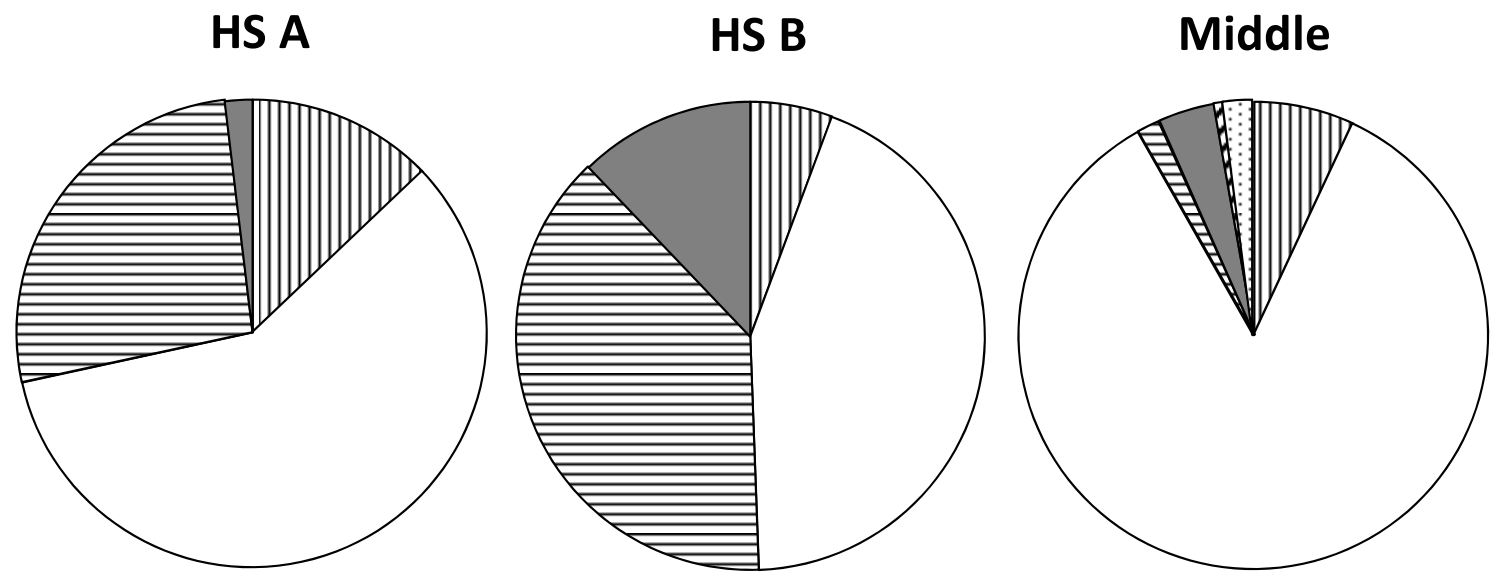

\section{South-West Margin}
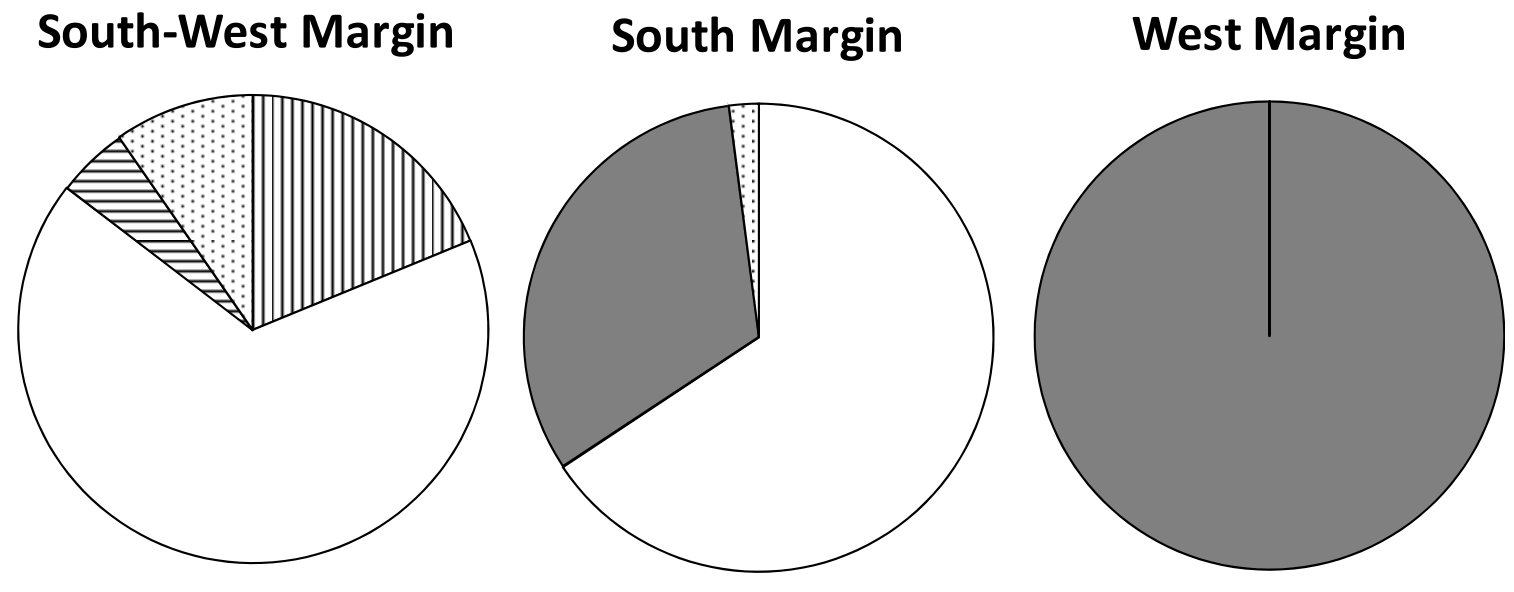

\section{Mouth}
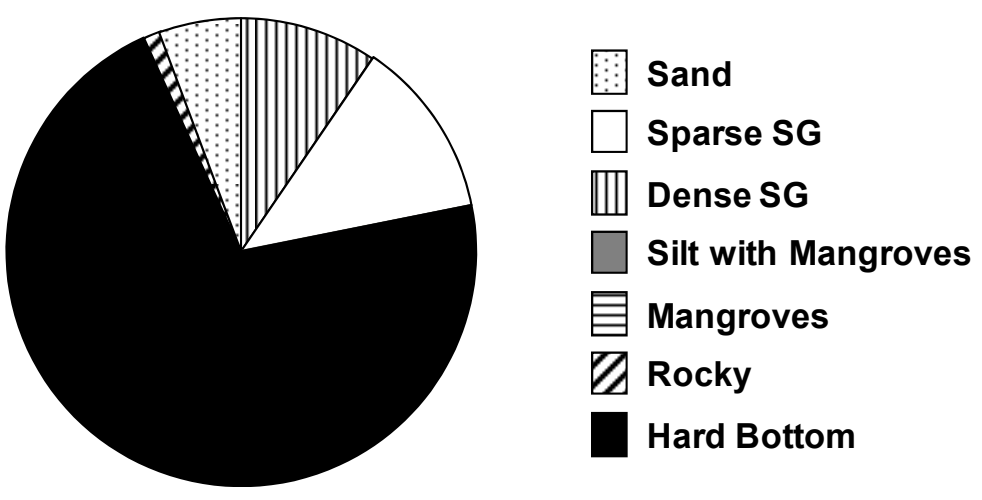

Fig. 2 Proportion of habitat types in each zone. HS: home site; SG: seagrass; Silt: mangrove-derived, rich sediment 

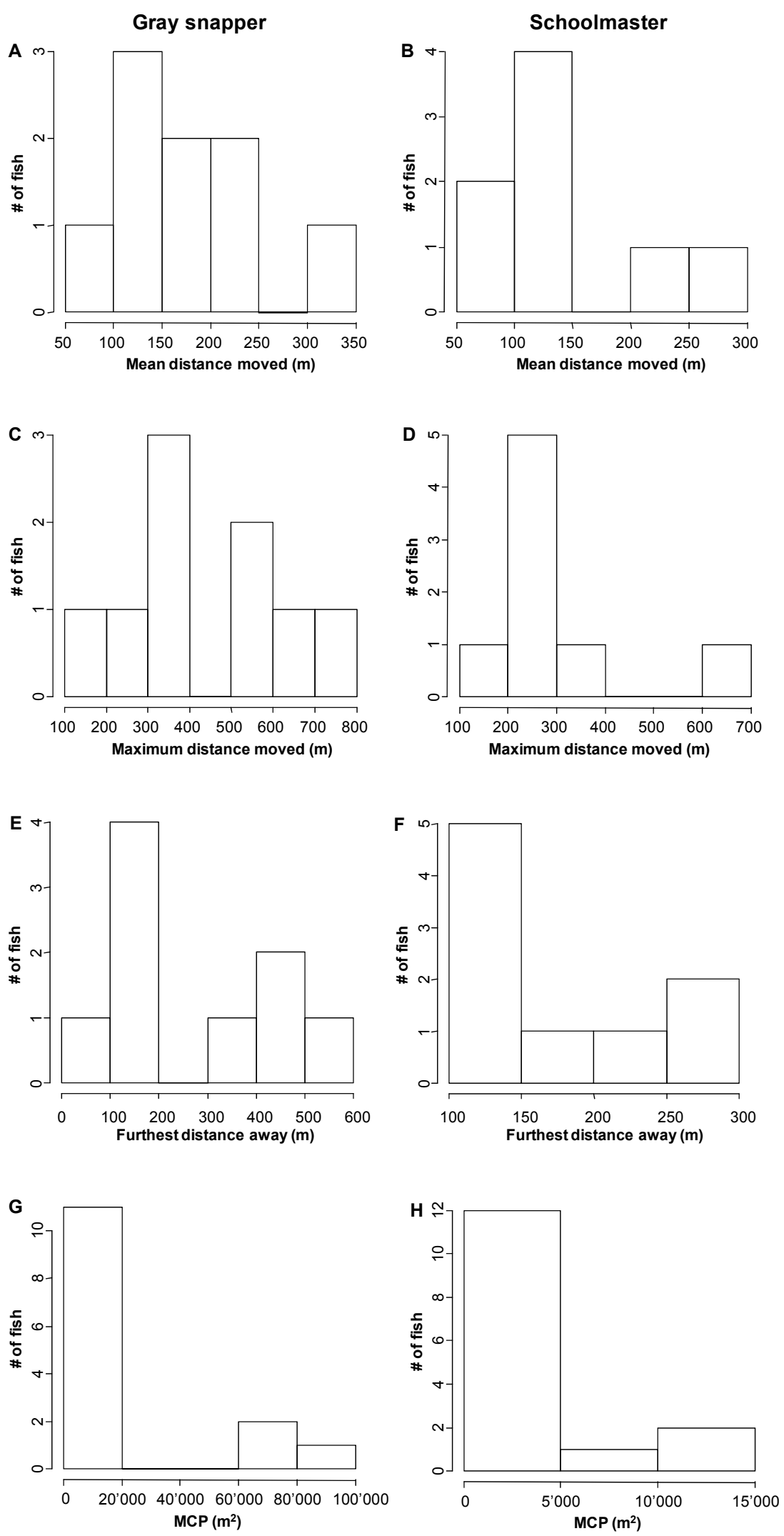
Fig. 3 Lutjanus griseus (left panels) and L. apodus (right panels). Frequency histograms of: 1) mean distance moved (average of daily movement distances, April 26 - May 24 2009) (A-B); 2) maximum distance moved (C-D); 3) furthest distance away from home sites (HS; E-F); 4) activity space on the basis of minimum convex polygon (MCP) estimates $(\mathrm{G}-\mathrm{H})$ 

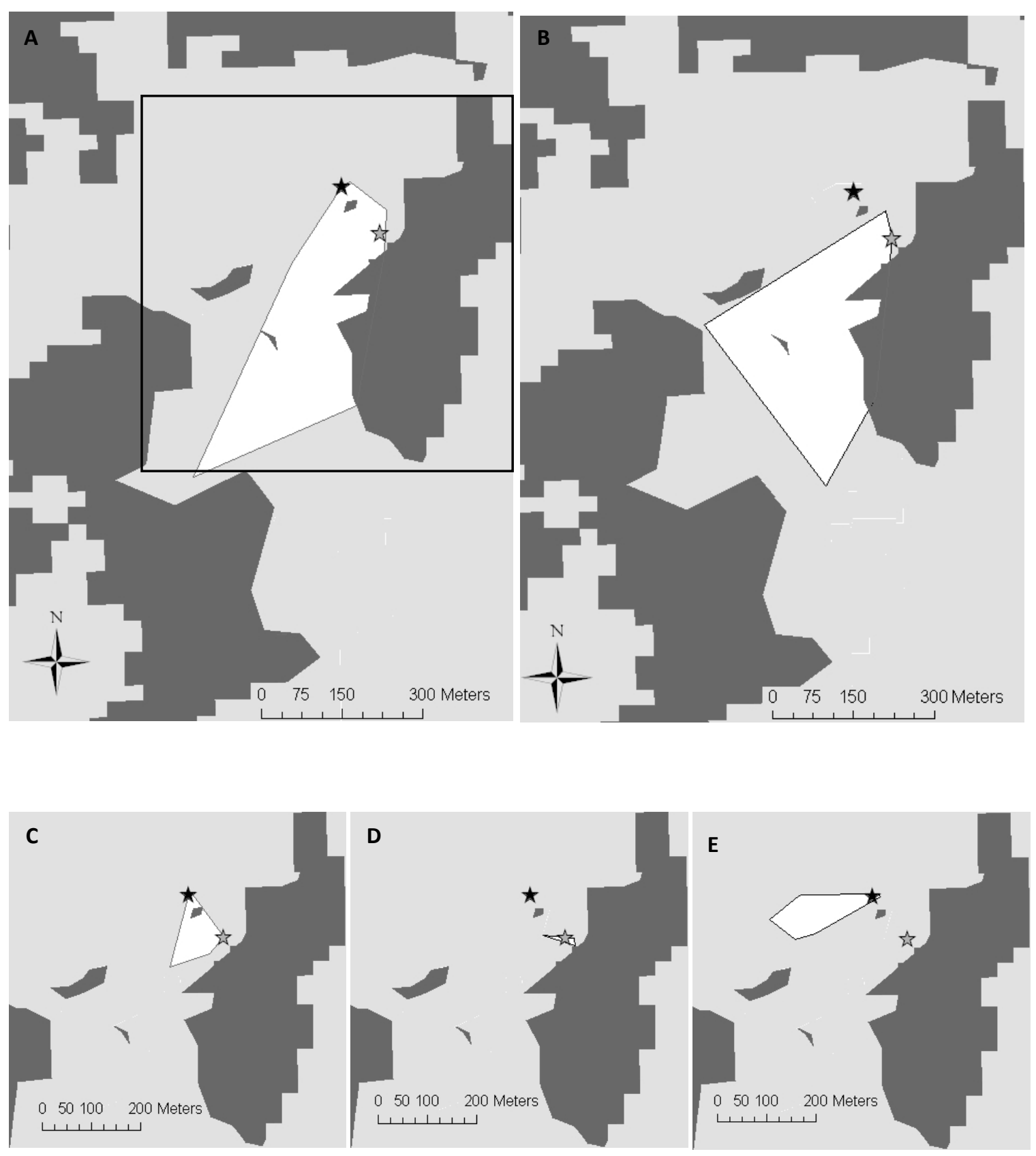

Fig. 4 Examples of the activity space for 5 individuals (gray snapper: A-C; schoolmaster snapper: D and E) in the study area (dark gray: land, light gray: aquatic habitat) from April 26 to May 24 2009. The black frame in A corresponds to the area represented in the smaller maps (C-E) 
A

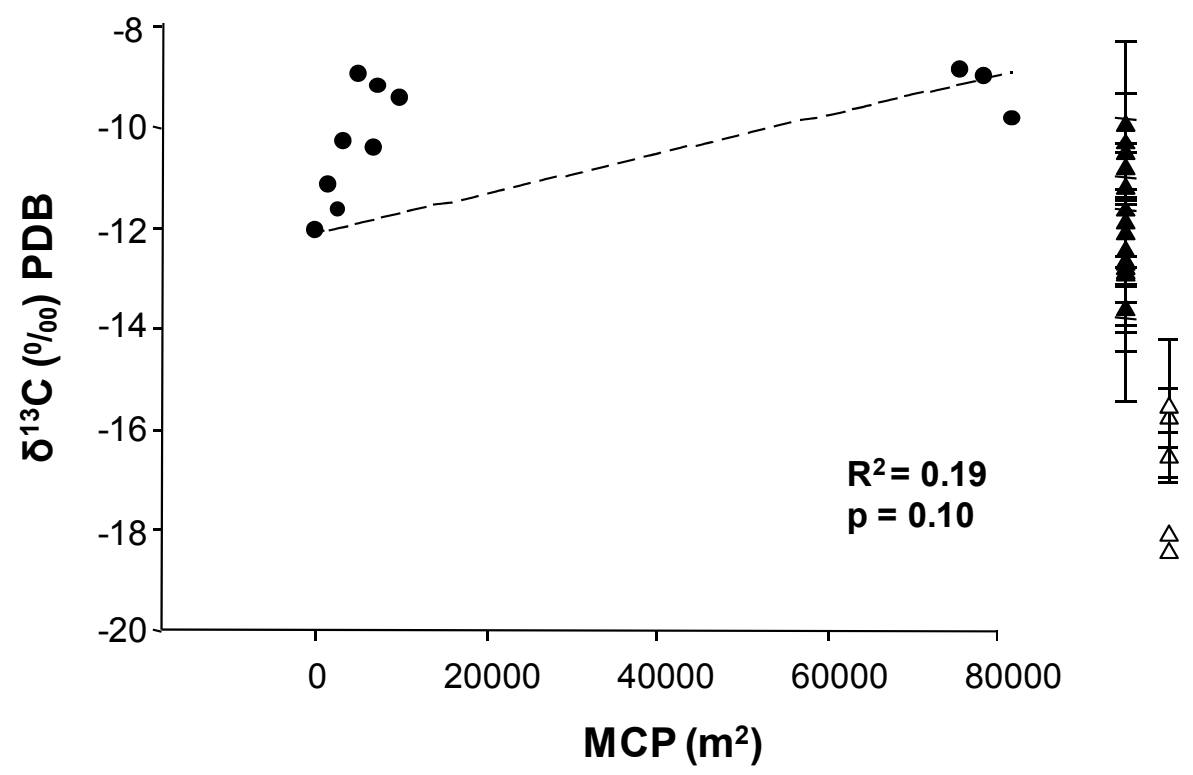

B

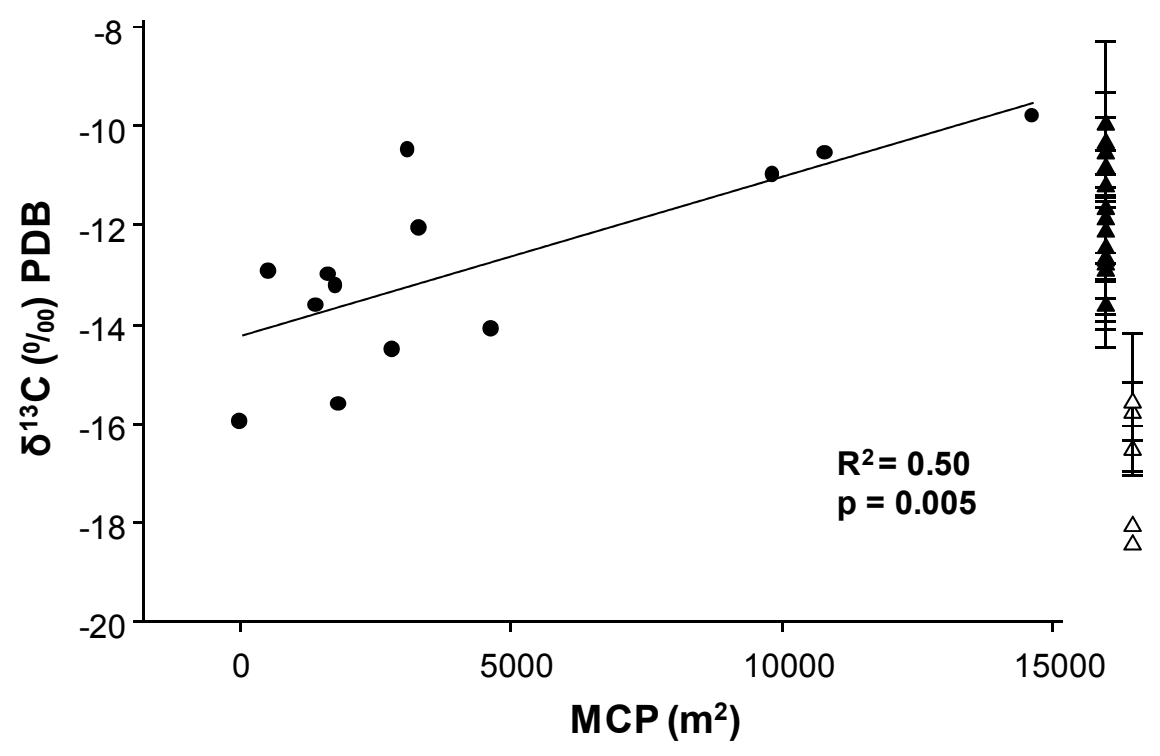

Fig. 5 Linear regression between $\delta^{13} \mathrm{C}$ and activity space (minimum convex polygon, MCP) for A) gray snapper and B) schoolmaster snapper. (•) Data for an individual snapper, while each triangle represents a mean $\delta^{13} \mathrm{C}$ value for individual taxa known to be 
snapper prey (error bars: SD). The $\delta^{13} \mathrm{C}$ values of prey items vary between creek mouth $(\Delta)$ and upstream $(\Delta)$ areas. PDB: PeeDee belemnite, global standard of $\delta^{13} \mathrm{C}$. The $\delta^{13} \mathrm{C}$ values of prey items were corrected for trophic discrimination $(1 \%$, according to Post 2002) 


\section{LITERATURE CITED}

Allen GR (1985) FAO species catalogue. Snappers of the world. An annotated and illustrated catalogue of lutjanid species known to date. FAO Fisheries Synopsis $6: 208$

Anderson DJ (1982) The Home Range - a new nonparametric-estimation technique. Ecology 63:103-112

Araujo MS, Bolnick DI, Machado G, Giaretta AA, dos Reis SF (2007) Using delta C-13 stable isotopes to quantify individual-level diet variation. Oecologia 152:643-654

Baillie J, Groombridge B (1996) 1996 IUCN Red List of Threatened Animals. IUCN, Gland, Switzerland

Bolnick DI, Svanbäck R, Fordyce JA, Yang LH, Davis JM, Hulsey CD, Forister ML (2003) The ecology of individuals: Incidence and implications of individual specialization. Am Nat 161:1-28

Bolnick DI, Yang LH, Fordyce JA, Davis JM, Svanbäck R (2002) Measuring individuallevel resource specialization. Ecology 83:2936-2941

Bourke P, Magnan P, Rodriguez MA (1997) Individual variations in habitat use and morphology in brook charr. J Fish Biol 51:783-794

Brown C, Laland KN (2003) Social learning in fishes: a review. Fish Fish 4:280-288

Carfagno GLF, Weatherhead PJ (2008) Energetics and space use: intraspecific and interspecific comparisons of movements and home ranges of two colubrid snakes. J Anim Ecol 77:416-424

Childs AR, Cowley PD, Naesje TF, Booth AJ, Potts WM, Thorstad EB, Okland F (2008) Do environmental factors influence the movement of estuarine fish? A case study using acoustic telemetry. Est Coast Shelf Sci 78:227-236

Coates DJ (2000) Defining conservation units in a rich and fragmented flora: implications for the management of genetic resources and evolutionary processes in south-west Australian plants. Aust J Bot 48:329-339

Coleman FC, Figueira WF, Ueland JS, Crowder LB (2004) The impact of United States recreational fisheries on marine fish populations. Science 305:1958-1960 
Cotter PA, Rodruck KJ (2006) Differential effects of anesthetics on electrical properties of the rainbow trout (Oncorhynchus mykiss) heart. Comp Biochem Physiol A $145: 158-165$

Durell S (2000) Individual feeding specialization in shorebirds: population consequences and conservation implications. Biol Rev 75:503-518

Egli DP, Babcock RC (2004) Ultrasonic tracking reveals multiple behavioural modes of snapper (Pagrus auratus) in a temperate no-take marine reserve. ICES J Mar Sci 61:1137-1143

Gosling SD (2001) From mice to men: What can we learn about personality from animal research? Psychol Bull 127:45-86

Gosling SD, John OP (1999) Personality dimensions in nonhuman animals: A crossspecies review. Curr Dir Psychol 8:69-75

Graham RT, Carcamo R, Rhodes KL, Roberts CM, Requena N (2008) Historical and contemporary evidence of a mutton snapper (Lutjanus analis Cuvier, 1828) spawning aggregation fishery in decline. Coral Reefs 27:311-319

Hammerschlag N, Morgan AB, Serafy JE (2010) Relative predation risk for fishes along a subtropical mangrove-seagrass ecotone. Mar Ecol Prog Ser 401:259-267

Heithaus MR, Frid A, Wirsing AJ, Worm B (2008) Predicting ecological consequences of marine top predator declines. Trends Ecol Evol 23:202-210

Hesslein RH, Hallard KA, Ramlal P (1993) Replacement of Sulfur, Carbon, and Nitrogen in tissue of growing broad whitefish (Corgonus nasus) in response to a change in diet traced by delta-S34, delta-C-13, and delta-N-15. Can J Fish Aquat Sci 50:2071-2076

Hiscock MJ, Scruton DA, Brown JA, Pennell CJ (2002) Diel activity pattern of juvenile Atlantic salmon (Salmo salar) in early and late winter. Hydrobiologia 483:161165

Hooge PN, Eichenlaub B (1997) Animal movement extension to ArcView ver. 1.1. Alaska Science Center, Biological Science Office, U.S. Geological Survey, Anchorage, AK, USA

Huijbers CM, Mollee EM, Nagelkerken I (2008) Post-larval French grunts (Haemulon flavolineatum) distinguish between seagrass, mangrove and coral reef water: 
Implications for recognition of potential nursery habitats. J Exp Mar Biol Ecol $357: 134-139$

Jackson JBC, Kirby MX, Berger WH, Bjorndal KA, Botsford LW, Bourque BJ, Bradbury RH, Cooke R, Erlandson J, Estes JA, Hughes TP, Kidwell S, Lange CB, Lenihan HS, Pandolfi JM, Peterson CH, Steneck RS, Tegner MJ, Warner RR (2001) Historical overfishing and the recent collapse of coastal ecosystems. Science 293:629-638

Kieckbusch DK, Koch MS, Serafy JE, Anderson WT (2004) Trophic linkages among primary producers and consumers in fringing mangroves of subtropical lagoons. Bull Mar Sci 74:271-285

Kobler A, Klefoth T, Mehner T, Arlinghaus R (2009) Coexistence of behavioural types in an aquatic top predator: a response to resource limitation? Oecologia 161:837-847

Koster WM, Crook DA (2008) Diurnal and nocturnal movements of river blackfish (Gadopsis marmoratus) in a south-eastern Australian upland stream. Ecol Freshw Fish 17:146-154

Laegdsgaard P, Johnson CR (1995) Mangrove habitats as nurseries - unique assemblages of juvenile fish in subtropical mangroves in eastern Australia. Mar Ecol Prog Ser 126:67-81

Layman CA (2007) What can stable isotope ratios reveal about mangroves as fish habitat? Bull Mar Sci 80:513-527

Layman CA, Quattrochi JP, Peyer CM, Allgeier JE (2007) Niche width collapse in a resilient top predator following ecosystem fragmentation. Ecol Lett 10:937-944

Lotze HK, Worm B (2009) Historical baselines for large marine animals. Trends Ecol Evol 24:254-262

Lowry MB, Suthers IM (1998) Home range, activity and distribution patterns of a temperate rocky-reef fish, Cheilodactylus fuscus. Mar Biol 132:569-578

Luo JG, Serafy JE, Sponaugle S, Teare PB, Kieckbusch D (2009) Movement of gray snapper Lutjanus griseus among subtropical seagrass, mangrove, and coral reef habitats. Mar Ecol Prog Ser 380:255-269

MacArthur RH, Pianka ER (1966) On optimal use of a patchy environment. Am Nat 100:603-609 
Magurran AE (1986) Individual differences in fish behaviour. In: Pitcher TJ (ed) The behaviour of teleost fishes. Croom Helm, London, p 338-365

Meyer JL, Schultz ET, Helfman GS (1983) Fish schools - an asset to corals. Science 220:1047-1049

Minns CK (1995) Allometry of home-range size in lake and river fishes. Can J Fish Aquat Sci 52:1499-1508

Morbey YE, Addison P, Shuter BJ, Vascotto K (2006) Within-population heterogeneity of habitat use by lake trout Salvelinus namaycush. J Fish Biol 69:1675-1696

Moritz C (1994) Application of mitochondrial-DNA analysis in conservation - a critical review. Mol Ecol 3:401-411

Munro JL (1983) Caribbean coral reef fishery resources. ICLARM, Philippines, ICLARM

Nagelkerken I, van der Velde G (2004) Relative importance of interlinked mangroves and seagrass beds as feeding habitats for juvenile reef fish on a Caribbean island. Mar Ecol Prog Ser 274:153-159

Nagelkerken I, Dorenbosch M, Verberk W, de la Moriniere EC, van der Velde G (2000) Importance of shallow-water biotopes of a Caribbean bay for juvenile coral reef fishes: patterns in biotope association, community structure and spatial distribution. Mar Ecol Prog Ser 202:175-192

Ng CL, Able KW, Grothues TM (2007) Habitat use, site fidelity, and movement of adult striped bass in a Southern New Jersey estuary based on mobile acoustic telemetry. Trans Am Fish Soc 136:1344-1355

Nieland DL, Wilson CA, Fischer AJ (2007) Declining size at age among red snapper in the northern Gulf of Mexico off Louisiana, USA: Recovery or collapse? In: Patterson WF, Cowan JH, Fitzhugh GR, Nieland DL (eds) Red Snapper Ecology and Fisheries in the US Gulf of Mexico. American Fisheries Society Symposium 60

Nowak GM, Quinn TP (2002) Diel and seasonal patterns of horizontal and vertical movements of telemetered cutthroat trout in Lake Washington, Washington. Trans Am Fish Soc 131:452-462 
Orth RJ, Heck KL, Vanmontfrans J (1984) Faunal communities in seagrass beds - a review of the influence of plant structure and prey characteristics on predator-prey relationships. Estuaries 7:339-350

Parsons DM, Babcock RC, Hankin RKS, Willis TJ, Aitken JP, O'Dor RK, Jackson GD (2003) Snapper Pagrus auratus (Sparidae) home range dynamics: acoustic tagging studies in a marine reserve. Mar Ecol Prog Ser 262:253-265

Pauly D, Christensen V, Dalsgaard J, Froese R, Torres F (1998) Fishing down marine food webs. Science 279:860-863

Pittman SJ, Caldow C, Hile SD, Monaco ME (2007) Using seascape types to explain the spatial patterns of fish in the mangroves of SW Puerto Rico. Mar Ecol Prog Ser 348:273-284

Post DM (2002) Using stable isotopes to estimate trophic position: Models, methods, and assumptions. Ecology 83:703-718

Post DM, Layman CA, Arrington DA, Takimoto G, Quattrochi J, Montana CG (2007) Getting to the fat of the matter: models, methods and assumptions for dealing with lipids in stable isotope analyses. Oecologia 152:179-189

Quevedo M, Svanbäck R, Eklov P (2009) Intrapopulation niche partitioning in a generalist predator limits food web connectivity. Ecology 90:2263-2274

Ringler NH (1983) Variation in foraging tactics in fishes. In: Noakes DLG, Lindquist DG, Helfman GS, Ward JA (eds) Predation and Prey in Fishes. Junk, The Hague, p 159-171

Roth TC, BD Greene (2006) Movement patterns and home range use of the Northern Watersnake (Nerodia sipedon). Copeia 3:544-551

Roughgarden J (1972) Evolution of Niche Width. Am Nat 106:683-718

Roughgarden J (1974) Niche Width: Biogeographic Patterns among Anolis Lizard Populations. Am Nat 108:429-442

Roughgarden J (1979) Theory of population genetics and evolutionary ecology: an introduction. Macmillan, New York, USA 
Russell PA (1983) Psychological studies of exploration in animals: a reappraisal. In: Birke LIA, Archer J (eds) Exploration in animals and humans. Van Nostrand, New York, p 22-54

Rypel AL, Layman CA (2008) Degree of aquatic ecosystem fragmentation predicts population characteristics of gray snapper (Lutjanus griseus) in Caribbean tidal creeks. Can J Fish Aquat Sci 65:335-339

Rypel AL, Layman CA, Arrington DA (2007) Water depth modifies relative predation risk for a motile fish taxon in Bahamian tidal creeks. Est Coasts 30:518-525

Sackett DK, Able KW, Grothues TM (2007) Dynamics of summer flounder, Paralichthys dentatus, seasonal migrations based on ultrasonic telemetry. Est Coast Shelf Sci $74: 119-130$

Sadovy YJ (1997) The case of the disappearing grouper: Epinephelus striatus, the Nassau grouper in the Caribbean and western Atlantic. Proc Gulf Carib Fish Inst 45:5-22

Sakaris PC, Ferrara AM, Kleiner KJ, Irwin ER (2003) Movements and Home Ranges of Alligator Gar in the Mobile-Tensaw Delta, Alabama. Proc Annu Conf Southeast Assoc Fish and Wildl Agencies 57:102-111

Schindler DE, Hodgson JR, Kitchell JF (1997) Density-dependent changes in individual foraging specialization of largemouth bass. Oecologia 110:592-600

Sih A, Bell A, Johnson JC (2004a) Behavioral syndromes: an ecological and evolutionary overview. Trends Ecol Evol 19:372-378

Sih A, Bell AM, Johnson JC, Ziemba RE (2004b) Behavioral syndromes: An integrative overview. Q Rev Biol 79:241-277

Sladky KK, Swanson CR, Stoskopf MK, Loomis MR, Lewbart GA (2001) Comparative efficacy of tricaine methanesulfonate and clove oil for use as anesthetics in red pacu (Piaractus brachypomus). Am J Vet Res 62:337-342

Smith TB, Kark S, Schneider CJ, Wayne RK, Moritz C (2001) Biodiversity hotspots and beyond: the need for preserving environmental transitions. Trends Ecol Evol $16: 431-431$

Starck WA, Schroeder RE (1971) Investigations on the Gray Snapper, Lutjanus griseus. University of Miami Press, Coral Gables, Florida 
Suring E, Wing SR (2009) Isotopic turnover rate and fractionation in multiple tissues of red rock lobster (Jasus edwardsii) and blue cod (Parapercis colias):

Consequences for ecological studies. J Exp Mar Biol Ecol 370:56-63

Svanbäck R, Bolnick DI (2007) Intraspecific competition drives increased resource use diversity within a natural population. Proc R Soc B-Biol Sci 274:839-844

Svanbäck R, Eklov P, Fransson R, Holmgren K (2008) Intraspecific competition drives multiple species resource polymorphism in fish communities. Oikos 117:114-124

Valentine-Rose L, Cherry JA, Culp JJ, Perez KE, Pollock JB, Arrington DA, Layman CA (2007a) Floral and faunal differences between fragmented and unfragmented Bahamian tidal creeks. Wetlands 27:702-718

Valentine-Rose L, Layman CA, Arrington DA, Rypel AL (2007b) Habitat fragmentation decreases fish secondary production in Bahamian tidal creeks. Bull Mar Sci 80:863-877

Van den Avyle MJ, Evans JW (1990) Temperature Selection by Striped Bass in a Gulf of Mexico Coastal River System. North Am J Fish Manage 10:58-66

Van Valen L (1965) Morphological Variation and Width of Ecological Niche. Am Nat 99:377-390

Verweij MC, Nagelkerken I, Hol KEM, van den Beld A, van der Velde G (2007) Space use of Lutjanus apodus including movement between a putative nursery and a coral reef. Bull Mar Sci 81:127-138

Verweij MC, Nagelkerken I, de Graaff D, Peeters M, Bakker EJ, van der Velde G (2006) Structure, food and shade attract juvenile coral reef fish to mangrove and seagrass habitats: a field experiment. Mar Ecol Prog Ser 306:257-268

Weller RR, Winter JD (2001) Seasonal variation in home range size and habitat use of flathead catfish in buffalo springs lake, Texas. North Am J Fish Manage 21:792800

Whitham TG (1978) Habitat selection by pemphigus aphids in response to resource limitation and competition. Ecology 59:1164-1176

Willis TJ, Parsons DM, Babcock RC (2001) Evidence for long-term site fidelity of snapper (Pagrus auratus) within a marine reserve. N Z J Mar Freshw Res 35:581590 
Wilson DS, Coleman K, Clark AB, Biederman L (1993) Shy-bold continuum in pumpkinseed sunfish (Lepomis gibbosus) - an ecological study of a psychological trait. J Comp Psychol 107:250-260

Worm B, Barbier EB, Beaumont N, Duffy JE, Folke C, Halpern BS, Jackson JBC, Lotze HK, Micheli F, Palumbi SR, Sala E, Selkoe KA, Stachowicz JJ, Watson R (2006) Impacts of biodiversity loss on ocean ecosystem services. Science 314:787-790 
CHAPTER III

FACTORS AFFECTING RESOURCE USE VARIATION FOR AN ABUNDANT COASTAL FISH PREDATOR, LUTJANUS APODUS, IN A BAHAMIAN WETLAND SYSTEM 


\begin{abstract}
Studies of resource use by fishes reflect important ecological interactions, and provide insight into the structure of aquatic food webs. To this end, fish stocks are often viewed as homogeneous units despite increasing evidence that among-individual variation in resource use within populations is common. Such intraspecific variation in resource use can be a result of ontogenetic-based diet shifts, differences in individual feeding behavior within age groups (i.e., individual specialization), and temporal variation in resource pools. I examined trophic interactions in schoolmaster snapper Lutjanus apodus (Walbaum, 1972), over multiple seasons and across size classes, in a Bahamian wetland system. Using combined stable isotope and stomach content analyses, I found that, as with many other fishes, sub-adults fed at higher trophic levels than juveniles, likely because of a shift from feeding predominantly on smaller prey taxa (e.g., shrimps) to larger prey taxa (e.g., crabs and teleosts). Sub-adults seem to extend their foraging range to adjacent seagrass beds, whereas juveniles predominantly feed within mangrove prop root habitats. Niche width and degree of individual dietary specialization varied among years, suggesting important levels of temporal variation. In sum, I show that individual snapper did not use resources homogeneously, and outline some of the factors that underlie this variation.
\end{abstract}




\section{Introduction}

Overfishing and habitat degradation have driven drastic declines in many coastal fish stocks (Jackson et al. 2001, Myers et al. 2007, Worm et al. 2009). These declines are of great concern given fishes' economic and ecological importance in coastal ecosystems (Jackson et al. 2001, Hilborn et al. 2003). Understanding resource use of focal species can aid in documenting the wide ranging impacts that population declines may have on ecosystem function. For instance, severe declines of top predators on the east coast of the United States ultimately led to the widespread collapse of scallop populations (Myers et al. 2007). An understanding of such cascading impacts can be gleaned from the study of the underlying trophic relationships and resource use patterns of the focal organisms.

Fish populations are often treated as homogeneous units, despite increasing evidence that fishes exhibit great among individual variation in resource use (Bolnick et al. 2003, Chassot et al. 2008, Adams et al. 2009). Intrapopulation variation in resource use can be related to ontogenetic diet shifts (Polis 1984, Werner \& Gilliam 1984), but also to differences in feeding behavior within certain life history stages (Bolnick et al. 2003, Bolnick et al. 2011, Araujo et al. 2011). For example, individual specialization, defined as a significantly smaller dietary niche of an individual than the population niche for reasons not attributable to its sex, body size, or age classes, has been identified in a number of diverse taxa (Ringler 1983, Magurran 1986, Schindler et al. 1997, Bolnick et al. 2003, Araujo et al. 2011). In addition, individuals may experience temporal differences in resource availability that may drive variation in resource use (Weliange \& Amarasinghe 2003, Swanson et al. 2008, Hammerschlag et al. 2010). Such resource variation can influence community dynamics and ecosystem function, with important 
evolutionary, ecological and conservation implications (Van Valen 1965, Roughgarden 1972, 1974, Schindler et al. 1997, Bolnick et al. 2003, Filin \& Ovadia 2007, Okuyama 2008, Byron \& Link 2010).

In the present study, I investigated diet and feeding behavior of the schoolmaster snapper Lutjanus apodus (Walbaum, 1972) within a Bahamian wetland system, and examined various factors that may affect resource use within this population. Specifically, I investigated whether (1) diet changed through ontogeny, (2) diet specialization was present within ontogenetic groups, and (3) season and year affected diet within and between ontogenetic groups. To address these questions, I employed stable isotope and stomach content analyses, two complimentary methods used to characterize trophic relationships (Layman \& Post 2008). Combined, these approaches revealed extensive insight into schoolmaster feeding patterns, and suggested the multiple levels at which diet variation can occur.

\section{Materials and Methods}

\section{Study Site and Species}

Jungle Creek $\left(26^{\circ} 21^{\prime} 36^{\prime \prime} \mathrm{N}, 77^{\circ} 00^{\prime} 59^{\prime \prime} \mathrm{W}\right)$ is a mangrove dominated tidal wetland, locally called a "tidal creek", situated on the east side of Abaco Island, Bahamas. Jungle Creek is $\sim 40$ hectares in size with a maximum low tide depth of $\sim 1 \mathrm{~m}$. The system has semi-diurnal tidal regime and mean daily tidal amplitude of $\sim 0.8 \mathrm{~m}$. There is little freshwater input to this system and thus it is marine-dominated throughout its extent. The most prevalent benthic habitat types are seagrass beds (primarily Thalassia testudinum, 
Banks ex. König, 1805), submerged mangrove prop roots (predominantly Rhizophora mangle, Linnaeus) and sand flats.

Schoolmaster snapper L. apodus is a generalist fish predator in many nearshore ecosystems in the tropics and subtropics of the Atlantic (Allen 1985), and are locally abundant throughout Caribbean coastal ecosystems, likely playing an important ecological role (Nagelkerken et al. 2000, Valentine-Rose et al. 2007). Reproductively immature individuals mainly use mangroves and seagrass beds as nursery habitats, while adults often migrate to patch and coral reefs (Allen 1985). Immature individuals are highly abundant fishes in Bahamian tidal creeks, likely playing an important role in estuarine food webs (Valentine-Rose et al. 2007, Hammerschlag-Peyer \& Layman 2010, Valentine-Rose et al. In Press) and potentially providing new individuals to the adult populations on nearby patch and coral reefs as they mature (Nagelkerken et al. 2000, Adams et al. 2006). Since the size range of schoolmaster snapper in Jungle Creek does not include reproductively mature adults ( $>250 \mathrm{~mm}$ fork length; Munro 1983), I a priori divided individuals into juveniles ( $<125 \mathrm{~mm}$ standard length, SL; including age class 1 and 2) and sub-adults ( $\geq 125 \mathrm{~mm} \mathrm{SL}$; including age classes 3 to 7 years) on the basis of schoolmaster otolith readings (A. Rypel, University of Alabama, unpublished data). Ideally, size categories for comparisons would be on the basis of ecologically relevant divisions, e.g., on the basis of year classes of individuals or on the basis of a priori sizes at which Gestalt diet shifts occur (Werner \& Gilliam 1984). Such clear divisions were not available in my case, so I chose a size division that would best balance sample sizes among groups. In using such an approach, I increased my power to identify overall 
differences among larger and smaller individuals, providing the foundation for more detailed size-based analyses.

\section{Data Collection}

Schoolmaster snapper were caught using baited hooks, fish traps, and cast nets during two consecutive wet (May - August) and dry seasons (December - February) from 2007 to 2009 (i.e., Wet 2007, Dry 2008, Wet 2008, Dry 2009). Sizes of individuals sampled in this study were representative of the size structure of schoolmaster in these systems (Hammerschlag-Peyer \& Layman 2010). Upon capture, each fish was anesthetized in a mixture of fresh seawater and clove oil (active ingredient: eugenol), a commonly used fish anesthetic (Cotter \& Rodruck 2006). After measuring standard length, non-lethal stomach regurgitation was performed on each individual for gut content analysis following methods modified from Layman and Winemiller (2004). During stomach regurgitation, the entire stomach was inverted to ensure collection of all contents. After the procedure, each fish was immediately transferred to a cooler with fresh seawater for recovery and a small sample of the dorsal fin tissue $\left(\sim 1 \mathrm{~cm}^{2}\right)$ was removed for stable isotope analysis. After $\sim 15 \mathrm{~min}$, individual fish were released at their capture location. Fifty individuals were sacrificed to verify the effectiveness of the regurgitation method; only $2 \%(\mathrm{n}=1)$ of the sacrificed individuals had additional stomach contents remaining after regurgitation. Stomach contents were identified to the lowest taxonomic level possible, and the volume of each prey item was measured via displacement with a graduated cylinder. Fin clips were transported on ice to a field station, stored in a freezer, and later processed at Florida International University. 
All stable isotope values are reported in the $\delta$ notation where $\delta^{13} \mathrm{C}$ or $\delta^{15} \mathrm{~N}=$ $\left[\left(R_{\text {sample }} / R_{\text {standard }}\right)-1\right] \times 1000$, and $R$ is the ${ }^{13} \mathrm{C} /{ }^{12} \mathrm{C}$ or ${ }^{15} \mathrm{~N} /{ }^{14} \mathrm{~N}$ ratio. I focused on ratios of $\delta^{15} \mathrm{~N}$ and $\delta^{13} \mathrm{C}$ because each reveals a distinct aspect of the consumer's long-term (for fin: week to months) trophic niche. The $\delta^{15} \mathrm{~N}$ values exhibit stepwise enrichment with trophic transfers, and can thus be used to estimate an organism's trophic position relative to that of others in a food web (DeNiro \& Epstein 1981, Minagawa \& Wada 1984, Peterson \& Fry 1987). The $\delta^{13} \mathrm{C}$ values vary substantially among primary producers with different photosynthetic pathways (e.g., C3 vs. C4 plants) and are subject to diverse environmental conditions (e.g., productivity), but change little with trophic transfers, and can thus be used to infer sources of dietary carbon (Rounick \& Winterbourn 1986, Peterson \& Fry 1987, France \& Peters 1997, Layman 2007).

Prey taxa (identified in stomach content analysis) were collected in Jungle Creek using dip and cast nets during 2008 and 2009. At least three individuals of each prey item were sampled. Each prey organism was dried at $60^{\circ}$ Celsius for a minimum of 48 hours and subsequently dry weight was measured. For stable isotope analysis, the whole organism for prey taxa and the fin tissue of schoolmaster snapper were used. The $\delta^{13} \mathrm{C}$ and $\delta^{15} \mathrm{~N}$ of schoolmaster snapper fin and muscle tissue are highly correlated within individuals $\left(\delta^{13} \mathrm{C}\right.$ fin $=1.06 * \delta^{13} \mathrm{C}$ muscle $+2.84, \mathrm{R}^{2}=0.97$; and $\delta^{15} \mathrm{~N}$ fin $=1.13 * \delta^{15} \mathrm{~N}$ muscle $-1.8, \mathrm{R}^{2}=0.82, \mathrm{~N}=23$ individuals). For shrimps and crabs, separate analyses were performed for $\delta^{13} \mathrm{C}$ and $\delta^{15} \mathrm{~N}$, with samples for $\delta^{13} \mathrm{C}$ first acidified to remove inorganic carbon following Kolasinski et al. (2008). Stable isotope preparation of prey and fin tissues followed Post et al. (2007) and the analysis was conducted at the Yale 
Earth System Center for Stable Isotopic Studies (ESCSIS). Internal standards used were trout muscle with a precision (SD) of $0.14 \%$ for $\delta^{13} \mathrm{C}$ and $0.22 \%$ for $\delta^{15} \mathrm{~N}$ values.

\section{Data Analysis}

I first applied stable isotope analysis to examine shifts in niche width and isotopic position between sample years, seasons and ontogenetic groups. I then investigated stomach content data for differences in diet between years, seasons and size classes. Finally, I used the combination of stable isotope and stomach content data to measure the degree of individual specialization for each group and potential changes of their degree with time. Details for these analyses are outlined herein.

For stable isotope data, univariate analysis was applied to examine potential differences in $\delta^{13} \mathrm{C}$ and $\delta^{15} \mathrm{~N}$ values between years (2007-08 and 2008-09), seasons (wet and dry) and size classes (juveniles and sub-adults). The $\delta^{13} \mathrm{C}$ and $\delta^{15} \mathrm{~N}$ values were tested for normality and homogeneity of variance in $\mathrm{R}$ version 2.11.1 (R Development Core Team 2008). The $\delta^{13} \mathrm{C}$ values met the model assumptions, thus stepwise one-way analysis of variance (ANOVA) was used to assess the influence of each factor (year, season, size class) separately (Ley \& Halliday 2007, Hammerschlag \& Serafy 2009). The $\delta^{15} \mathrm{~N}$ values did not meet model assumptions, so stepwise one-way Kruskal-Wallis analysis was employed. Analyses were performed in SYSTAT version 10.2 (SYSTAT 2002) and statistical significance was declared at $\alpha<0.05$.

One representation of niche width of a given group is the total area of a subset of individuals of that group within a bivariate isotope space (here within a $\delta^{13} \mathrm{C}-\delta^{15} \mathrm{~N}$ biplot). It can be calculated as the minimum convex polygon (MCP; Anderson 1982), i.e., the 
area of the smallest convex polygon that contains all individuals of the sample group (Layman et al. 2007). I measured MCP of each size class in ArcMap GIS version 9.3.1 (ERSI 2008) and verified that the sample size of each group was sufficient to adequately represent the niche width of that particular group on the basis of performed bootstraps (1000 replicates) in Animal Movements extension (Hooge \& Eichenlaub 1997) for ArcView GIS version 3.2 (ERSI 1999). If the curve of the relationship between sample size and niche width reaches an asymptote, it can be assumed that enough individuals were sampled (Hurturbia 1973, Cailliet 1977, Ferry \& Cailliet 1996).

The MCP approach offers some advantages for characterizing niche width when compared to alternative analyses. The MCP approach is powerful because it incorporates each individual of the population's sub-sample, and thus includes information about the niche width of the population including every sampled individual. Conversely, other approaches are targeted at identifying the "core" niche of the population, a niche metric which could exclude particular individual niches from the characterization of the population niche (Jackson et al. 2011). Either of these approaches may be more relevant with respect to a particular question of interest and/or the nature of the underlying data set. Herein, I chose to examine niche width of juvenile and sub-adult schoolmaster snapper using the MCP approach, as the importance of individual level niche variation is increasingly recognized as an important component of ecological dynamics and evolutionary trajectories (Bolnick et al. 2003, Bolnick et al. 2011).

To identify any changes in resource use between the two size classes, I performed a multivariate test for differences in central tendency and dispersion following Turner et al. (2010) in R version 2.11.1 (R Development Core Team 2008). In the context of this 
study, differences in central tendency represent a shift in isotopic niche position, and differences in dispersion represent a change in niche width between the two size classes. Difference in central tendency was measured by computing Euclidean distance between the centroids (bivariate means) of the two groups and was considered to be different between the two groups if the Euclidean distance between them was significantly greater than zero (Turner et al. 2010). Similarly, the mean distance to centroid was computed to test for differences in dispersion (for more details, see Turner et al. 2010).

Gut contents of schoolmaster snapper were analyzed on the basis of the volume of prey items from various taxonomic groups. For analysis, I omitted all empty stomachs, as well as prey items that were classified as unidentifiable crustacean, crab, or shrimp. Although the proportion of unidentifiable crustacean and shrimp were relatively low $(<3.3 \%$, see below), the proportion of unidentifiable crab was relatively high (11\%). Despite the omission of this group, identifiable crabs (i.e., Panopeus sp., Aratus sp. and Xanthoidea) still constituted a large percentage of the schoolmaster diet and thus, their importance was well represented (see Results, Fig. 3). The external features of teleost fishes disintegrate rather quickly once ingested (Randall 1967, Brulé \& Canché 1993), and are thus difficult to identify to species. Consequently, I grouped all consumed fishes into a teleost category. Several other prey taxa constituted a relatively small volume in the schoolmaster diets. Since small volumes of prey taxa can bias stomach content analysis (Clarke \& Warwick 1994), I used a quantitative criterion following Araujo et al. (2007b) to determine which prey categories to include in the analysis. This criterion consists of calculating the reciprocal of the number $k$ of prey categories consumed $(1 / k)$, and using this value as a cutoff for inclusion of prey categories in further analyses. A 
category $j$ is included if its proportion in the population diet $q_{j} \geq 1 / k$. The cut-off value for schoolmaster snapper was 0.033 , so that categories representing less than $3.3 \%$ of diet items in each species were eliminated. Prey categories included were teleosts (fishes), Panopeus sp. (mud crabs), Aratus sp. (mangrove tree crab), Xanthoidae (superfamily of mud crabs, excluding Panopeus sp.), Alpheus spp. (snapping shrimp), Palaemonetes sp. (grass shrimp), and Farfantepenaeus sp. (pink shrimp).

As with stable isotope data, univariate analysis was applied to examine potential differences in diet among years, seasons and size classes using stomach content data. Stepwise one-way $\chi^{2}$ analysis was performed on volumes of prey taxa to assess the influence of each factor (year, season, size class) separately (Ley \& Halliday 2007, Hammerschlag \& Serafy 2009). Average dissimilarity between groups was measured when necessary using similarity percentages (SIMPER) in PRIMER 5.2.9 (Clarke \& Warwick 1994).

When used together, stable isotope and stomach content analysis are powerful tools to quantify the degree of individual specialization (Votier et al. 2003, Matthews \& Mazumder 2004, Araujo et al. 2007a). To this end, I employed the model of Araujo et al. (2007a) separately for $\delta^{13} \mathrm{C}$ and $\delta^{15} \mathrm{~N}$ values on both juvenile and sub-adult schoolmaster snapper. This model uses the variance in individual stable isotope values (i.e., $\delta^{13} \mathrm{C}$ or $\delta^{15} \mathrm{~N}$ ) of a size class, the stable isotope values (i.e., $\delta^{13} \mathrm{C}$ or $\delta^{15} \mathrm{~N}$ ) of each prey taxa, and the dietary proportion for each prey taxa to estimate the index of individual specialization (i.e., WIC/TNW, WIC = within-individual component, $\mathrm{TNW}=$ total niche width; Bolnick et al. 2002). In this approach, null populations with varying degrees of individual specialization are generated, for which both isotope variances and indices of individual 
specialization are calculated. A curve relating the expected isotopic variances and indices of individual specialization is built, and is then used to interpolate a measure of individual specialization given an empirical variance in isotopes (i.e., given the actual estimated variance in $\delta^{13} \mathrm{C}$ or $\delta^{15} \mathrm{~N}$ for a selected sample of individual consumers). The calculations were performed in the program "VarIso" (http://www2.fiu.edu/ marine/araujo/software.html) using 100 simulations following Araújo et al (2007a). Output data were applied to calculate the expected index of individual specialization for schoolmaster snapper (WIC/TNW). Indices of WIC/TNW close to zero imply strong individual specialization within a size class, while WIC/TNW indices close to 1 suggest homogeneous resource use among individuals of a size class.

\section{Results}

I performed stomach regurgitation on 842 individual schoolmaster snapper during the study period (May 2007-February 2009) with mean SL of $122.6 \pm 29.6 \mathrm{~mm}$ (mean \pm SD; range 45-245 mm) and used a subsample of 150 individuals for my stable isotope analysis (Table 1) with mean SL of $135.4 \pm 34.5 \mathrm{~mm}$ (mean $\pm \mathrm{SD}$; range 63-245 mm). Stepwise one-way analysis of variance revealed that $\delta^{13} \mathrm{C}$ values were not significantly affected by year or season, but were affected by size class (Table 2). The $\delta^{15} \mathrm{~N}$ values did not vary between seasons, yet differed significantly between sampling years and between size classes (Table 3). Linear regression revealed a significant increase in $\delta^{13} \mathrm{C}$ values with body size (i.e., standard length; $\mathrm{R}^{2}=0.16, P<0.0001, \mathrm{n}=150$, Fig. 1A). Similarly, $\delta^{15} \mathrm{~N}$ values increased significantly with body size in $2007-08\left(\mathrm{R}^{2}=0.22, P<0.0001, \mathrm{n}=\right.$ $90)$ and in $2008-09\left(\mathrm{R}^{2}=0.32, P<0.0001, \mathrm{n}=60\right.$, Fig. 1B). 
The MCP of all juveniles (pooled across years and seasons) was 20.7, and the MCP of all sub-adults 17.9 (Fig. 2A). There was a significant difference in isotopic niche position (central tendency) between juveniles $\left(\delta^{13} \mathrm{C}=-13.8 \%, \delta^{15} \mathrm{~N}=7.3 \%\right.$ ) and subadults $\left(\delta^{13} \mathrm{C}=-12.4 \%, \delta^{15} \mathrm{~N}=8 \%\right.$; Euclidean distance $\left.=1.52, P=0.001\right)$, but no change in niche width (dispersion; centroid distance $=0.09, P=0.63$; Fig. 2A) for both years combined. When niche widths of size classes were separated into the two sampling years, the niche width of juveniles and sub-adults was 7.0 and 9.5, respectively, for 2007-2008 (Fig. 2B). There was a significant difference in isotopic niche position between juveniles $\left(\delta^{13} \mathrm{C}=-13.8 \%, \delta^{15} \mathrm{~N}=7.9 \%\right)$ and sub-adults in $2007-08\left(\delta^{13} \mathrm{C}=-12.4 \%, \delta^{15} \mathrm{~N}=8.2 \%\right.$; Euclidean distance $=1.47, P=0.001)$, but no significant shift in niche width (centroid distance $=0.01, P=0.95$; Fig. 2B). In contrast, juveniles in 2008-09 did not only have a different isotopic niche position $\left(\delta^{13} \mathrm{C}=-13.8 \%\right.$, $\left.\delta^{15} \mathrm{~N}=6.6 \%\right)$ as the sub-adults $\left(\delta^{13} \mathrm{C}=\right.$ $12.6 \%, \delta^{15} \mathrm{~N}=7.5 \%$; Euclidean distance $=1.51, P=0.008$ ), but also their niche width was significantly smaller than that of sub-adults (11.9 vs. 13.6 ; centroid distance $=0.69$, $P=0.012$; Fig. 2C).

From the 842 sampled individuals, 261 individuals (31\%) with mean SL of 120.7 $\pm 30.6 \mathrm{~mm}$ (mean $\pm \mathrm{SD}$; range $63-245 \mathrm{~mm}$ ) had identifiable prey items in their stomachs (Table 4). The stepwise one-way $\chi^{2}$ analysis revealed that there was only a statistically significant difference in diet composition between juveniles and sub-adults in 2008-09 $\left(\chi^{2}\right.$ $=17.7, \mathrm{df}=6, P=0.007$; Table 5). Prey taxa that were primarily responsible for the observed difference in dietary composition between juveniles and sub-adults in 2008-09 were Aratus sp. (30.1\%) and teleosts (26.3\%, percent contribution to the overall dissimilarity from SIMPER). Diet comparison between juveniles and sub-adults (pooled 
across years) revealed that juveniles mostly consumed Aratus sp. crabs (35\%), Alpheus spp. shrimps (27\%), and teleosts (20\%), while sub-adults' diets were dominated by teleosts (29\%) and Aratus sp. (24\%) (Fig. 3A). The diets of the two groups were significantly different $\left(\chi^{2}=18.7, \mathrm{df}=6, P=0.005\right.$; Fig. 3A, Table 5). When their diet was compared within each year, juveniles in 2007-08 mostly consumed teleosts (36\%) and Aratus sp. (26\%), and sub-adults teleosts (48\%) and Alpheus spp. (14\%), but the diets between the two groups did not differ significantly $\left(\chi^{2}=5.6, \mathrm{df}=6, P=0.47\right.$; Fig. 3B, Table 5). In 2008-09, juveniles mainly fed on Aratus sp. (39\%) and Alpheus spp. (31\%), and sub-adults Aratus sp. (33\%), Panopeus sp. (19\%) and teleosts (18\%). The diet of both groups in 2008-09 differed significantly $\left(\chi^{2}=17.7, \mathrm{df}=6, P=0.007\right.$; Fig. $3 \mathrm{C}$, Table 5). Regardless of year, the proportion of teleosts, Panopeus sp., Xanthoidea, and Farfantepenaeus sp. was higher, and the proportion of Aratus sp., Alpheus spp., and Palaemonetes sp. was lower in sub-adult schoolmaster snapper (Fig. 3).

The estimated degree of individual specialization (WIC/TNW) for juvenile and sub-adult schoolmaster snapper (pooled across years and seasons) on the basis of $\delta^{13} \mathrm{C}$ values were relatively low (i.e., relatively high $\mathrm{WIC} / \mathrm{TNW} ; 0.71$ and 0.67 , respectively). Likewise, the magnitude of individual specialization on the basis of $\delta^{15} \mathrm{~N}$ values was relatively low for juveniles and sub-adults in 2007-08 ( 0.88 and 0.71 , respectively), whereas it was relatively higher for the two size classes in 2008-09 (0.71 and 0.50, respectively), suggesting some temporal variation in degree of dietary specialization. For comparison, natural populations across broad taxonomic groups have been found to have an average WIC/TNW index of $0.66 \pm 0.209$ (mean \pm s.d.; $\mathrm{N}=78$; Araujo et al. 2011). 


\section{Discussion}

Variation in resource use affects population dynamics, community structure and ecosystem functions (Werner \& Hall 1988, Polis \& Strong 1996, Claessen et al. 2002, Subalusky et al. 2009). For example, many fishes change their diet through ontogeny, which can decrease intrapopulation resource competition (Werner \& Gilliam 1984). An increasing number of studies also have revealed the occurrence of individual-level variation within size classes (Bolnick et al. 2003, Araujo et al. 2011). In this context, I examined patterns in resource use in one of the most abundant wetland fishes in The Bahamas. In doing so, I provide a framework for incorporating such intrapopulation variation into the study of coastal organisms' resource usage.

As $\delta^{13} \mathrm{C}$ can differ considerably among primary producers with different photosynthetic pathways (e.g., C3 vs. C4 plants) or with diverse environmental conditions (e.g., productivity), but changes little with trophic transfers (DeNiro \& Epstein 1981, Peterson \& Fry 1987, Post 2002), $\delta^{13} \mathrm{C}$ can be useful in help determining primary habitats or source pools utilized by consumers. The $\delta^{13} \mathrm{C}$ value is especially useful in coastal ecosystems because some of the most prominent habitat types, i.e., mangroves and seagrass beds, have distinct $\delta^{13} \mathrm{C}$ signatures, with mangroves (and mangroveassociated algae) being more depleted in $\delta^{13} \mathrm{C}$ than seagrass habitats (and seagrassassociated algae; Kieckbusch et al. 2004). Snappers (Lutjanidae) are known to reside in mangrove areas, but may either feed within this habitat or in others (HammerschlagPeyer \& Layman 2010). In my study, juvenile schoolmaster snapper were characterized by values similar to mangrove-based food webs, whereas sub-adult schoolmaster snapper had more enriched $\delta^{13} \mathrm{C}$ values than juveniles, likely reflecting greater reliance on 
seagrass-based food sources (Kieckbusch et al. 2004, Figs. 1, 2 and 4). Dietary information supported this interpretation. For example, sub-adults fed more on sp. that are common in seagrass beds (Fig. 4), than juveniles. Aratus sp., the primary diet item of juveniles (Fig. 3), is only found on mangrove prop roots where they feed on mangroveassociated epiphytic communities (and thus have a depleted $\delta^{13} \mathrm{C}$, Fig. 4). As such, my data suggest that sub-adults could have expanded their foraging range to adjacent seagrass beds, whereas juveniles remained closer to the mangrove fringe of the creeks feeding on local food sources in their protective nursery habitat.

Such an increase in foraging range with ontogeny is common in fishes (for a review: Minns 1995), often because of a decrease in predation risk (Werner \& Hall 1988) or change in resource requirements (Carfagno \& Weatherhead 2008) with increasing body size. In a previous study, I found that differences in foraging range of schoolmaster snapper (L.apodus) and a closely related species gray snapper (L. griseus), were not explained by body size (Hammerschlag-Peyer \& Layman 2010). Yet, I used larger individuals in that study (schoolmaster snapper: SL 110-272mm, gray snapper: SL 111$276 \mathrm{~mm}$ ) than in this focal study. Since the smallest individuals are the most susceptible to predators, juveniles used in this study (SL 45-124 mm) may be expected to have the most constrained foraging range to minimize predation risk. Once a certain size threshold is reached, individual-level foraging differences may override the apparent restricted foraging range of the juveniles (Hammerschlag-Peyer \& Layman 2010). These data again suggest how a combination of stable isotope, diet and movement data can be a powerful suite of tools to study resource use of coastal organisms (Hammerschlag-Peyer \& Layman 2010, Matich et al. 2010, Rosenblatt \& Heithaus 2011). 
Body size and trophic position are often correlated, such that larger animals feed at higher trophic levels (Sholtodouglas et al. 1991, Cohen et al. 1993, Fry \& Quinones 1994, France et al. 1998, Jennings et al. 2001). In my study, sub-adult schoolmaster snapper had more enriched $\delta^{15} \mathrm{~N}$ values than juveniles, suggesting a higher trophic position (Figs. 1, 2, 4). This higher trophic level of sub-adults could have been the result of their consumption of larger prey items and/or increased proportion of teleosts in their diet. On the basis of $\delta^{15} \mathrm{~N}$ values (and an assumed fractionation of $\sim 3 \%$ ) teleosts were approximately a trophic level higher than most other prey taxa (Fig. 3, Table 6). Studies on gray snapper (L. griseus) have shown that piscivory increases through ontogeny (Starck \& Schroeder 1971), and I would expect this trend to be even more pronounced in schoolmaster snapper if I would have included larger size classes in the diet analysis.

Temporal differences can be used to explore mechanisms driving ontogenetic niche shifts and individual specialization (Link \& Garrison 2002, Herrera et al. 2008). In the present study, niche width and degree of individual specialization differed between years. The data were consistent with the "niche variation hypothesis" (Van Valen 1965) which suggests that populations (or size/age groups) with broader niches are more variable in resource use (i.e., higher among-individual variation) than populations with narrower niches (Soule \& Stewart 1970). A wider niche width can be attained in one of two ways: (1) all individuals of that population/group utilize more resources (all individuals have large niche widths; low among individual variation) or (2) the entire population/group utilizes more resources, yet each individual maintains a narrow niche that overlaps little among conspecifics (high among individual variation; Bolnick et al. 2007, Araujo et al. 2011). In this study, juvenile and sub-adult schoolmaster snapper had 
a larger niche width and relatively higher degree of individual specialization in 2008-09, suggesting the occurrence of the latter scenario (\#2 above). These niche differences were mostly driven by juveniles and sub-adults presumably feeding on prey at different trophic levels, as suggested by the more variable $\delta^{15} \mathrm{~N}$ range of juvenile and sub-adult snappers in 2008-09.

Underlying factors driving changes in niche width and degree of individual specialization between years could have been related to temporal changes in the relative degree of intraspecific competition and/or resource abundance. For instance, several empirical studies found that niche width and magnitude of individual specialization increased with population density (a proxy for intraspecific competition; Svanbäck and Persson 2004, Svanbäck et al. 2008, Svanbäck and Persson 2009, Frederich et al. 2010). In the present example, varying recruitment rates of schoolmaster snapper between years may have driven different population densities. In addition, seagrass productivity might have fluctuated between years (Fourqurean et al. 2001), which could have affected prey abundance. Additional research is needed to explore mechanisms which drive niche variation in these systems.

Some other factors might have affected the findings of my study. For example, variation in stable isotope ratios between juvenile and sub-adult schoolmaster snapper could also have been driven by differences in isotopic turnover rates (i.e., renewal process of molecules in a given tissue commonly measured when half of the tissue composition has changed; Martinez del Rio et al. 2009) between the two size classes, rather than a shift in resource use. Some studies have shown that turnover rates of $\delta^{13} \mathrm{C}$ and $\delta^{15} \mathrm{~N}$ can change with body size in fishes, with smaller individuals having faster 
turnover rates as a result of higher growth rates or increased metabolic rates (Hesslein et al. 1993, Suring \& Wing 2009). Yet, my stomach content data corroborate the isotope pattern of a shift in resource use between juvenile and sub-adult schoolmaster snapper, especially in 2008-09 (Table 5, Fig. 3). Another potential study limitation could have been the low resolution of the taxonomic identification level of teleosts in the stomach content analysis, especially because teleosts were an important component of the schoolmaster diet (Fig. 3). My stable isotope analysis, however, supports the stomach content findings that schoolmaster snapper increasingly were relaying on teleosts in their diet (Figs. 2 and 4). Lastly, potential spatial and temporal variability in isotopic values of primary producers could also have affected my isotopic findings (Fourqurean et al. 2005, Fourqurean et al. 2007). Yet, patterns found on the basis of stable isotope analysis were greatly confirmed by stomach content analysis. Consequently, although my findings might have been affected by the limitations of stable isotope and stomach content analyses (Votier et al. 2003, Newsome et al. 2007, Layman \& Post 2008), my results of these two methods are largely consistent and thus suggest real ecological patterns.

I show that schoolmaster snapper do not use resources homogeneously, and offer a framework that illustrates how to investigate several levels of intrapopulation resource variation. Specifically, my study demonstrates that the combined use of stable isotope and gut content analysis can be very powerful in providing in-depth insights on resource use (Layman \& Post 2008). My study also provides additional evidence of the need to change the common management perspective that populations consist of homogeneous individuals (Hammerschlag-Peyer \& Layman 2010). The incorporation of intrapopulation 
resource variability in population models has the potential to help generate and improve management strategies.

\section{Acknowledgements}

This study was funded by NSF OCE \#0746164, FIU Graduate School Dissertation Year Fellowship, Judith Evans Parker Travel Scholarship, and Biscayne Bay Research Scholarship. I thank Friends of the Environment (Abaco) and Kaye Rennirt for their logistical support and all people who helped with field and lab work, data analysis and manuscript editing, especially M. Seese, C. Villegas, L. Yeager, S. Giery, M. Araujo and N. Hammerschlag. Sampling of Lutjanus griseus was permitted by the Bahamas

Department of Marine Resources and the FIU Institutional Animal Care and Use Committee (IACUC; Permit Numbers: 09-009, 08-008). 
Table 1: Sample size of stable isotope analysis of fin tissue of individual schoolmaster snapper (Lutjanus apodus)

\begin{tabular}{cccc}
\hline Season & Juveniles & Sub-adults & Total \\
\hline Wet 07 & 16 & 41 & 57 \\
Dry 08 & 15 & 18 & 33 \\
Wet 08 & 10 & 17 & 27 \\
Dry 09 & 20 & 13 & 33 \\
Total & 61 & 89 & 150 \\
\hline
\end{tabular}


Table 2 Results of stepwise one-way ANOVA on $\delta^{13} \mathrm{C}$. Bold $P$-values indicate statistically significant findings $(P<0.05)$. For each test, $\mathrm{df}=1$

\begin{tabular}{ccccc}
\hline Step & Grouping factor & Factor analyzed & F & $P$ \\
\hline 1 & none & Year & 1.0 & 0.32 \\
1 & none & Season & 3.3 & 0.07 \\
1 & none & Size Group & 18.0 & $<\mathbf{0 . 0 0 1}$ \\
\hline
\end{tabular}


Table 3 Results of stepwise one-way Kruskal-Wallis analysis on $\delta^{15} \mathrm{~N}$. Bold $P$-values indicate statistically significant findings $(P<0.05)$. For each test, $\mathrm{df}=1$

\begin{tabular}{ccccc}
\hline Step & Grouping factor & Factor analyzed & $\mathrm{U}$ & $P$ \\
\hline 1 & none & Year & 4558 & $<\mathbf{0 . 0 0 1}$ \\
1 & none & Season & 1978 & $\mathbf{0 . 0 0 3}$ \\
1 & none & Size Group & 1538 & $<\mathbf{0 . 0 0 1}$ \\
2 & Year (07-08) & Season & 742 & 0.10 \\
2 & Year (07-08) & Size Group & 620 & $\mathbf{0 . 0 1}$ \\
2 & Year (08-09) & Season & 330 & 0.12 \\
2 & Year (08-09) & Size Group & 156 & $<\mathbf{0 . 0 0 1}$ \\
\hline
\end{tabular}


Table 4: Sample size of gut contents in schoolmaster snapper (Lutjanus apodus)

\begin{tabular}{cccc}
\hline Season & Juveniles & Sub-adults & Total \\
\hline Wet 07 & 20 & 45 & 65 \\
Dry 08 & 39 & 14 & 53 \\
Wet 08 & 40 & 27 & 67 \\
Dry 09 & 66 & 10 & 76 \\
Total & 165 & 96 & 261 \\
\hline
\end{tabular}


Table 5 Results of stepwise one-way $\chi^{2}$ analysis on gut content data. Bold $P$-values indicate statistically significant findings $(P<0.05)$. For each test, $\mathrm{df}=6$

\begin{tabular}{ccccc}
\hline Step & Grouping factor & Factor analyzed & $\chi^{2}$ & $P$ \\
\hline 1 & none & Year & 12.9 & $\mathbf{0 . 0 4}$ \\
1 & none & Season & 11.3 & 0.08 \\
1 & none & Size Group & 18.7 & $\mathbf{0 . 0 0 5}$ \\
2 & Year (07-08) & Size Group & 5.6 & 0.47 \\
2 & Year (08-09) & Size Group & 17.7 & $\mathbf{0 . 0 0 7}$ \\
\hline
\end{tabular}


Table 6: $\delta^{13} \mathrm{C}$ values, $\delta^{15} \mathrm{~N}$ values and sample size (n) for prey items used in the individual specialization model (see text for more detail)

\begin{tabular}{lccc}
\hline Prey Category & Mean $\delta^{13} \mathrm{C}$ & Mean $\delta^{15} \mathrm{~N}$ & $\mathrm{n}$ \\
\hline Teleost & -13.25 & 6.09 & 32 \\
Panopeus & -14.33 & 3.52 & 12 \\
Aratus & -20.40 & 2.90 & 6 \\
Xanthoidea & -13.62 & 2.58 & 5 \\
Alpheus & -12.70 & 3.65 & 5 \\
Palaemonetes & -13.36 & 5.38 & 8 \\
Farfantepenaeus & -10.27 & 4.49 & 3 \\
Total & & & 71 \\
\hline
\end{tabular}



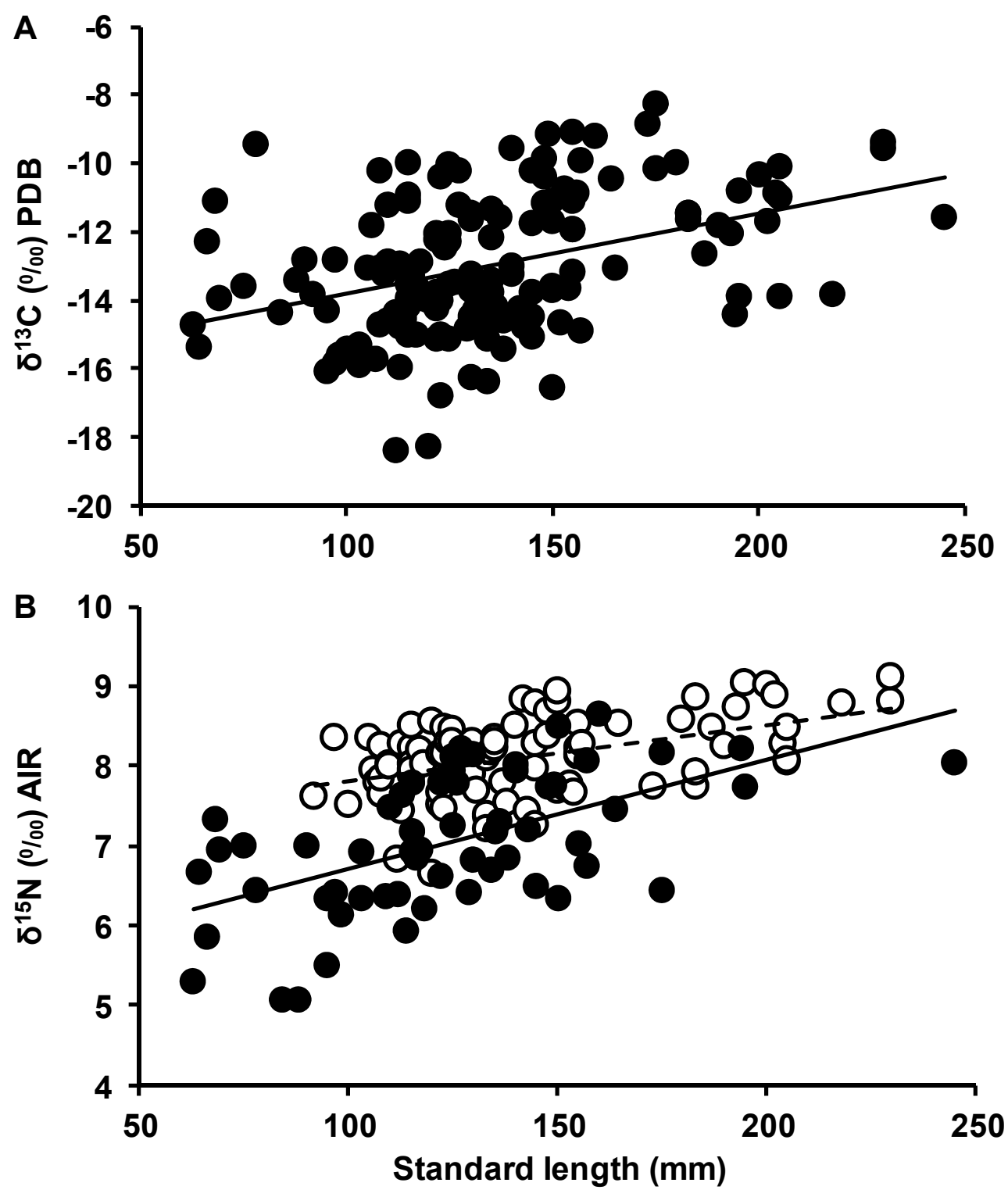

Fig. 1: Significant linear regression between body size (i.e., standard length) and A) $\delta^{13} \mathrm{C}$ $\left(\mathrm{R}^{2}=0.16, P<0.0001, \mathrm{n}=150\right)$ and $\left.\mathrm{B}\right) \delta^{15} \mathrm{~N}$ values. In panel $\mathrm{B}$, open circles represent $\delta^{15} \mathrm{~N}$ of individual schoolmaster snapper for 2007-08 $\left(\mathrm{R}^{2}=0.22, P<0.0001, \mathrm{n}=90\right.$; dashed trendline), and closed circles indicate snapper in the year 2008-09 $\left(\mathrm{R}^{2}=0.32, P<\right.$ 0.0001, $\mathrm{n}=60$; solid trendline). PDB (PeeDee belemnite) and AIR (atmospheric nitrogen) are the global standards of $\delta^{13} \mathrm{C}$ and $\delta^{15} \mathrm{~N}$, respectively 

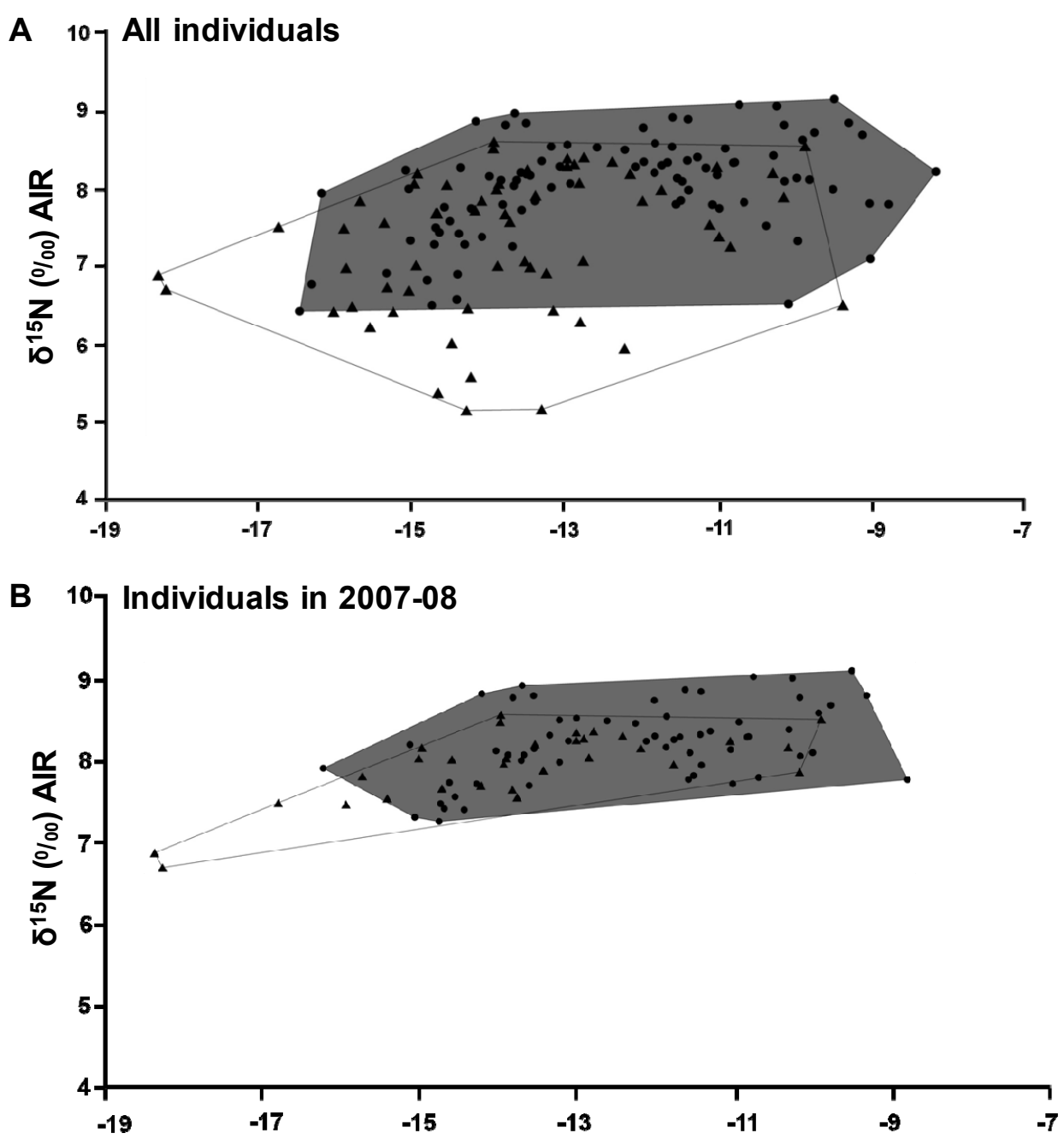

C ${ }^{10}$ Individuals in 2008-09

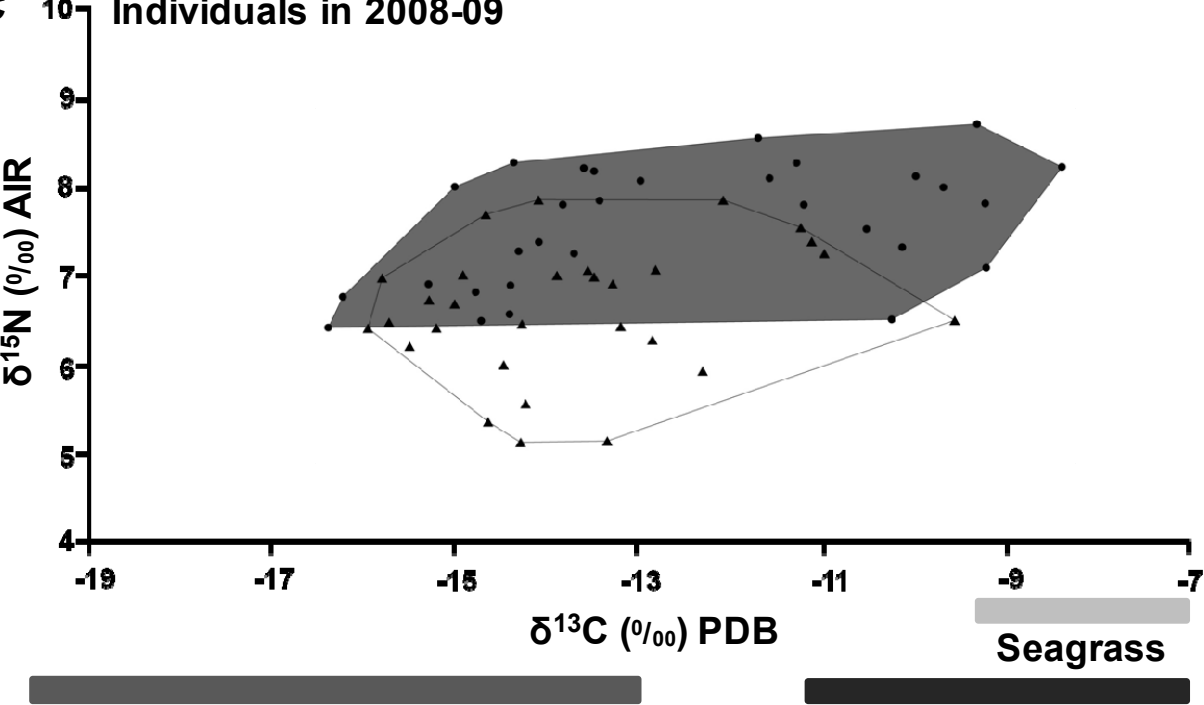

Algae in Mangroves

Algae in Seagrass

-22.4 to -13.0 
Fig. 2 Niche width (estimated using minimum convex polygon, MCP) of juveniles (white) and sub-adults (gray) of schoolmaster snapper Lutjanus apodus represented in a $\delta^{13} \mathrm{C}-\delta^{15} \mathrm{~N}$ niche space. Triangles represent isotope data of individual juveniles and circles individual sub-adults. A) includes all individuals from both sampling years, B) from 2007-08, and C) from 2008-09. The $\delta^{13} \mathrm{C}$ ranges of primary producers are represented by gray bars below the $\mathrm{x}$-axis in Panel $\mathrm{C}$ and are on the basis of stable isotope data from Bahamian primary producers in similar study systems (Kieckbusch et al. 2004). PDB (PeeDee belemnite) and AIR (atmospheric nitrogen) are the global standards of $\delta^{13} \mathrm{C}$ and $\delta^{15} \mathrm{~N}$, respectively 


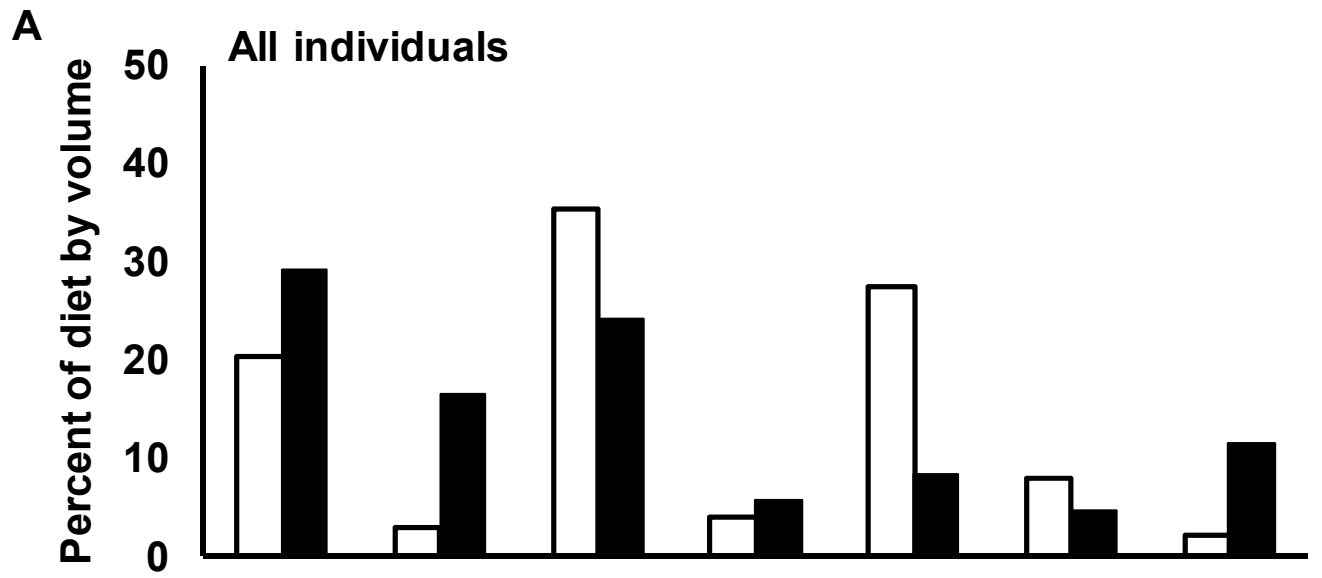

B

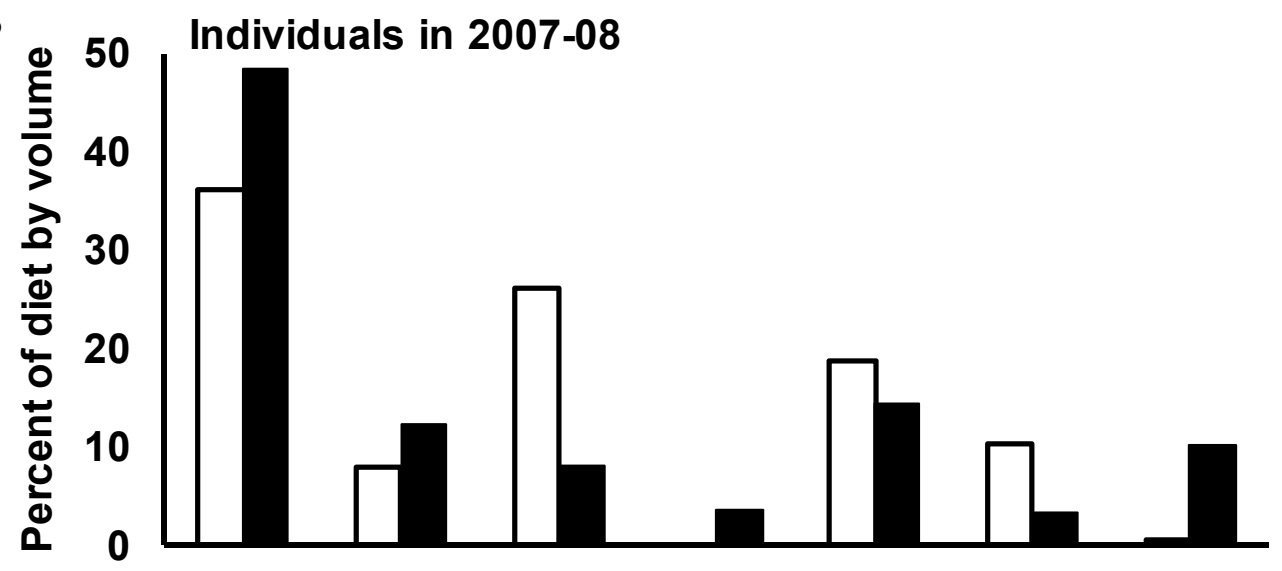

C

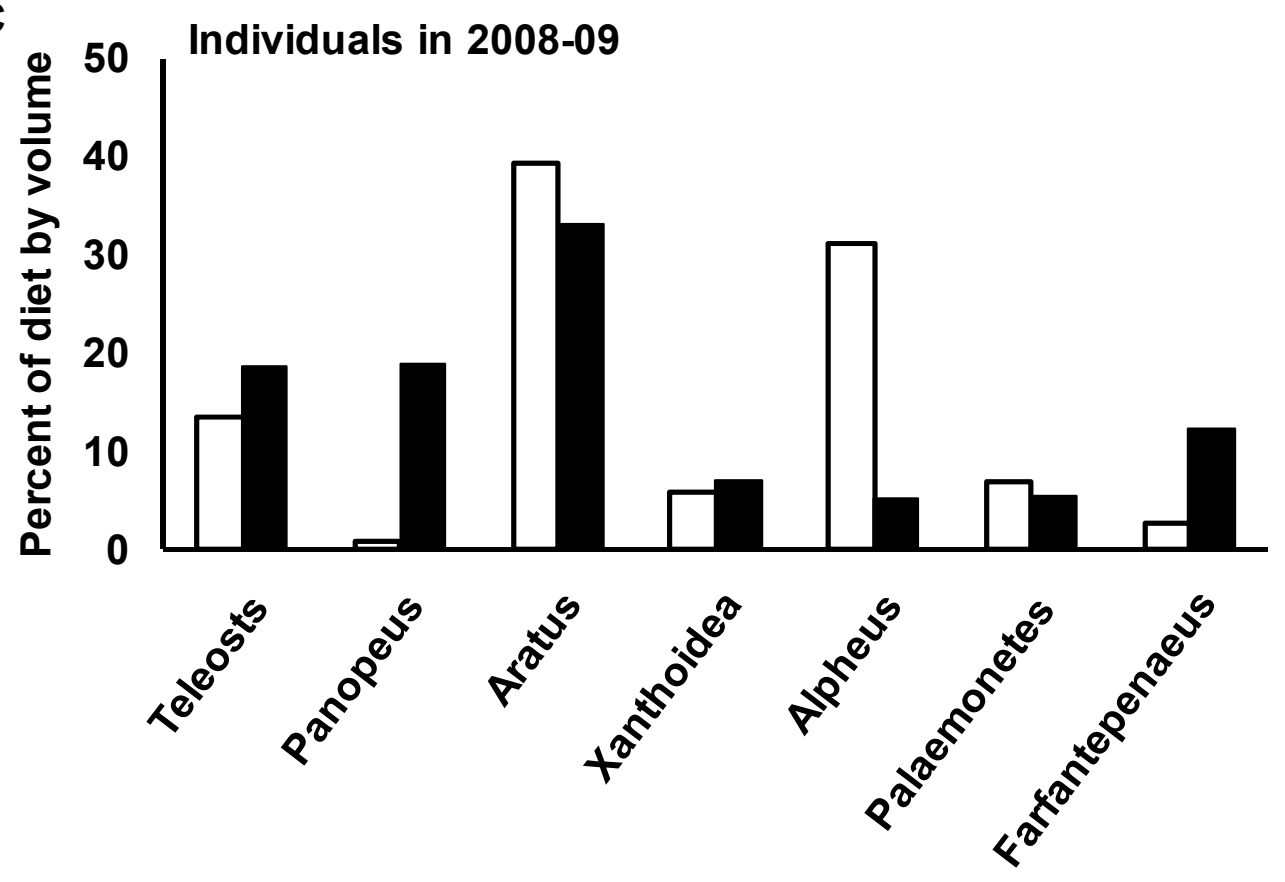


Fig. 3 Percent of diet by volume in individual stomachs of A) all schoolmaster snapper (pooled across years), B) schoolmaster snapper in 2007-08, and C) in 2008-09. White bars represent stomach contents of juveniles and gray bars of sub-adults. Panopeus and Aratus are a crab genera, Xanthidoidae a crab superfamily, while Alpheus, Palaemonetes and Farfantepenaeus are shrimp genera 


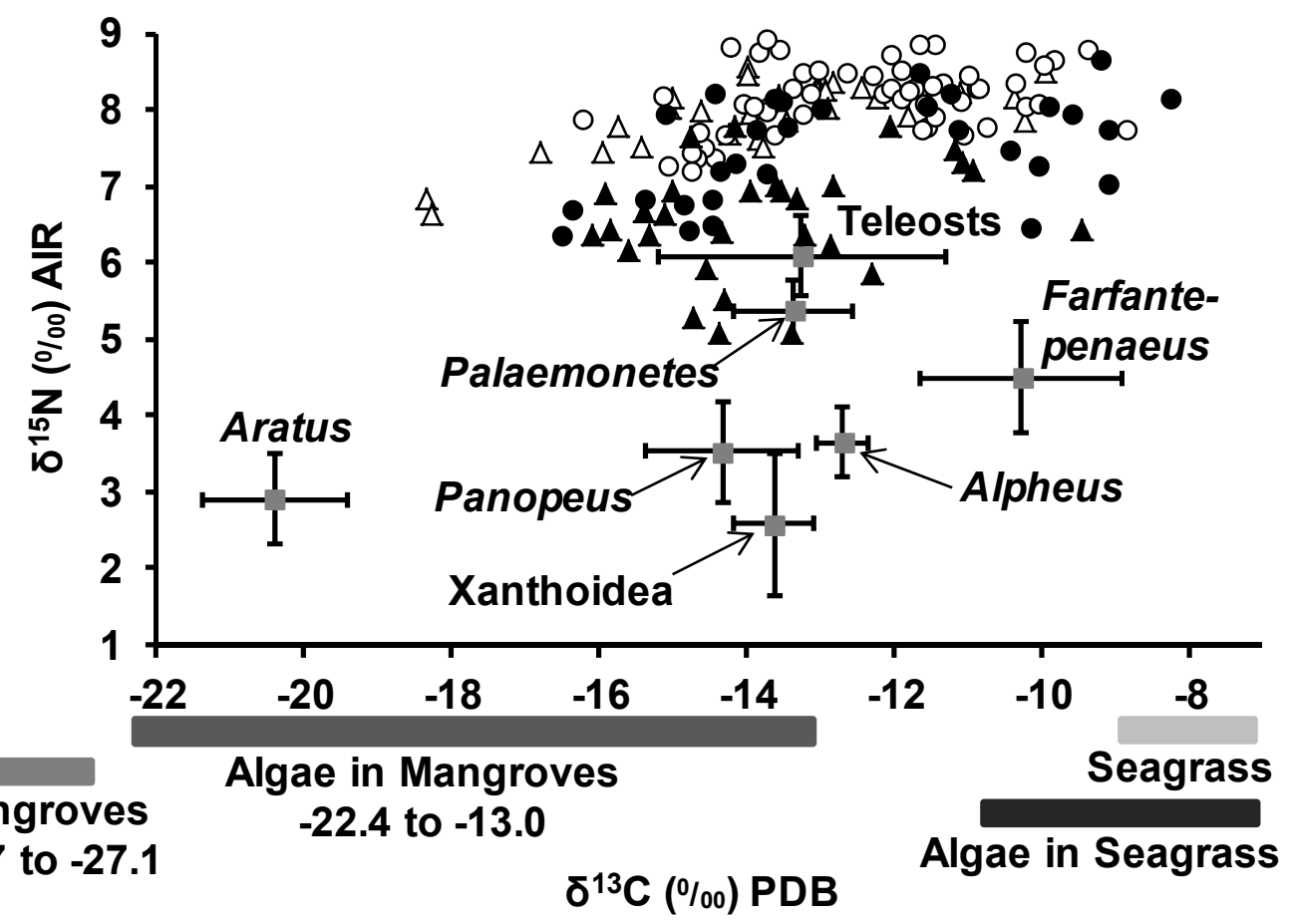

Fig. 4 Stable isotope data of prey taxa (mean value; gray squares), as well as individual juvenile (triangles) and sub-adult (circles) schoolmaster snapper sampled during the sampling year of 2007-08 (white symbols) and of 2008-09 (black symbols) represented in a $\delta^{13} \mathrm{C}-\delta^{15} \mathrm{~N}$ niche space. For the teleost group, I used frillfin goby $(\mathrm{n}=8)$, crested goby $(n=3)$, banded goby $(n=1)$, and rosy blenny $(n=1)$. Error bars represent standard deviation of prey taxa stable isotope values. The $\delta^{13} \mathrm{C}$ ranges of primary producers are represented by gray bars below the $\mathrm{x}$-axis according to stable isotope data from Bahamian primary producers (Kieckbusch et al. 2004). PDB (PeeDee belemnite) and AIR (atmospheric nitrogen) are the global standards of $\delta^{13} \mathrm{C}$ and $\delta^{15} \mathrm{~N}$, respectively 


\section{LITERATURE CITED}

Adams AJ, Dahlgren CP, Kellison GT, Kendall MS, Layman CA, Ley JA, Nagelkerken I, Serafy JE (2006) Nursery function of tropical back-reef systems. Mar Ecol Prog Ser 318:287-301

Adams AJ, Wolfe RK, Layman CA (2009) Preliminary Examination of How Humandriven Freshwater Flow Alteration Affects Trophic Ecology of Juvenile Snook (Centropomus undecimalis) in Estuarine Creeks. Estuar Coasts 32:819-828

Allen GR (1985) FAO species catalogue. Snappers of the world. An annotated and illustrated catalogue of lutjanid species known to date. FAO Fish Synop 6:208

Anderson DJ (1982) The Home Range - a new nonparametric-estimation technique. Ecology 63:103-112

Araujo MS, Bolnick DI, Layman CA (2011) The ecological causes of individual specialization. Ecol Lett 14:948-958

Araujo MS, Bolnick DI, Machado G, Giaretta AA, dos Reis SF (2007a) Using delta C-13 stable isotopes to quantify individual-level diet variation. Oecologia 152:643-654

Araujo MS, dos Reis SF, Giaretta AA, Machado G, Bolnick DI (2007b) Intrapopulation diet variation in four frogs (Leptodactylidae) of the Brazilian Savannah. Copeia:855-865

Bolnick DI, Amarasekare P, Araujo MS, Burger R, Levine JM, Novak M, Rudolf VHW, Schreiber SJ, Urban MC, Vasseur DA (2011) Why intraspecific trait variation matters in community ecology. Trends Ecol Evol 26:183-192

Bolnick DI, Svanback R, Araujo MS, Persson L (2007) Comparative support for the niche variation hypothesis that more generalized populations also are more heterogeneous. Proc Natl Acad Sci U S A 104:10075-10079

Bolnick DI, Svanback R, Fordyce JA, Yang LH, Davis JM, Hulsey CD, Forister ML (2003) The ecology of individuals: Incidence and implications of individual specialization. Am Nat 161:1-28

Bolnick DI, Yang LH, Fordyce JA, Davis JM, Svanback R (2002) Measuring individuallevel resource specialization. Ecology 83:2936-2941 
Brulé T, Canché LGR (1993) Food habits of juvenile red grouper, Epinephelus morio (Valenciennes, 1828), from Campeche Bank, Yucatan, Mexico. Bull Mar Sci 52:772-779

Byron CJ, Link JS (2010) Stability in the feeding ecology of four demersal fish predators in the US Northeast Shelf Large Marine Ecosystem. Mar Ecol Prog Ser 406:239250

Cailliet GM (1977) Several approaches to the feeding ecology of fishes. In: Simenstad C, Lipovsky S (eds) Fish food habit studies: proceedings of the first Pacific Northwest technical workshop. Washington Sea Grant Program, University of Washington, Seattle

Carfagno GLF, Weatherhead PJ (2008) Energetics and space use: intraspecific and interspecific comparisons of movements and home ranges of two Colubrid snakes. J Anim Ecol 77:416-424

Chassot E, Rouyer T, Trenkel VM, Gascuel D (2008) Investigating trophic-level variability in Celtic Sea fish predators. J Fish Biol 73:763-781

Claessen D, Van Oss C, de Roos AM, Persson L (2002) The impact of size-dependent predation on population dynamics and individual life history. Ecology 83:16601675

Clarke KR, Warwick RM (1994) Change in marine communities: an approach to statistical analysis and interpretation, 1st edition, Vol. PRIMER-E, Plymouth

Cohen JE, Pimm SL, Yodzis P, Saldana J (1993) Body sizes of animal predators and animal prey in food webs. J Anim Ecol 62:67-78

Cotter PA, Rodruck KJ (2006) Differential effects of anesthetics on electrical properties of the rainbow trout (Oncorhynchus mykiss) heart. Comp Biochem Physiol A $145: 158-165$

DeNiro MJ, Epstein S (1981) Influence of diet on the distribution of nitrogen isotopes in animals. Geochim Cosmochim Acta 45:341-351

ERSI (1999) ArcView GIS v. 3.2. Redlands, CA

ERSI (2008) ArcMap GIS v. 9.3 Redlands, CA 
Ferry LA, Cailliet GM (1996) Sample size sufficiency and data analysis: are we characterizing and comparing diet properly? In: MacKinlay D, Shearer K (eds) Feeding ecology and nutrition in fish: proceedings of the symposium on the feeding ecology and nutrition in fish. International Congress on the Biology of Fishes, San Francisco, CA

Filin I, Ovadia O (2007) Individual size variation and population stability in a seasonal environment: A discrete-time model and its calibration using grasshoppers. Am Nat 170:719-733

Fourqurean JW, Escorcia SP, Anderson WT, Zieman JC (2005) Spatial and seasonal variability in elemental content, delta C-13, and delta N-15 of Thalassia testudinum from South Florida and its implications for ecosystem studies. Estuaries 28:447-461

Fourqurean JW, Marba N, Duarte CM, Diaz-Almela E, Ruiz-Halpern S (2007) Spatial and temporal variation in the elemental and stable isotopic content of the seagrasses Posidonia oceanica and Cymodocea nodosa from the Illes Balears, Spain. Mar Biol 151:219-232

Fourqurean JW, Willsie A, Rose CD, Rutten LM (2001) Spatial and temporal pattern in seagrass community composition and productivity in south Florida. Mar Biol $138: 341-354$

France R, Chandler M, Peters R (1998) Mapping trophic continua of benthic foodwebs: body size-delta N-15 relationships. Mar Ecol Prog Ser 174:301-306

France RL, Peters RH (1997) Ecosystem differences in the trophic enrichment of C-13 in aquatic food webs. Can J Fish Aquat Sci 54:1255-1258

Frederich B, Lehanse O, Vandewalle P, Lepoint G (2010) Trophic Niche Width, Shift, and Specialization of Dascyllus aruanus in Toliara Lagoon, Madagascar. Copeia:218-226

Fry B, Quinones RB (1994) Biomass spectra and stable isotope indicators of trophic level in zooplankton of the northwest Atlantic. Mar Ecol Prog Ser 112:201-204

Hammerschlag-Peyer CM, Layman CA (2010) Intrapopulation variation in habitat use by two abundant coastal fish species. Mar Ecol Prog Ser 415:211-220

Hammerschlag N, Ovando D, Serafy JE (2010) Seasonal diet and feeding habits of juvenile fishes foraging along a subtropical marine ecotone. Aquat Biol 9:279-290 
Hammerschlag N, Serafy JE (2009) Nocturnal fish utilization of a subtropical mangroveseagrass ecotone. Mar Ecol Evol Persp 31:364-374

Herrera LG, Korine C, Fleming TH, Arad Z (2008) Dietary implications of intrapopulation variation in nitrogen isotope composition of an old world fruit bat. J Mammal 89:1184-1190

Hesslein RH, Hallard KA, Ramlal P (1993) Replacement of Sulfur, Carbon, and Nitrogen in tissue of growing broad whitefish (Corgonus nasus) in response to a change in diet traced by delta-S34, delta-C-13, and delta-N-15. Can J Fish Aquat Sci 50:2071-2076

Hilborn R, Branch TA, Ernst B, Magnusson A, Minte-Vera CV, Scheuerell MD, Valero JL (2003) State of the world's fisheries. Annl Rev Environ Res 28:359-399

Hooge PN, Eichenlaub B (1997) Animal movement extension to ArcView ver. 1.1. In. Alaska Science Center, Biological Science Office, U.S. Geological Survey, Anchorage, AK, USA

Hurturbia J (1973) Trophic diversity measurement in sympatric predatory species. Ecology 54:885-890

Jackson AL, Inger R, Parnell AC, Bearhop S (2011) Comparing isotopic niche widths among and within communities: SIBER - Stable Isotope Bayesian Ellipses in R. J Anim Ecol 80:595-602

Jackson JBC, Kirby MX, Berger WH, Bjorndal KA, Botsford LW, Bourque BJ, Bradbury RH, Cooke R, Erlandson J, Estes JA, Hughes TP, Kidwell S, Lange CB, Lenihan HS, Pandolfi JM, Peterson CH, Steneck RS, Tegner MJ, Warner RR (2001) Historical overfishing and the recent collapse of coastal ecosystems. Science 293:629-638

Jennings S, Pinnegar JK, Polunin NVC, Boon TW (2001) Weak cross-species relationships between body size and trophic level belie powerful size-based trophic structuring in fish communities. J Anim Ecol 70:934-944

Kieckbusch DK, Koch MS, Serafy JE, Anderson WT (2004) Trophic linkages among primary producers and consumers in fringing mangroves of subtropical lagoons. Bull Mar Sci 74:271-285 
Kolasinski J, Rogers K, Frouin P (2008) Effects of acidification on carbon and nitrogen stable isotopes of benthic macrofauna from a tropical coral reef. Rapid Communications in Mass Spectrometry 22:2955-2960

Layman CA (2007) What can stable isotope ratios reveal about mangroves as fish habitat? Bull Mar Sci 80:513-527

Layman CA, Arrington DA, Montana CG, Post DM (2007) Can stable isotope ratios provide for community-wide measures of trophic structure? Ecology 88:42-48

Layman CA, Post DM (2008) Can stable isotope ratios provide for community-wide measures of trophic structure? Reply. Ecology 89:2358-2359

Layman CA, Winemiller KO (2004) Size-based responses of prey to piscivore exclusion in a species-rich neotropical river. Ecology 85:1311-1320

Ley JA, Halliday IA (2007) Diel variation in mangrove fish abundances and trophic guilds of northeastern Australian estuaries with a proposed trophodynamic model. Bull Mar Sci 80:681-720

Link JS, Garrison LP (2002) Trophic ecology of Atlantic cod Gadus morhua on the northeast US continental shelf. Mar Ecol Prog Ser 227:109-123

Magurran AE (1986) Individual differences in fish behaviour. In: Pitcher TJ (ed) The behaviour of teleost fishes. Croom Helm, London

Martinez del Rio C, Sabat P, Anderson-Sprecher R, Gonzalez SP (2009) Dietary and isotopic specialization: the isotopic niche of three Cinclodes ovenbirds. Oecologia $161: 149-159$

Matich P, Heithaus MR, Layman CA (2010) Size-based variation in inter-tissue comparisons of stable carbon and nitrogen isotopic signatures of bull sharks and tiger sharks. Can J Fish Aquat Sci 67:877-885

Matthews B, Mazumder A (2004) A critical evaluation of intrapopulation variation of delta C-13 and isotopic evidence of individual specialization. Oecologia 140:361371

Minagawa M, Wada E (1984) Stepwise enrichment of N-15 along food-chains - Further evidence and the relation between Delta-N-15 and animal age. Geochim Cosmochim Acta 48:1135-1140 
Minns CK (1995) Allometry of home-range size in lake and river fishes. Can J Fish Aquat Sci 52:1499-1508

Munro JL (1983) Caribbean coral reef fishery resources, Vol. ICLARM, Manila

Myers RA, Baum JK, Shepherd TD, Powers SP, Peterson CH (2007) Cascading effects of the loss of apex predatory sharks from a coastal ocean. Science 315:1846-1850

Nagelkerken I, Dorenbosch M, Verberk W, de la Moriniere EC, van der Velde G (2000) Importance of shallow-water biotopes of a Caribbean bay for juvenile coral reef fishes: patterns in biotope association, community structure and spatial distribution. Mar Ecol Prog Ser 202:175-192

Newsome SD, del Rio CM, Bearhop S, Phillips DL (2007) A niche for isotopic ecology. Front Ecol Environ 5:429-436

Okuyama T (2008) Individual behavioral variation in predator-prey models. Ecol Res 23:665-671

Peterson BJ, Fry B (1987) Stable isotopes in ecoysystem studies. Annu Rev Ecol Syst 18:293-320

Polis GA (1984) Age structure component of niche width and intraspecific resource partitioning - Can age-groups function as ecological species. Am Nat 123:541564

Polis GA, Strong DR (1996) Food web complexity and community dynamics. Am Nat $147: 813-846$

Post DM (2002) Using stable isotopes to estimate trophic position: Models, methods, and assumptions. Ecology 83:703-718

Post DM, Layman CA, Arrington DA, Takimoto G, Quattrochi J, Montana CG (2007) Getting to the fat of the matter: models, methods and assumptions for dealing with lipids in stable isotope analyses. Oecologia 152:179-189

R-Development-Core-Team (2008) R: A language and environment for statistical computing. In. R Foundation for Statistical Computing, Vienna, Austria

Randall JE (1967) Food habits of reef fishes of the West Indies. Stud Trop Oceanogr 5:665-847 
Ringler NH (1983) Variation in foraging tactics in fishes. In: Noakes DLG, Lindquist DG, Helfman GS, Ward JA (eds) Predation and Prey in Fishes. Junk, The Hague

Rosenblatt AE, Heithaus MR (2011) Does variation in movement tactics and trophic interactions amongAmerican alligators create habitat linkages? J Anim Ecol

Roughgarden J (1972) Evolution of Niche Width. Am Nat 106:683-718

Roughgarden J (1974) Niche Width: Biogeographic Patterns among Anolis Lizard Populations. Am Nat 108:429-442

Rounick JS, Winterbourn MJ (1986) Stable carbon isotopes and carbon flow in ecosystems. Bioscience 36:171-177

Schindler DE, Hodgson JR, Kitchell JF (1997) Density-dependent changes in individual foraging specialization of largemouth bass. Oecologia 110:592-600

Sholtodouglas AD, Field JG, James AG, Vandermerwe NJ (1991) C-13/C-12 and N$15 / \mathrm{N}-14$ isotope ratios in the southern Benguela ecosystem - indicators of food web relationships among different size-classes of plankton and pelagic fish differences between fish muscle and bone-collagen tissues. Mar Ecol Prog Ser 78:23-31

Soule M, Stewart BR (1970) The "niche-variation" hypothesis: a test and alternatives. Am Nat 104:85-97

Starck WA, Schroeder RE (1971) Investigations on the Gray Snapper, Lutjanus griseus, Vol. University of Miami Press, Coral Gables, Florida

Subalusky AL, Fitzgerald LA, Smith LL (2009) Ontogenetic niche shifts in the American Alligator establish functional connectivity between aquatic systems. Biol Conserv 142:1507-1514

Suring E, Wing SR (2009) Isotopic turnover rate and fractionation in multiple tissues of red rock lobster (Jasus edwardsii) and blue cod (Parapercis colias):

Consequences for ecological studies. J Exp Mar Biol Ecol 370:56-63

Svanbäck R, Eklov P, Fransson R, Holmgren K (2008) Intraspecific competition drives multiple species resource polymorphism in fish communities. Oikos 117:114-124

Svanbäck R, Persson L (2004) Individual diet specialization, niche width and population dynamics: implications for trophic polymorphisms. J Anim Ecol 73:973-982 
Svanbäck R, Persson L (2009) Population Density Fluctuations Change the Selection Gradient in Eurasian Perch. Am Nat 173:507-516

Swanson BO, Gibb AC, Marks JC, Hendrickson DA (2008) Variation in foraging behavior facilitates resource partitioning in a polymorphic cichlid, Herichthys minckleyi. Environ Biol Fishes 83:147-154

SYSTAT I (2002) SYSTAT 10.2: data, Vol. Systat, 2002

Turner TF, Collyer ML, Krabbenhoft TJ (2010) A general hypothesis-testing framework for stable isotope ratios in ecological studies. Ecology 91:2227-2233

Valentine-Rose L, Layman CA, Arrington DA, Rypel AL (2007) Habitat fragmentation decreases fish secondary production in Bahamian tidal creeks. Bull Mar Sci 80:863-877

Valentine-Rose L, Layman CA, Rypel AL (In Press) Community secondary production as a composite measure of effects from aquatic ecosystem fragmentation. Bull Mar Sci

Van Valen L (1965) Morphological Variation and Width of Ecological Niche. Am Nat 99:377-390

Votier SC, Bearhop S, MacCormick A, Ratcliffe N, Furness RW (2003) Assessing the diet of great skuas, Catharacta skua, using five different techniques. Polar Biol $26: 20-26$

Weliange WS, Amarasinghe US (2003) Seasonality in dietary shifts in size-structured freshwater fish assemblages in three reservoirs of Sri Lanka. Environ Biol Fishes 68:269-282

Werner EE, Gilliam JF (1984) The ontogenetic niche and species interactions in size structured populations. Annu Rev Ecol Syst 15:393-425

Werner EE, Hall DJ (1988) Ontogenetic habitat shifts in bluegill - the foraging rate predation risk trade-off. Ecology 69:1352-1366

Worm B, Hilborn R, Baum JK, Branch TA, Collie JS, Costello C, Fogarty MJ, Fulton EA, Hutchings JA, Jennings S, Jensen OP, Lotze HK, Mace PM, McClanahan TR, Minto C, Palumbi SR, Parma AM, Ricard D, Rosenberg AA, Watson R, Zeller D (2009) Rebuilding Global Fisheries. Science 325:578-585 
CHAPTER IV

A HYPOTHESIS-TESTING FRAMEWORK FOR STUDIES INVESTIGATING ONTOGENETIC NICHE SHIFTS USING STABLE ISOTOPE RATIOS 


\begin{abstract}
Ontogenetic niche shifts occur across diverse taxonomic groups, and can have critical implications for population dynamics, community structure and ecosystem function. Most studies that have used stable isotope ratios to examine ontogenetic niche shifts applied qualitative methods, or quantitative approaches that analyzed isotope elements separately. Yet, multivariate analyses are beneficial in identifying the nature of dietary shifts through ontogeny because they can provide an enhanced understanding of changes in niche width, niche position and niche overlap, which are important factors in investigating changes in resource use. Herein, I provide a hypothesis-testing framework combining univariate and multivariate analyses to examine ontogenetic niche shifts using stable isotope ratios. The framework is founded on three main ontogenetic niche shift scenarios. For identifying each ontogenetic niche shift scenario, I developed specific criteria, as well as provided an empirical example for illustration purposes. The present framework provides a foundation for future studies on ontogenetic niche shifts and can also be applied to examine resource variability among other population groupings (e.g., by sex or phenotype).
\end{abstract}




\section{Introduction}

Changes in resource use with body size or age, i.e., ontogenetic niche shifts, may occur in $80 \%$ of animal taxa (Werner \& Hall 1988) and have been shown to affect the structure and dynamics of populations, communities and ecosystems (Werner \& Hall 1988, Polis \& Strong 1996, Claessen et al. 2002). For instance, species often feed at higher trophic levels as they mature (Stein et al. 1988, Polis et al. 1989) and thus, interactions with other species may shift from competition to predation through ontogeny (Persson 1988, Olson et al. 1995). Many organisms increase their foraging range with ontogeny (Minns 1995), thereby changing the nature of nutrient and energy flow through different habitats or ecosystems (Subalusky et al. 2009). Finally, ontogenetic niche shifts may render life stages as functionally distinct groups that should be considered as distinct nodes in food web models (Olson 1996). Hence, the study of ontogenetic niche shifts is of core interest in the ecological sciences.

In a classic paper, Werner and Gilliam (1984) proposed three possible scenarios for how organism's resource use (e.g., diet, habitat use) may (or may not) change through ontogeny. First, a consumer may have no substantial ontogenetic changes in resource use (Fig. 1A, 1D). Second, the niche of a smaller size class may be a subset of the niche of a larger size class, e.g., because larger individuals expand their foraging range and incorporate prey items that smaller individuals do not encounter (Fig. 1B, 1E). Finally, consumers may switch to a different resource pool during ontogenetic development (Fig. $1 \mathrm{C}, 1 \mathrm{~F})$. Ontogenetic differences in resource use therefore will translate into changes in niche width, niche position and/or niche overlap between size groups. As such, measures 
of niche width, niche position and niche overlap can be used to distinguish among these different ontogenetic niche shift scenarios.

Stable isotope analysis often is applied to investigate ontogenetic niche shifts because they provide a time- and space-integrated representation of diet and/or are useful for those organisms whose diets are difficult to characterize directly (Hentschel 1998). The majority of diet studies have employed stable isotope ratios of carbon (i.e., $\delta^{13} \mathrm{C}$ ) and nitrogen (i.e., $\delta^{15} \mathrm{~N}$ ), as they provide information related to a consumer's basal resource pool and trophic position, respectively (Peterson \& Fry 1987, Newsome et al. 2007). Most studies using stable isotopes to examine ontogenetic changes in diet rely on qualitative observations or analyze $\delta^{13} \mathrm{C}$ and $\delta^{15} \mathrm{~N}$ separately, either against a continuous body size gradient (e.g., regression analysis; Rolff 2000, Cocheret de la Morinière 2003, Post 2003) or among size/age groups (e.g., t-test, analysis of variance; Quevedo \& Olsson 2006, Zimmerman et al. 2009, Young et al. 2010; Fig. 1A-C). Yet, recent food web studies have shown the power of simultaneously analyzing $\delta^{13} \mathrm{C}$ and $\delta^{15} \mathrm{~N}$ to better characterize overall patterns in niche variation (Layman et al. 2007b, Semmens et al. 2009, Turner et al. 2010, Jackson et al. 2011).

My aim was to provide a single hypothesis-testing framework to examine the ontogenetic niche shift scenarios outlined by Werner and Gilliam (1984) using stable isotopes. My proposed framework incorporates both univariate and multivariate analyses to investigate shifts in niche width, niche position and niche overlap through ontogeny. I developed specific criteria characterizing each ontogenetic niche shift category and provide empirical examples to illustrate each of them. 


\section{Materials and Methods}

I evaluated three aspects of the niches of size classes through ontogeny, including (1) niche width (variety in resources consumed), (2) niche position (i.e., types of resources consumed), and (3) niche overlap (similarity in resource use among individuals). I examined changes in niche width and niche position through ontogeny using multivariate analyses (see below). If niche width and/or niche position were found to differ through ontogeny, conventional univariate tests were performed to elucidate which niche axis (e.g., $\left.\delta^{13} \mathrm{C}, \delta^{15} \mathrm{~N}\right)$ drove the observed niche shift (Fig. 1). For example, ontogenetic shifts in $\delta^{13} \mathrm{C}$ values could indicate dissimilar use of habitats or source pools by different size groups (Rounick \& Winterbourn 1986, Peterson \& Fry 1987, France \& Peters 1997 , Layman 2007), whereas changes in $\delta^{15} \mathrm{~N}$ values typically imply a shift in trophic position (DeNiro \& Epstein 1981, Minagawa \& Wada 1984, Peterson \& Fry 1987). I then measured niche overlap between size groups in a two-dimensional niche space (i.e., $\delta^{13} \mathrm{C}-\delta^{15} \mathrm{~N}$-biplot space) using a \% overlap measure (Vaudo \& Heithaus 2011). Niche width, niche position and niche overlap are important aspects to identify ontogenetic niche shifts and can be used to classify an organism into one of the three categories proposed in the classic paper of Werner and Gilliam (1984).

The criteria for the first ontogenetic niche shift scenario, involving no change in diet through ontogeny are: no significant difference in (1) niche width and (2) niche position, imparting (3) high degree of overlap in individuals' isotope values (Figs. 1A, 1D, 2). For the second scenario, resource use (i.e., diet or habitat use) is larger in one group than in the other, resulting in (1) significant difference in niche width and (2) potentially a change in mean niche position. More specifically, the isotopic niche width 
of one group is statistically larger than that of the other and the niche of the latter group is largely encompassed by the former, leading to (3) an asymmetry in niche overlap (Figs. 1B, 2). Niche position may or may not differ between groups, depending on whether resource expansion takes place from the center of the isotopic niche space (no niche shift) or is directed away from that center (Figs. 1B, 1E, 2). For the third scenario, involving a discrete ontogenetic diet shift, (1) niche width of one group can either be the same, smaller or larger than the other (Fig. 1C, 1F), and (2) there is a significant shift in niche position, resulting in (3) little or no overlap in isotopic niche (Figs. 1C, 1F, 2).

I used empirical data to illustrate these different niche shift scenarios. I chose these examples specifically to illustrate the methodological framework discussed herein, and not as independent tests of the nature of niche shifts in these particular taxa. For these taxa, direct diet data (or in one case, published diet information) were collected to further help me characterize and understand niche variation. Post-metamorphic Eupemphix nattereri frogs (i.e., no tadpoles), gray snapper (Lutjanus griseus) and hardhead silversides (Atherinomorus stipes) constituted the model species.

Post-metamorphic Eupemphix nattereri specimens were collected from an area of Brazilian savannahs locally known as Cerrado in the municipality of Uberlândia (1855' $\mathrm{S}, 48^{\circ} 17^{\prime} \mathrm{W}$ ) in southeastern Brazil, a region characterized by shrubby grassland areas surrounding wet areas such as veredas (marshes with buriti-palms Mauritia flexuosa) or temporal and permanent ponds. Frogs were collected from October 1999 to October 2001 and immediately killed upon collection, preserved in 5\% formalin and later transferred to $70 \%$ ethanol. Since all individuals were preserved in the same manner, differences in isotope values among individuals should have not been affected by preservatives (Araujo 
et al. 2009). Gut content analysis was performed via dissection and prey items were counted and identified to the lowest taxonomic level. Upon dissection, individuals were sexed by examination of gonads and classified as adults if the gonads were fully developed (reproductive) or as juveniles if gonads were underdeveloped (nonreproductive). After preservation, a piece of muscle was used from the thigh to measure $\delta^{13} \mathrm{C}$ and $\delta^{15} \mathrm{~N}$ (Araujo et al. 2009).

Gray snapper (Lutjanus griseus) were collected in the Loxahatchee River $\left(26^{\circ} 7^{\prime}\right.$ $\left.\mathrm{N}, 80^{\circ} 06^{\prime} \mathrm{W}\right)$ located on the southeast Atlantic coast of Florida, USA. Snappers were caught during the summers of $2007-2009$ by angling and electrofishing in the mesohaline areas of the river. Fish were anesthetized using eugenol (i.e., clove oil in sea water; Cotter \& Rodruck 2006) and their standard length was measured. Each individual was forced to regurgitate their stomach contents by pressing on the abdomen while using a metal spatula to help invert the stomach. A small sample $\left(\sim 1 \mathrm{~cm}^{2}\right)$ of dorsal fin tissue was taken from each fish for stable isotope analysis. After sampling their stomach contents, fish were returned to cool, fresh, ambient water and allowed to recover before being released. Since the size range of $L$. griseus in the Loxahatchee River does not include reproductively mature adults, I a priori divided the individuals into juveniles $(<100 \mathrm{~mm} \mathrm{SL})$ and sub-adults $(\geq 100 \mathrm{~mm} \mathrm{SL})$ according to observed differences in habitat use between these two life-history stages (Hammerschlag \& Serafy 2009).

Hardhead silversides (Atherinomorus stipes) were collected with cast-nets in a tidal creek $\left(26^{\circ} 21^{\prime} 36.58^{\prime \prime} \mathrm{N}, 77^{\circ} 00^{\prime} 58.91^{\prime \prime} \mathrm{W}\right)$ on Abaco Island, Bahamas on November $15^{\text {th }} 2009$. This creek is lined by mangroves (primarily red mangrove, Rhizophora mangle) and supports extensive seagrass beds predominantly consisting of turtle grass, 
Thalassia testudinum. The creek is dominated by marine waters with relatively little topographic relief, a small watershed, and little freshwater input (Layman et al. 2007b). All captured individuals were immediately put on ice and later frozen. The whole organism was used for stable isotope analysis. Diet information of A. stipes was obtained by Boveri and Quiros (2002). On the basis of gonad inspections, A. stipes was divided into juveniles (underdeveloped gonads) and adults (fully developed gonads).

I focused on ratios of $\delta^{15} \mathrm{~N}$ and $\delta^{13} \mathrm{C}$ because each reveals a distinct aspect of the consumer's long-term trophic niche (see above). Stable isotope values are reported in the $\delta$ notation where $\delta^{13} \mathrm{C}=\left[\left(R_{\text {sample }} / R_{\text {standard }}\right)-1\right] \times 1000$, and where $R$ is ${ }^{13} \mathrm{C} /{ }^{12} \mathrm{C}$ and ${ }^{15} \mathrm{~N} /$ ${ }^{14} \mathrm{~N}$, respectively. Isotope sample preparation and analysis followed Post et al. (Post et al. 2007) and was conducted at the Yale Earth System Center for Stable Isotopic Studies using a ThermoFinnigan DeltaPlus mass spectrometer (for Lutjanus griseus and Atherinomorus stipes) and at the Centro de Energia Nuclear na Agricultura of the Universidade de São Paulo using a Micromass 602E mass spectrometer (for Eupemphix nattereri).

To evaluate which model species met the criteria for one of the ontogenetic niche shift scenarios, I performed multivariate analyses, using $\delta^{13} \mathrm{C}$ and $\delta^{15} \mathrm{~N}$ simultaneously, and "post-hoc" univariate analyses, separately on $\delta^{13} \mathrm{C}$ and $\delta^{15} \mathrm{~N}$. For the multivariate analyses, I first examined significant differences in (1) niche width and (2) niche position between the two groups, and then (3) niche overlap (Fig. 2). To do so, I performed a test for differences in dispersion and central tendency, respectively, following Turner et al. (2010) in R version 2.12.2. In the context of this study, difference in dispersion represents a change in niche width because this metric measures the average trophic variability 
within size groups. More precisely, using analysis of nested linear models and residual permutation procedure, the mean distance to centroid (bivariate mean) was computed for each size group separately, and then the absolute value of the difference was evaluated between size groups. An absolute value greater than zero indicates a difference in niche width between size groups (Turner et al. 2010). Similarly, the difference in central tendency represents a shift in isotopic niche position and was measured by computing the Euclidean distance between the centroids of the two groups (Turner et al. 2010). The isotopic niche position was considered to be different if the Euclidean distance between the two groups was significantly greater than zero ( $\mathrm{R}$ codes for the test of dispersion and central tendency are provided in the Appendix of Turner et al. 2010). The test statistics for dispersion and central tendency are herein referred to as "mean distance to centroid" and "Euclidean distance", respectively.

Conventional univariate analysis was applied after significant results from multivariate analysis to provide additional detail. To this end, I first tested all data for normality (Shapiro-Wilk test) and square-root transformed them when applicable. Then, I examined shifts in niche width and niche position for each stable isotope element by measuring (1) homogeneity of variance between size groups using Bartlett test and (2) by comparing mean isotopic values between size groups using t-test for independent samples (for normally distributed data) or Wilcox test (for non-normally distributed data). All tests were performed in $\mathrm{R}$ version 2.12.2. Significance was declared at $\alpha \leq 0.05$.

I measured niche overlap between groups by quantifying, for each group, the percentage of individuals that were encompassed by the other group's convex hull 
(Vaudo \& Heithaus 2011), which is the area of the smallest convex polygon that contains all individuals of a group in a $\delta^{13} \mathrm{C}-\delta^{15} \mathrm{~N}$-biplot (Figs. 1, 3) (Layman et al. 2007a).

Since for many organisms body size is more important in determining life history characteristics than age per se (Kirkpatrick 1984), I used body size as a proxy for ontogenetic stage. More specifically, I used categorical size groups instead of continuous body size data (Fig. 1). Yet, for the univariate analyses, my framework could easily be applied to a continuous body size gradient using linear regression (to test for non-zero slope, instead of comparing means between groups) when examining shifts in niche position and testing for changes in niche width with body size (instead of between groups). When categorical size groups are used, biologically meaningful size classes should be chosen (as in this study), or a break point analysis (Gomez \& Gomez 1984) could be performed, to determine the size at which change in resource use occur.

Finally, the convex hull approach offers some advantages for characterizing niche width when compared to alternative analyses. The convex hull approach is powerful because it incorporates each individual of the population's sub-sample, and thus includes information about the niche width of the population including every sampled individual. Conversely, other approaches are targeted at identifying the "core" niche of the population, a niche metric which could exclude particular individual niches from the characterization of the population niche (Jackson et al. 2011). Either of these approaches may be more relevant with respect to a particular question of interest and/or the nature of the underlying data set. Herein, I chose to measure niche overlap on the basis of the convex hull approach, as the importance of individual level niche variation is 
increasingly recognized as an important component of ecological dynamics and evolutionary trajectories (Bolnick et al. 2003, Bolnick et al. 2011).

\section{Results}

For the illustration of the first ontogenetic niche shift scenario, I used 25 postmetamorphic juveniles (size range: 13-33mm Snout-Vent Length (SVL)) and 26 adults (size range: $34-47 \mathrm{~mm} \mathrm{SVL}$ ) of E. nattereri. Juvenile and adult E. nattereri did not statistically differ in their (1) niche widths (mean distance to centroid $=0.08, P=0.87$ ), and (2) isotopic niche position (Euclidean distance $=0.41, P=0.58$; Fig. 3A). Thus, (3) individuals of both groups overlapped substantially with each other (juveniles $=92 \%$ overlap with adults, adults $=85 \%$ overlap with juveniles, Fig. $3 \mathrm{~A}$ ).

For the illustration of the second ontogenetic niche shift scenario, juvenile $(\mathrm{n}=$ 31, size range: 40-96mm Standard Length (SL)) and sub-adult ( $\mathrm{n}=89$, size range: 101204mm SL) L. griseus differed significantly in their (1) niche width (mean distance to centroid $=1.22, P=0.006$, Fig. $3 \mathrm{~A}$ ), which was driven by a difference in variance of $\delta^{13} \mathrm{C}$ values (Bartlett: $\left.\mathrm{K}^{2}=10.37, \mathrm{df}=1, P=0.001\right)$, not $\delta^{15} \mathrm{~N}\left(\right.$ Bartlett: $\mathrm{K}^{2}=1.07, \mathrm{df}=1$, $P=0.3$ ). There was no shift in (2) isotopic niche position (Euclidean distance $=0.94, P=$ 0.13; Fig. 3B) and (3) most juvenile L. griseus overlapped with the niche width of subadults ( $97 \%$ of individuals), whereas only $35 \%$ of sub-adults were encompassed by the convex hull of the juveniles (Fig. 3B).

For illustration of the third ontogenetic niche shift scenario, juveniles $(n=16$, size range: $23-35 \mathrm{~mm} \mathrm{SL})$ and adults ( $\mathrm{n}=14$, size range: $40-61 \mathrm{~mm} \mathrm{SL}$ ) of $A$. stipes differed significantly in (1) niche width (mean distance to centroid $=0.51, P=0.01$; Fig. 3C), 
which was mainly caused by differences in variance of $\delta^{15} \mathrm{~N}\left(\right.$ Bartlett: $\mathrm{K}^{2}=10.6, \mathrm{df}=1$, $P=0.001)$, but also by $\delta^{13} \mathrm{C}\left(\right.$ Bartlett: $\left.\mathrm{K}^{2}=3.85, \mathrm{df}=1, P=0.05\right)$. In addition, the (2) isotopic niche position changed significantly between juvenile and adult $A$. stipes (Euclidean distance $=1.5, P<0.0001$; Fig. 3C), which was driven by a change in their mean $\delta^{15} \mathrm{~N}$ values (Wilcox: $\mathrm{W}=224, P<0.001$ ), but not mean $\delta^{13} \mathrm{C}$ values ( $\mathrm{t}$-test: $\mathrm{t}=$ 0.29, $\mathrm{df}=20.3, P=0.77$ ). Consequently, (3) no individuals were encompassed by the convex hull of the other group (Fig. 3C).

\section{Discussion}

Because of the significant effects ontogenetic niche shifts can have on the structure and dynamics of populations, communities and ecosystems, it is important to identify the nature of these dietary shifts using quantitative techniques (Werner \& Hall 1988, Polis \& Strong 1996, Claessen et al. 2002). Stable isotope analysis is especially useful for this purpose because of its time- and space-integrated representation of diet. Yet, most studies using stable isotope ratios have examined ontogenetic niche shifts either qualitatively or by analyzing stable isotope elements separately (Landman et al. 1983, Mueller-Lupp et al. 2003, Post 2003, Lukeneder et al. 2010, Taylor \& Mazumder 2010). My study provides a hypothesis-testing framework to investigate ontogenetic niche shifts in organisms by applying univariate and multivariate analyses simultaneously on stable isotope elements. In doing so, I provide a foundation for exploring the three major categories of ontogenetic niche shifts originally outlined by Werner and Gilliam (1984) in their review of ontogenetic niche shifts. 
Post-metamorphic juveniles and adults of E. nattereri illustrate the first ontogenetic niche shift scenario: there were no differences in niche width, niche space or niche overlap between the two size groups (Fig. 3A). Since frogs grow substantially after metamorphosis to reach adult size, they could be expected to experience considerable diet shifts during the terrestrial phase of their life cycle, but this was not found to be the case here. Stomach content analysis supported the isotope findings by showing that both juvenile and adult E. nattereri tend to specialize on ants and termites (Araujo et al. 2009). Since stable isotope ratios of muscle tissue represent diet over a long time period (weeks to months, Sweeting et al. 2005), it can be inferred that the observed diet specialization was long-term, and not just driven by local prey availability at the time of sampling (an advantage of stable isotope analysis over stomach content analysis, Araujo et al. 2007).

Gray snapper illustrate the second ontogenetic niche shift scenario: sub-adult $L$. griseus expanded their isotopic niche to include diet items with more depleted $\delta^{13} \mathrm{C}$ values (Fig. 3B). Direct diet analysis confirmed that the feeding of juvenile L. griseus was essentially confined to the oyster reef matrix of the Loxahatchee River, where their diet was composed almost entirely of oyster reef-associated prey items. Conversely, subadult $L$. griseus move to the adjacent mangrove habitats to feed on mangrove-associated prey (Yeager \& Layman 2011). Prey items in oyster reef habitats are largely supported by microalgae- and phytoplankton-based trophic pathways that are more enriched in $\delta^{13} \mathrm{C}$ values $(\sim-18 \%$, whereas prey from mangrove-based food web modules are more depleted $\left(\delta^{13} \mathrm{C} \sim-27 \%\right.$ ) (Kieckbusch et al. 2004, Yeager \& Layman 2011). Sub-adults most likely increased their foraging area because of decreased predation pressure or increased mobility because of larger body size (Werner \& Hall 1988). Such foraging and 
predation risk trade-offs and/or increase in mobility with body size can drive many ontogenetic niche shifts, and stable isotope ratios can be a prime tool to reflect such longterm feeding shifts when isotopic signatures of sources are distinct.

Juvenile and adult $A$. stipes displayed a distinct niche shift, mainly along the $\delta^{15} \mathrm{~N}$ axis (Fig. 3C). Since A. stipes is a visual feeder that actively selects zooplankton (Boveri \& Quiros 2002), no major ontogenetic niche shifts would be expected for that species. Yet, my stable isotope data suggest that adults likely fed exclusively on larger-sized zooplankton prey, as larger zooplankton are often more enriched in $\delta^{15} \mathrm{~N}$ (Rolff 2000). Since adult and juvenile $A$. stipes share the same resources (i.e., habitat and diet), adults might shift to larger prey sizes as a means to reduce intrapopulation niche competition (Bolnick et al. 2003).

My empirical examples highlight the benefit of using both univariate and multivariate measures, as each was useful to identify different aspects of the niche differences. For example, in the case of gray snapper, multivariate approaches were useful in identifying degree of niche width and niche overlap, whereas univariate analysis was important to elucidate niche expansion in the larger size group primarily along the carbon axis. It would be difficult to differentiate among the three major niche shift scenarios by using univariate analyses alone (Fig. 1D-F).

When applying the proposed framework, it is important to consider that the three ontogenetic niche shift scenarios outlined in this study should be understood as endpoints of a continuum. Some organisms might fall between two of the proposed scenarios. Yet, my framework will allow for the identification of such "in-between scenarios" as well. In addition, the much discussed limitations of isotopes must be considered when interpreting 
their application to study ontogenetic diet shifts (Newsome et al. 2007, Layman \& Post 2008). For instance, source pools need to have distinct isotopic signatures for stable isotopes to be useful, and $\delta$ values can be particularly sensitive to spatial and temporal variation in isotope values of source pools (Newsome et al. 2007). As such, scattering among consumers in a $\delta^{13} \mathrm{C}-\delta^{15} \mathrm{~N}$ biplot could be the result of a broad resource use among individuals, or because of high variation in isotope values of source pools (Matthews \& Mazumder 2004). To avoid this problem, Newsome et al. (2007) proposed to convert the " $\delta$-space" (e.g., $\delta^{13} \mathrm{C}$ - $\delta^{15} \mathrm{~N}$ biplot space) into "p-space" according to dietary proportions of different isotopic sources using mixing models. However, in order for the mixing models to work, the study system can have only one more source pool than the number of isotopes used (Phillips \& Gregg 2001). Since most study systems, such the ones from which my example taxa were collected, have many more than two or three source pools, this p-space approach is not applicable. Consequently, the use of a complimentary method such as stomach content analysis (as applied in this study), fecal analysis, or direct observations are useful to interpret and better understand patterns in isotope signatures. When stable isotope ratios are put in the proper context, they can be a very powerful tool (Layman \& Post 2008) and provide insights that would not be possible with some conventional methods (Hentschel 1998).

Intrapopulation resource variation has critical ecological, evolutionary and conservation implications (Bolnick et al. 2003, Bolnick et al. 2011), and ontogenetic niche shifts are one primary driver of this variation (Bolnick et al. 2011). My approach provides a framework for exploring questions related to ontogenetic diet shifts, as well as other among-group (e.g., sex or phenotype) comparisons. Such studies are critical for 
understanding interactions among individuals at population, community and ecosystem levels.

\section{Acknowledgements}

I especially would like to thank M. Araujo and L. Yeager for providing the empirical data on Eupemphix nattereri and Lutjanus griseus, respectively, to illustrate the different ontogenetic niche shift scenarios in my hypothesis-testing framework. I also thank all the people that helped with field work, data analysis, and manuscript editing, especially L. Yeager, M. Araujo, J. Vaudo, A. Mercado, A. Yoc-Kim, and C. Villegas. This research was possible with the support of the FIU Graduate School Dissertation Year Fellowship and National Science Foundation grants, OCE \#0746164 and DEB \# 0842196. Sampling of the model species was conducted with the required authorization from the review boards of the Brazilian Institute of Environment and Renewable Natural Resources (IBAMA; Permit Numbers: 0121586BR, 0123253BR), the Bahamas Department of Marine Resources and the FIU Institutional Animal Care and Use Committee (IACUC; Permit Numbers: 09-009, 08-008). 

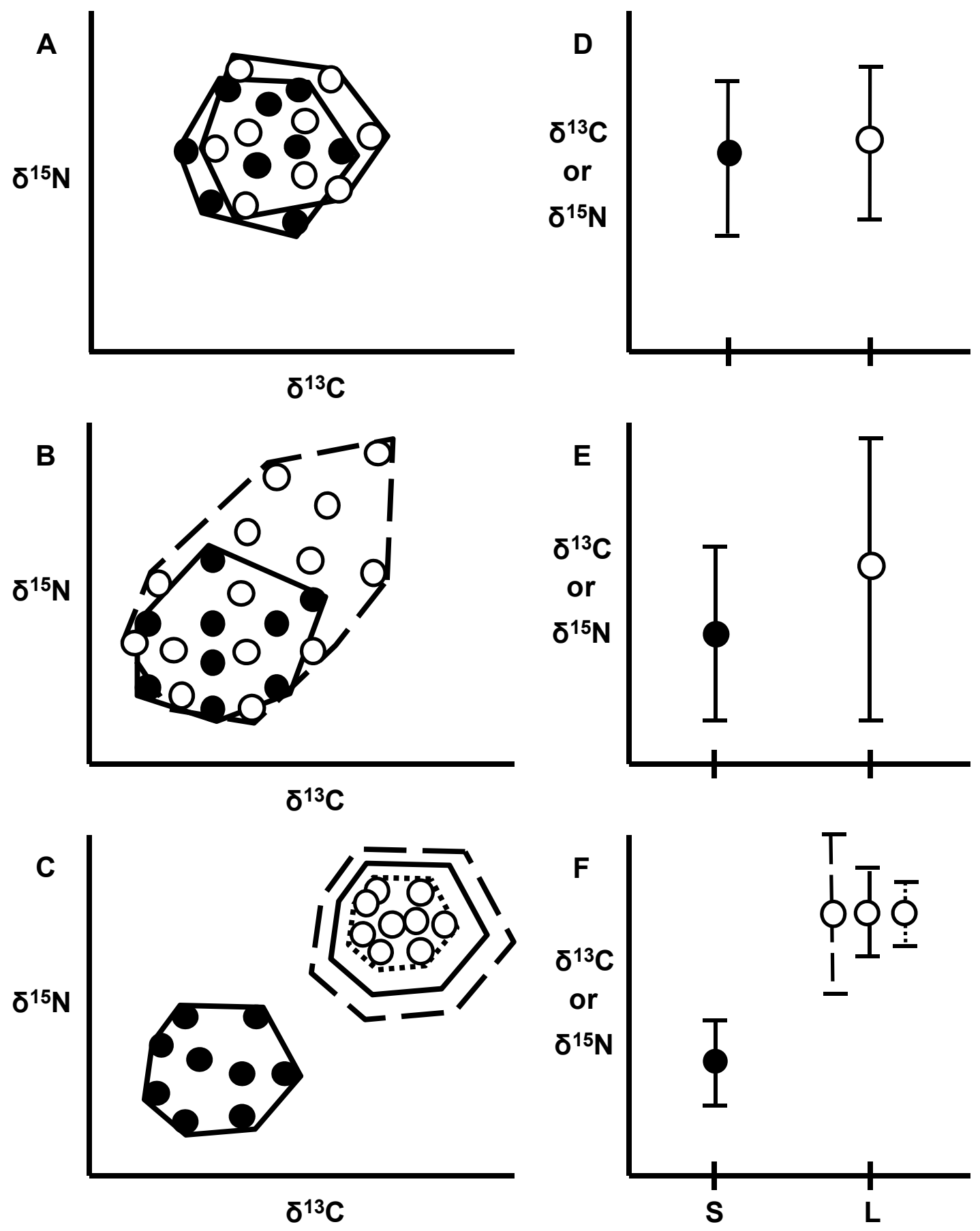

Fig. 1 Representation of three possible ontogenetic niche shift scenarios using stable isotope ratios. Horizontally adjacent panels represent the same ontogenetic niche shift 
scenario. (A-C) Multivariate illustration of potential differences in niche width (represented by convex hull polygons), niche position and niche overlap (see text for more details) between two size groups in $\delta^{13} \mathrm{C}-\delta^{15} \mathrm{~N}$ niche space. (D-F) Univariate representation of niche width (variance of isotope values) and niche position (mean isotopic value) of either $\delta^{13} \mathrm{C}$ or $\delta^{15} \mathrm{~N}$ between size groups. Closed circles represent isotope data of small individuals and open circles of large individuals. Solid line = constant niche width, dotted line $=$ niche reduction, dashed line $=$ niche expansion; $\mathrm{S}=$ small size group, $\mathrm{L}=$ large size group. In panel $\mathrm{F}$, solid line $=$ constant variance, dotted line $=$ reduced variance, dashed line $=$ increased variance 


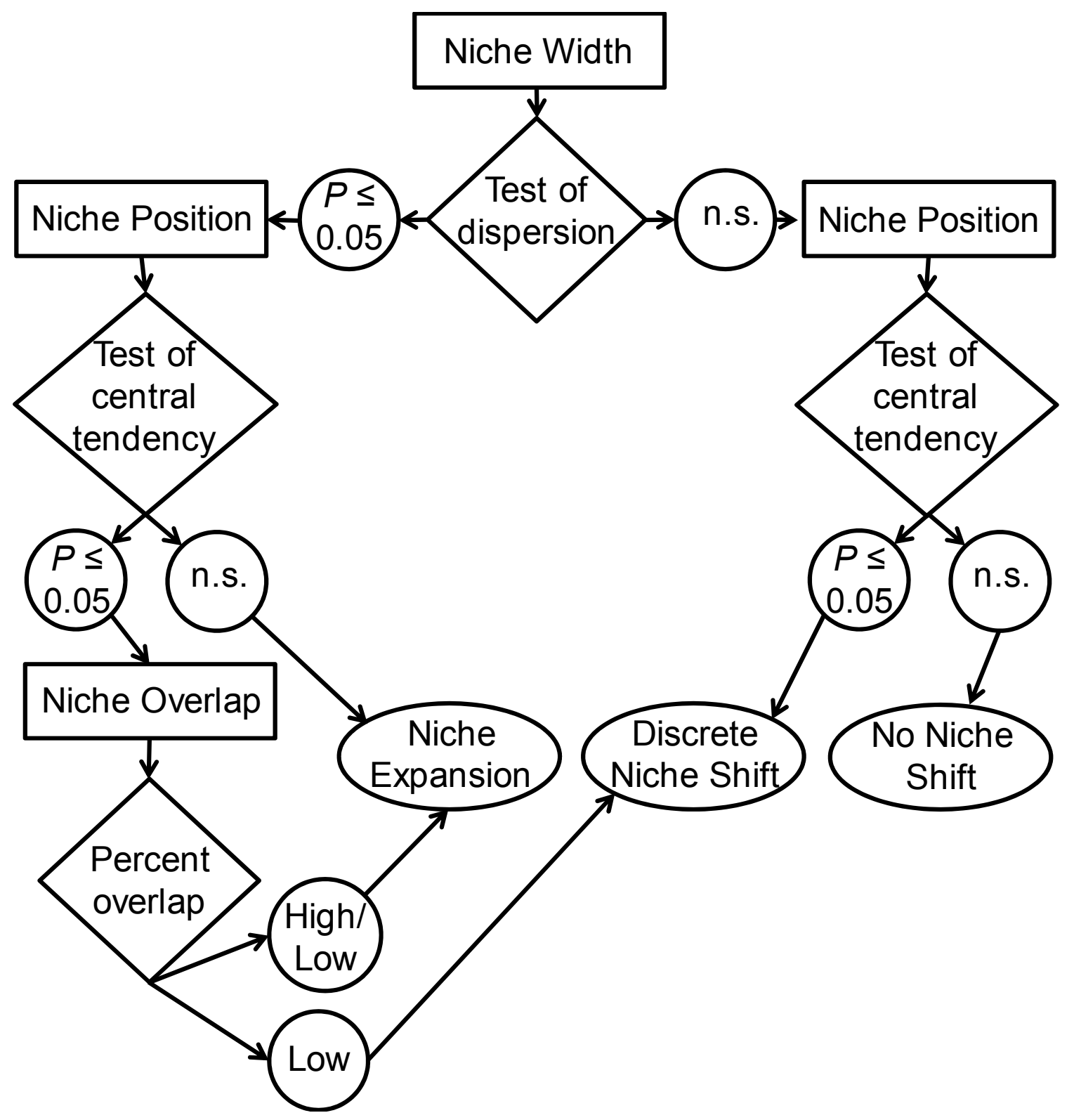

Fig. 2 Flow chart of the hypothesis-testing framework. Niche aspects (i.e., niche width, niche position, and niche overlap) are shown in rectangles, test types in diamonds, and possible test results in circles; n.s. = non-significant. The three possible scenarios are represented in ovals, with "No Niche Shift" = first scenario, "Niche Expansion" = second scenario, and "Discrete Niche Shift" = third scenario. Low = low niche overlap for both size groups; High/Low = asymmetric niche overlap between two size groups 

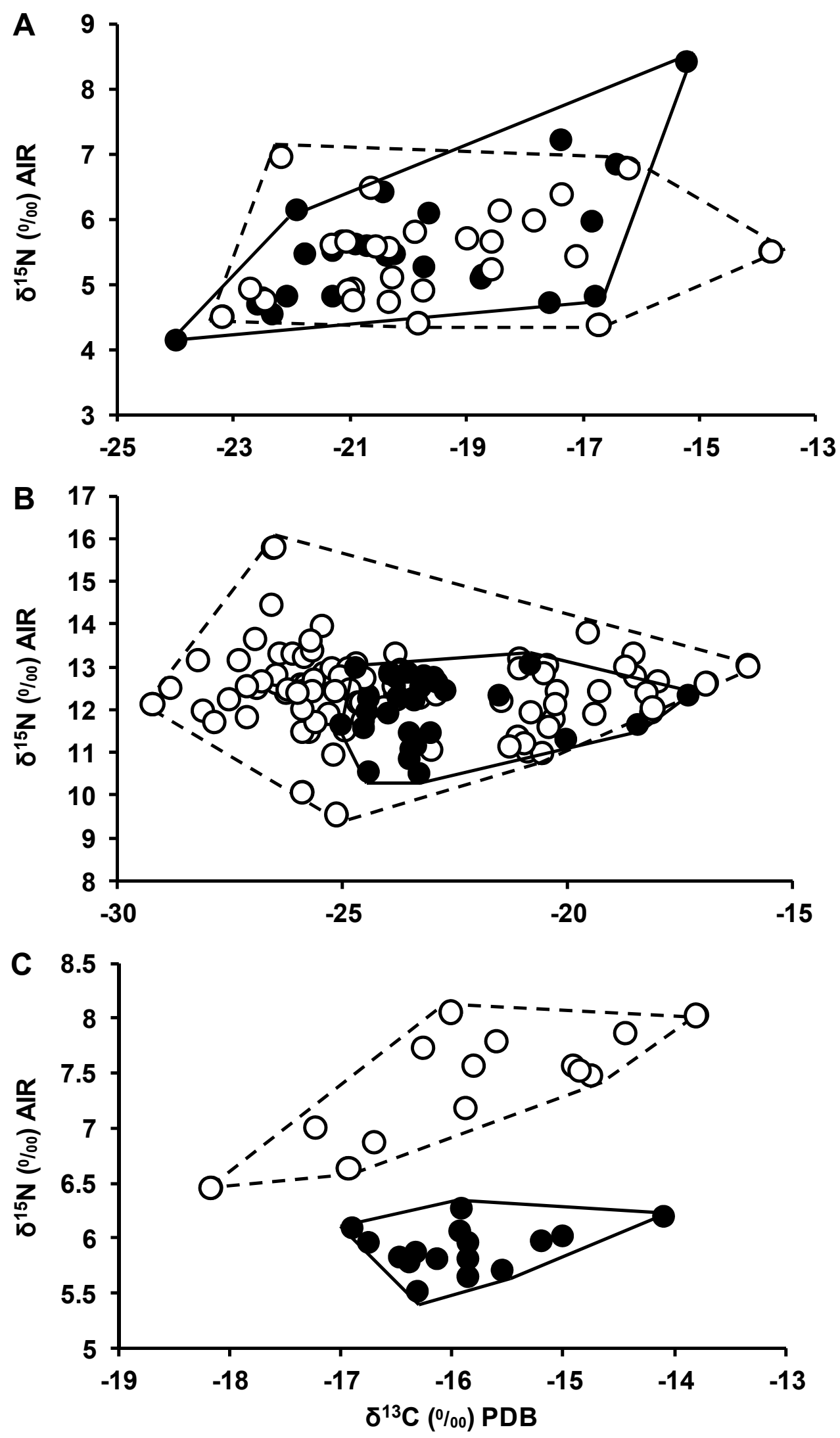
Fig. 3 Isotopic niche use of two ontogenetically distinct groups. Differences in niche width (for illustration purposes represented by convex hull polygons) of a small (solid line) and large (dashed line) size group of A) Eupemphix nattereri, B) Lutjanus griseus, and C) Atherinomorus stipes represented in a $\delta^{13} \mathrm{C}-\delta^{15} \mathrm{~N}$ niche space. Closed circles represent isotope data of individual juveniles and open circles individual adults (or subadults in case of L. griseus). PDB (PeeDee belemnite) and AIR (atmospheric nitrogen) are the global standards of $\delta^{13} \mathrm{C}$ and $\delta^{15} \mathrm{~N}$, respectively 


\section{LITERATURE CITED}

Araujo MS, Bolnick DI, Machado G, Giaretta AA, dos Reis SF (2007) Using delta C-13 stable isotopes to quantify individual-level diet variation. Oecologia 152:643-654

Araujo MS, Bolnick DI, Martinelli LA, Giaretta AA, dos Reis SF (2009) Individual-level diet variation in four species of Brazilian frogs. J Anim Ecol 78:848-856

Bolnick DI, Amarasekare P, Araujo MS, Burger R, Levine JM, Novak M, Rudolf VHW, Schreiber SJ, Urban MC, Vasseur DA (2011) Why intraspecific trait variation matters in community ecology. Trends Ecol Evol 26:183-192

Bolnick DI, Svanback R, Fordyce JA, Yang LH, Davis JM, Hulsey CD, Forister ML (2003) The ecology of individuals: Incidence and implications of individual specialization. Am Nat 161:1-28

Boveri MB, Quiros R (2002) Tropic interactions in pampean shallow lakes: evaluation of silverside predatory effects in mesocosm experiments. Vehr int Verein theor angew Limnol 28:1-5

Claessen D, Van Oss C, de Roos AM, Persson L (2002) The impact of size-dependent predation on population dynamics and individual life history. Ecology 83:16601675

Cocheret de la Morinière E, Pollux BJA, Nagelkerken I, Hemminga MA, Huiskes AHL, van der Velde $\mathrm{G}$ (2003) Ontogenetic dietary changes of coral reef fishes in the mangrove-seagrass-reef continuum: stable isotopes and gut-content analysis. Mar Ecol Prog Ser 246:279-289

Cotter PA, Rodruck KJ (2006) Differential effects of anesthetics on electrical properties of the rainbow trout (Oncorhynchus mykiss) heart. Comp Biochem Physiol A $145: 158-165$

DeNiro MJ, Epstein S (1981) Influence of diet on the distribution of nitrogen isotopes in animals. Geochim Cosmochim Acta 45:341-351

France RL, Peters RH (1997) Ecosystem differences in the trophic enrichment of C-13 in aquatic food webs. Can J Fish Aquat Sci 54:1255-1258

Gomez KA, Gomez AA (1984) Statistical Procedures for Agricultural Research, Vol. Wiley Interscience, New York 
Hammerschlag N, Serafy JE (2009) Nocturnal fish utilization of a subtropical mangroveseagrass ecotone. Mar Ecol Evol Persp 31:364-374

Hentschel BT (1998) Intraspecific variations in delta C-13 indicate ontogenetic diet changes in deposit-feeding polychaetes. Ecology 79:1357-1370

Jackson AL, Inger R, Parnell AC, Bearhop S (2011) Comparing isotopic niche widths among and within communities: SIBER - Stable Isotope Bayesian Ellipses in R. J Anim Ecol 80:595-602

Kieckbusch DK, Koch MS, Serafy JE, Anderson WT (2004) Trophic linkages among primary producers and consumers in fringing mangroves of subtropical lagoons. Bull Mar Sci 74:271-285

Kirkpatrick M (1984) Demographic-models based on size, not age, for organisms with indeterminate growth. Ecology 65:1874-1884

Landman NH, Rye DM, Shelton KL (1983) Early ontogeny of eutrephoceras compared to recent nautilus and mesozoic ammonites - evidence from shell morphology and light stable isotopes. Paleobiology 9:269-279

Layman CA (2007) What can stable isotope ratios reveal about mangroves as fish habitat? Bull Mar Sci 80:513-527

Layman CA, Arrington DA, Montana CG, Post DM (2007a) Can stable isotope ratios provide for community-wide measures of trophic structure? Ecology 88:42-48

Layman CA, Post DM (2008) Can stable isotope ratios provide for community-wide measures of trophic structure? Reply. Ecology 89:2358-2359

Layman CA, Quattrochi JP, Peyer CM, Allgeier JE (2007b) Niche width collapse in a resilient top predator following ecosystem fragmentation. Ecol Lett 10:937-944

Lukeneder A, Harzhauser M, Mullegger S, Piller WE (2010) Ontogeny and habitat change in Mesozoic cephalopods revealed by stable isotopes (delta O-18, delta C13). Earth Planet Sci Lett 296:103-114

Matthews B, Mazumder A (2004) A critical evaluation of intrapopulation variation of delta C-13 and isotopic evidence of individual specialization. Oecologia 140:361371 
Minagawa M, Wada E (1984) Stepwise enrichment of N-15 along food-chains - Further evidence and the relation between Delta-N-15 and animal age. Geochim Cosmochim Acta 48:1135-1140

Minns CK (1995) Allometry of home-range size in lake and river fishes. Can J Fish Aquat Sci 52:1499-1508

Mueller-Lupp T, Erlenkeuser H, Bauch HA (2003) Seasonal and interannual variability of Siberian river discharge in the Laptev Sea inferred from stable isotopes in modern bivalves. Boreas 32:292-303

Newsome SD, del Rio CM, Bearhop S, Phillips DL (2007) A niche for isotopic ecology. Front Ecol Environ 5:429-436

Olson MH (1996) Ontogenetic niche shifts in largemouth bass: Variability and consequences for first-year growth. Ecology 77:179-190

Olson MH, Mittelbach GG, Osenberg CW (1995) Competition between predator and prey - resource-based mechanisms and implications for stage-structured dynamics. Ecology 76:1758-1771

Persson L (1988) Asymmetries in competitive and predatory interactions in fish populations. In: Ebenman B, Persson L (eds) Size-structured populations: ecology and evolution. Springer-Verlag, Berlin, Germany

Peterson BJ, Fry B (1987) Stable isotopes in ecoysystem studies. Annu Rev Ecol Syst $18: 293-320$

Phillips DL, Gregg JW (2001) Uncertainty in source partitioning using stable isotopes. Oecologia 127:171-179

Polis GA, Myers CA, Holt RD (1989) The ecology and evolution of intraguild predation potential competitiors that eat each other. Annu Rev Ecol Syst 20:297-330

Polis GA, Strong DR (1996) Food web complexity and community dynamics. Am Nat 147:813-846

Post DM (2003) Individual variation in the timing of ontogenetic niche shifts in largemouth bass. Ecology 84:1298-1310 
Post DM, Layman CA, Arrington DA, Takimoto G, Quattrochi J, Montana CG (2007) Getting to the fat of the matter: models, methods and assumptions for dealing with lipids in stable isotope analyses. Oecologia 152:179-189

Quevedo M, Olsson J (2006) The effect of small-scale resource origin on trophic position estimates in Perca fluviatilis. J Fish Biol 69:141-150

Rolff C (2000) Seasonal variation in delta C-13 and delta N-15 of size-fractionated plankton at a coastal station in the northern Baltic proper. Mar Ecol Prog Ser 203:47-65

Rounick JS, Winterbourn MJ (1986) Stable carbon isotopes and carbon flow in ecosystems. Bioscience 36:171-177

Semmens BX, Ward EJ, Moore JW, Darimont CT (2009) Quantifying Inter- and IntraPopulation Niche Variability Using Hierarchical Bayesian Stable Isotope Mixing Models. PLoS ONE 4

Stein RA, Threlkeld ST, Sandgren CD, Sprules WG, Persson L, Werner EE, Neill WE, Dodson SI (1988) Size-structured interactions in lake communities. In: Carpenter SR (ed) Complex interactions in lake communities. Springer-Verlag, New York, USA

Subalusky AL, Fitzgerald LA, Smith LL (2009) Ontogenetic niche shifts in the American Alligator establish functional connectivity between aquatic systems. Biol Conserv 142:1507-1514

Sweeting CJ, Jennings S, Polunin NVC (2005) Variance in isotopic signatures as a descriptor of tissue turnover and degree of omnivory. Funct Ecol 19:777-784

Taylor MD, Mazumder D (2010) Stable isotopes reveal post-release trophodynamic and ontogenetic changes in a released finfish, mulloway (Argyrosomus japonicus). Mar Freshw Res 61:302-308

Turner TF, Collyer ML, Krabbenhoft TJ (2010) A general hypothesis-testing framework for stable isotope ratios in ecological studies. Ecology 91:2227-2233

Vaudo JJ, Heithaus MR (2011) Dietary niche overlap in a nearshore elasmobranch mesopredator community. Mar Ecol Prog Ser 425:247-260

Werner EE, Gilliam JF (1984) The ontogenetic niche and species interactions in size structured populations. Annu Rev Ecol Syst 15:393-425 
Werner EE, Hall DJ (1988) Ontogenetic habitat shifts in bluegill - the foraging rate predation risk trade-off. Ecology 69:1352-1366

Yeager LA, Layman CA (2011) Energy flow to two abundant consumers in a sub-tropical oyster reef food web. Aquat Ecol 45:267-277

Young HS, Shaffer SA, McCauley DJ, Foley DG, Dirzo R, Block BA (2010) Resource partitioning by species but not sex in sympatric boobies in the central Pacific Ocean. Mar Ecol Prog Ser 403:291-301

Zimmerman MS, Schmidt SN, Krueger CC, Vander Zanden MJ, Eshenroder RL (2009) Ontogenetic niche shifts and resource partitioning of lake trout morphotypes. Can J Fish Aquat Sci 66:1007-1018 
CHAPTER V

PREDATOR EFFECTS ON FAUNAL COMMUNITY COMPOSITION IN SHALLOW SEAGRASS BEDS OF THE BAHAMAS 


\begin{abstract}
Over the past fifty years, much emphasis has been placed on predator effects that cascade through food webs. Such top-down effects are most common in systems with relatively simple food chains, and rather rare in species-rich systems where numerous interactions among species and high omnivory (feeding at $>1$ trophic level) typically buffer strong predator effects. Seagrass ecosystems are typically species-rich and are characterized by complex food webs, but evidence of top-down effects in these systems has been mixed. I examined the effect of predatory fishes on the species richness, total biomass, total density, and composition of the epifaunal community in a shallow seagrass system of The Bahamas. I used exclusion experiments at two different spatial scales, and applied mesh sizes that excluded different-sized predator individuals. My study found some evidence of species-level top-down effects (i.e., strong interactions within a subset of the community), driving higher biomass in some decapod mesopredators and overall lower species richness in the exclusion treatments than in the controls. In contrast, community-level predator effects were rather weak, with predator size and spatial scale of experiments displaying no detectable impact on the epifaunal community. Multiple factors may have contributed to these patterns such as species richness, omnivory, water depth, microhabitat features, as well as size range and abundance of predators. Because of the rapid global decline of seagrasses and their associated fauna, an increased knowledge of predator effects on faunal communities of seagrass beds are critical for conservation efforts.
\end{abstract}




\section{Introduction}

Over the past five decades, much emphasis has been placed on cascading effects of predators in food webs (Polis et al. 2000), and strong top-down effects have been observed in many aquatic ecosystems (Strong 1992). Often these systems are relatively simple, low-diversity food webs, with little omnivory or intraguild predation (Polis \& Strong 1996, Chase 2000, Shurin et al. 2002, Bruno \& O'Connor 2005, Finke \& Denno 2005, Shurin et al. 2006, Fox 2007, Heck \& Valentine 2007). Classic examples of strong top-down effects have been especially well studied in freshwater lentic and marine benthic systems, rocky intertidal zones and kelp forests (Paine 1966, Estes et al. 1998, Shurin et al. 2002). Species-rich ecosystems are less likely to have such strong top-down effects, largely because of the inherently reticulate food webs with many weak interaction links (Strong 1992, McCann et al. 1998).

Seagrass beds are species-rich ecosystems that provide food and shelter to numerous ecologically and economically important organisms (Orth et al. 1984, Beck et al. 2001). Evidence of predator effects in these ecosystems has been mixed, with some studies suggesting strong (Ambrose 1984, Heck et al. 2000, Hindell et al. 2000, Moksnes et al. 2008), and others weak to no top-down effects on faunal seagrass communities (Summerson \& Peterson 1984, Leber 1985, Gacia et al. 1999, Hindell et al. 2001, Valentine et al. 2008, Moore \& Hovel 2010). Predator effects in seagrass ecosystems have been suggested to be rather weak because other factors may play more important roles than predation, such as landscape context (i.e., the spatial position of a given patch within a larger mosaic of habitats or landscape features, Turner 1989) or structural complexity of seagrass beds (Orth et al. 1984, Summerson \& Peterson 1984, Leber 1985, 
Rypel et al. 2007, Moore \& Hovel 2010). In contrast, high local abundances of predatory fishes have been proposed to drive strong top-down effects in seagrass systems (Hindell et al. 2001).

In marine ecosystems, such as seagrass beds, predators can span broad ranges in body size (Costa 2009), which may be another factor determining the strength of topdown effects in these systems. In terrestrial, freshwater and temperate marine ecosystems, predator size has been shown to play an important role in regulating prey communities (Radloff \& Du Toit 2004, Winkler \& Greve 2004, Langlois et al. 2006, Rudolf 2006, Magnusson \& Williams 2009, Perez et al. 2009). Consequently, the removal of differentsized predators would be expected to differently affect community structure and composition. For instance, in a marine food web, the removal of large-bodied predators has been shown to increase the abundance of mesopredators, which subsequently suppress the densities of their prey (Myers et al. 2007). As many seagrass-associated organisms are threatened by overexploitation and extinction (Hughes et al. 2009), it is critical to examine whether different-sized predators have divergent effects on seagrass communities.

I examined predator effects on the seagrass epifaunal community in a shallow Bahamian wetland system. I employed exclusion experiments at two different spatial scales, and utilized mesh sizes that excluded different-sized predator individuals. Specifically, I investigated how predatory fishes affected species richness, total biomass and density, and community composition of the epifaunal community. Given the high abundance of predatory fishes, especially schoolmaster (Lutjanus apodus) and gray snapper (L. griseus), in this study system, I hypothesized strong predator effects on 
epifaunal community. Furthermore, because these predators have been observed to shift their diet through ontogeny (Starck \& Schroeder 1971, Hammerschlag et al. 2010, Hammerschlag-Peyer \& Layman In Revision), I also hypothesized divergent responses between the two exclusion treatments that excluded different-sized predators.

\section{Materials and Methods}

I examined effects of predatory fishes using exclusion experiments at two spatial (and temporal) scales: 1) "small-scale" (i.e., $0.77 \mathrm{~m}^{2}$ treatment area, 34 days), and 2) "medium-scale" (i.e., $19.6 \mathrm{~m}^{2}$ treatment area, 77 days). On the basis of ecological theory, responses in the small-scale experiment would be expected to be driven predominantly by movements of epifaunal taxa (i.e., behavior mechanism) caused by indirect predator effects, while the medium-scale experiment more likely reflects changes in prey density because of direct predation (Englund 1997, Englund et al. 2001).

Both manipulations were conducted in the subtidal region of seagrass beds in Jungle Creek ( $26^{\circ} 21^{\prime} 36^{\prime \prime} \mathrm{N}, 77^{\circ} 00^{\prime} 58^{\prime \prime} \mathrm{W}$, same area as descript in Stoner et al. 2011 as North Bight of Old Robinson), a seagrass- and mangrove-dominated tidal wetland, locally called "tidal creek". This study site is located on the east side of Abaco Island, Bahamas and is $\sim 40$ hectares in size. Jungle Creek is lined by mangroves (predominantly Rhizophora mangle) and the most prevalent benthic habitat types are seagrass beds (primarily Thalassia testudinum), submerged mangrove prop roots and sand flats. The system has a semi-diurnal tidal regime and mean daily tidal amplitude of $\sim 0.8 \mathrm{~m}$; most of the area of the wetland has low tide depths $<0.5 \mathrm{~m}$. Consequently, fish predators were only able to access the seagrass beds twice daily for $\sim 3-4$ hours around high tide 
(depending on individual body size), and were restricted to deeper refuge areas, such as sink holes or mangrove-lined channels, during lower tidal levels (Hammerschlag-Peyer \& Layman 2010).

The most abundant fish predators in Jungle Creek were schoolmaster (Lutjanus apodus) and gray snapper (L. griseus) ( $>90 \%$ of total predator biomass, Fig. 1) which are generalist species that have been observed to feed primarily on benthic invertebrates and small teleosts in these seagrass systems (Layman \& Silliman 2002, Layman et al. 2007, Hammerschlag-Peyer \& Layman In Revision). These species mostly consist of juveniles (schoolmaster: $<12.5 \mathrm{~cm}$ standard length (SL); gray: $<10 \mathrm{~cm} \mathrm{SL}$ ) and sub-adults (schoolmaster: 12.5-25 cm SL; gray: 10-20 cm SL; Hammerschlag et al. 2010, Yeager \& Layman 2011, Hammerschlag et al. In Revision), likely because larger individuals move to deeper habitats, including coral reefs, as they grow (Nagelkerken et al. 2000, Sheridan \& Hays 2003). Other epibenthic predators observed at the study site were cubera snapper (L. cynopterus), sergeant major (Abudefduf saxatilis), beaugregory (Stegastes leucostictus), blennies, slippery dick (Halichoeres bivittatus), mojarras (including Gerres cinereus and Eucinostomus spp.), and grunts (Haemulidae), all of which were far less abundant than schoolmaster and gray snapper. Jungle Creek is not adjacent to human settlements (Stoner et al. 2011) and thus, likely experiences little fishing pressure.

Four treatments were applied in both the small- and medium-scale experiment: unmanipulated control (UC), manipulated control (MC), small-predator exclusion (SPE) and large-predator exclusion (LPE). The SPE and LPE consisted of green plastic fence material (Landware ${ }^{\circledR}$ ) of $2 \times 2 \mathrm{~cm}$ and $5 \times 5 \mathrm{~cm}$ mesh size, respectively. Visual observations during the medium-scale experiment confirmed that SPE and LPE excluded 
different-sized fish predators (Fig. 1), yet allowed for free movement of most epibenthic fauna (e.g., small fishes, crabs, shrimps, snails, mussels). For example, schoolmaster snapper (Lutjanus apodus) $\leq 8 \mathrm{~cm}$ total length (TL) and gray snapper (L. griseus) $\leq 6 \mathrm{~cm}$ TL were observed feeding in the SPE treatment, whereas schoolmaster snapper $\leq 12 \mathrm{~cm}$ TL and gray snapper $\leq 16 \mathrm{~cm}$ TL were seen feeding in the LPE treatment (Fig. 1A,B). Individuals that were able to forage in the SPE treatment were considered to be too small to substantially affect the epifaunal community. Specifically, gray and schoolmaster snapper $\leq 8 \mathrm{~cm}$ and $\leq 6 \mathrm{~cm}$ TL, respectively, mostly feed on very small $(<4 \mathrm{~mm})$ epifaunal organisms (e.g., copepods, small caridean shrimps; Starck \& Schroeder 1971) that were not sampled in this study (see below). MC treatments included approximately the same amount of fencing material with both mesh sizes, but had gaps on the sides (more details for each experiment below) allowing fish predators of all sizes to move freely in and out of the experimental area (Fig. 1C). UC treatments consisted of no "cage" material (i.e., no fencing or rebar stakes), but were comparable to the other treatments in terms of percent seagrass cover, distance to seagrass edge and water depth.

Small-scale experiment - I employed a randomized block design, with each block $(\mathrm{n}=4)$ located $\sim 50 \mathrm{~m}$ apart. The blocks were set up June $20^{\text {th }}-23^{\text {rd }} 2008$ (one block per day). Within each block, the four treatments (SPE, LPE, MC, and UC) were randomly assigned to four a priori identified sub-sites. The exact treatment locations specifically were selected in an attempt to minimize differences in water depth, distance to seagrass edge and percent cover of Thalassia testudinum ( $\geq 80 \%)$ since these factors have previously been shown to affect faunal seagrass communities and predation rates (Orth et al. 1984, Rypel et al. 2007, Moore \& Hovel 2010). 
The SPE, LPE and MC treatments were constructed as oval "cages" (1.16 x 0.85 $\mathrm{x} 0.3 \mathrm{~m}$, length $\mathrm{x}$ width $\mathrm{x}$ height) using plastic fencing material, rebar stakes and plastic ties. Sixteen $0.6 \mathrm{~m}$-long and $1 \mathrm{~cm}$-thick rebar stakes were spaced in equal intervals and the fencing material of the entire oval was pushed $\sim 5 \mathrm{~cm}$ into the substrate. Compared to SPE and LPE, MC had one large gap on each side of the simulated exclosure to allow the free movement of all organisms in and out of the experimental area. Since the fencing height was $\sim 0.3 \mathrm{~m}$ (i.e., lower than the water depth at high tide), the top of each cage was covered using two crossing $1.2 \mathrm{~m}$-long rebar stakes and fencing material.

After 34 days, an oval throw trap (1.16 x $0.85 \times 1 \mathrm{~m}$, length $\mathrm{x}$ width $\mathrm{x}$ height $)$ was placed over each treatment area during low tide. After removal of the fencing material and rebar stakes, I recorded percent cover of Thalassia testudinum within the throw trap. The area enclosed in the throw trap was sampled with two dip nets $(4 \mathrm{~mm}$ and $10 \mathrm{~mm}$ mesh) until three consecutive dips yielded no organisms. Since the smallest dip net had a mesh size of $4 \mathrm{~mm}$, I collected epibenthic organisms that were retained by this mesh size. All sampled organisms were immediately put on ice and later frozen. In the laboratory, organisms were sorted and identified to the lowest taxonomic level possible. I then measured, dried $\left(60^{\circ} \mathrm{C}\right)$, and weighed each organism to obtain dry biomass $\left(\mathrm{g} \mathrm{m}^{-2}\right)$. For all mollusks, only the soft tissue was measured for dry biomass.

Medium-scale experiment - A randomized block design also was employed (distances between blocks varied from 130 to $530 \mathrm{~m}$ ). Treatments (SPE, LPE, MC, and UC) were constructed from February $13^{\text {th }}$ to $16^{\text {th }} 2009$ (one block per day). The treatment “cages" were constructed as $5 \mathrm{~m}$-diameter circles with $1.8-\mathrm{m}$ rebar stakes spaced in $0.5-\mathrm{m}$ intervals. The same fencing material was applied as in the small-scale experiment and 
was pushed $\sim 5 \mathrm{~cm}$ into the substrate after cage construction. The height of the fencing $(\sim 1.2 \mathrm{~m})$ exceeded the height of the highest spring tides, and thus tops were not necessary. In addition, no birds were observed in any experimental area during the study period. The "cage" of the MC treatment had a 1-m opening every $\sim 2 \mathrm{~m}$ to allow the free movement of organisms of all sizes in and out the experimental area. Using the same throw trap as in the small-scale experiment, I collected three subsamples per treatment after 77 days of deployment ( 3 subsamples $\mathrm{x} 4$ treatments $\mathrm{x} 4$ blocks $=48$ subsamples $)$. Data collection and sample processing were performed as in the small-scale experiment.

Data Analyses - For both experiments, I examined the effect of treatment and block on 1) species richness, 2) total biomass and density (summed across all taxa), and 3) community composition of epifaunal community. For the medium-scale experiment, the three sub-samples of each treatment were averaged to obtain a mean value for each response variable. Hence, the total sample size was $n=16$ (4 blocks $\mathrm{x} 4$ treatments) for both exclusion experiments. I omitted sea cucumbers (Holothuria sp., n=27, $250 \mathrm{~g}$ ), sponges (Porifera, $1026 \mathrm{~g}$ ), and one large spider crab (Majidae, $23 \mathrm{~g}$ ) from the analyses because these taxa were unlikely prey of the excluded predators. All data were tested for normality and homogeneity of variance in $\mathrm{R}$ version 2.12 .2 .

Effects of block and treatment on species richness (\# of species $\mathrm{m}^{-2}$ ), total biomass $\left(\mathrm{g} \mathrm{m}^{-2}\right)$, and total density (\# of individuals $\mathrm{m}^{-2}$ ) were analyzed using randomizedblock ANOVA and pairwise comparisons of Least Significant Difference (LSD; on the basis of a priori decisions). For community structure analysis, rare taxa $(<3 \%$ of total biomass and density, respectively) were omitted (Clarke \& Warwick 1994). Taxa used for the community structure analysis are shown in Table 1. Biomass and density of taxa 
were $\ln (\mathrm{x}+1)$ - and $\operatorname{sqrt}(\mathrm{x}+1)$-transformed, respectively, and subsequently similarity matrices on biomass and density data were constructed using standardization and the Bray-Curtis similarity coefficient. Treatment and block effects were separately tested on biomass and density data of the epifaunal taxa using ANOSIM without replication (i.e., Spearman rank correlation method, with test statistic $=\rho)$ in PRIMER 5.2.9 (Clarke \& Warwick 1994). Statistical significance was tested at $\alpha=0.05$.

\section{Results}

I identified 60 species from 49 families in the small-scale experiment, and 68 species from 57 families in the medium-scale experiment. In total, I collected 951 (357 g) and 4,927 (1025.6 g) individuals in the small- and medium-scale experiments, respectively. In the small-scale experiment, the most dominant organisms in terms of biomass averaged across all treatments and blocks were 1) Panopeus sp. (mud crab, $6.2 \mathrm{~g}$ $\mathrm{m}^{-2}, 44 \%$ of overall biomass), 2) Pitho sp. (urn crab, $3 \mathrm{~g} \mathrm{~m}^{-2}, 21 \%$ of biomass), 3 ) Gobiidae (gobies, $2 \mathrm{~g} \mathrm{~m}^{-2}, 14 \%$ of biomass), and 4) Alpheus sp. (snapping shrimp, $1 \mathrm{~g} \mathrm{~m}^{-}$ ${ }^{2}, 7 \%$ of biomass). In the medium-scale experiment, the highest biomass was 1) Panopeus sp. (4.2 $\mathrm{g} \mathrm{m}^{-2}, 41 \%$ of biomass), 2) Phascolion $\mathrm{sp}$. (hermit sipunculid, $1 \mathrm{~g} \mathrm{~m}^{-2}, 10 \%$ of biomass), 3) Portunidae (swimming crabs, $0.99 \mathrm{~g} \mathrm{~m}^{-2}, 9 \%$ of biomass), and 4) Cerithium spp. (ceriths, $0.8 \mathrm{~g} \mathrm{~m}^{-2}, 8 \%$ of biomass). In terms of density, the most common epifaunal taxa were 1) Alpheus sp. (18 individuals $\mathrm{m}^{-2}, 25 \%$ of overall density), 2) Palaemonetes sp. (grass shrimp, 14 individuals $\mathrm{m}^{-2}, 20 \%$ of density), 3) Phascolion sp. (11 individuals $\mathrm{m}^{-2}, 15 \%$ of density), and 4) Cerithium spp. (5 individuals $\mathrm{m}^{-2}, 7 \%$ of density) in the small-scale experiment, and 1) Phascolion sp. (85 individuals $\mathrm{m}^{-2}, 60 \%$ of overall 
density), 2) Cerithium spp. (18 individuals $\mathrm{m}^{-2}, 12 \%$ of density) and 3) Alpheus sp. ( 9 individuals $\mathrm{m}^{-2}, 7 \%$ of density) in the medium-scale experiment.

Small-scale experiment - Species richness varied among treatments, and block had a marginally significant effect (Table 2, Fig. 2A). Pairwise comparisons demonstrated that there was a difference in species richness between LPE and MC (LSD: mean treatment difference $=7.5, P=0.007$ ), as well as between LPE and SPE treatments (LSD: mean treatment difference $=5.5, P=0.032 ;$ Fig. 2A). Total biomass had a marginally significant treatment effect and no block effect (Table 2, Fig. 2B). Yet, pairwise comparisons indicated that total biomass differed between the SPE and UC treatments (LSD: mean treatment difference $=17.2, P=0.026$; Fig. 2B). Total density did not vary among treatments, but did among blocks (Table 2, Fig. 2C). Finally, there were no treatment or block effects in community structure for biomass (ANOSIM, treatment: $\rho=-0.048, P=0.57$; block: $\rho=-0.105, P=0.67$ ) or density data (ANOSIM, treatment: $\rho=-0.105, P=0.65$; block: $\rho=0.01, P=0.41$ ).

Medium-scale experiment - Treatment and block had marginally significant effects on species richness (Table 2, Fig. 2D). Pairwise comparisons demonstrated that there was a difference in species richness between SPE and UC treatments (LSD: mean treatment difference $=5.3, P=0.019$; Fig. 2D). In terms of total biomass, the treatment effect was marginally significant, whereas there was no block effect (Table 2, Fig. 2E). Pairwise comparisons indicate that total biomass was different between the LPE and UC (LDS: mean treatment difference $=5.17, P=0.039$ ), as well as between SPE and UC treatments (LDS: mean treatment difference $=4.97, P=0.046$; Fig. 2E). For total density, there was no treatment effect, but a block effect (Table 2, Fig. 2F). Finally, there 
were no treatment or block effects in community structure for biomass (ANOSIM, treatment: $\rho=-0.095, P=0.65$; block: $\rho=-0.095, P=0.63$ ) or density data (ANOSIM, treatment: $\rho=-0.029, P=0.52$; block: $\rho=0.114, P=0.27)$.

\section{Discussion}

Predators may play fundamental roles in regulating population dynamics and community structure (Sih et al. 1985). Strong top-down effects, including communitylevel cascades (Polis 1999), typically garner the most attention, yet may be limited to ecosystems with low species diversity, little omnivory, and/or strong, concurrent interactions between trophic levels (Strong 1992, Polis \& Strong 1996, Estes et al. 1998, Shurin et al. 2002, Heck \& Valentine 2007, Ferretti et al. 2010). Although seagrass beds are species-rich systems, strong predator effects have sometimes been identified (Ambrose 1984, Heck et al. 2000, Hindell et al. 2000, Moksnes et al. 2008). I extended the assessment of predator effects on food web structure in seagrass ecosystems, focusing especially on potential effects of different-sized predators. Contrary to my hypotheses, my findings suggest (1) weak predator effects in these shallow seagrass ecosystems, supporting the notion that the complex nature of species-diverse ecosystems disables strong predator control on food web structure, and (2) no predator size impact on faunal community structure and composition. I discuss several factors that might underlie my findings.

Two of the characteristics that often define systems with weak top-down effects are high species richness and high incidence of omnivory (Strong 1992, Fox 2007), both of which are apparent in the shallow Bahamian seagrass systems. For example, I 
collected at least 60 species in my benthic throw traps alone, not including the diverse assemblage of meiofauna that is also present $(<4 \mathrm{~mm}$; Yeager et al. In Review). In similar Bahamian seagrass ecosystems, species richness of macroinvertebrates and fishes were also high (Layman \& Silliman 2002, Layman et al. 2004, Valentine-Rose et al. 2007), contrasting sharply to systems where strong predator effects are often observed (e.g., Paine 1966). Furthermore, omnivory is expected to be high in seagrass ecosystems (Livingston 1982, Marguillier et al. 1997, Jaschinski et al. 2008). For example, the two most common fish mesopredators in my study site (gray snapper and schoolmaster snapper) are well-known generalists that feed on a variety of prey items from different trophic levels (Starck \& Schroeder 1971, Hammerschlag et al. 2010, Yeager \& Layman 2011, Hammerschlag-Peyer \& Layman In Revision). Likewise, typical prey items of snappers, such as many of the crabs and small teleosts, are omnivorous as well (Silliman et al. 2004, Yeager \& Layman 2011). Consequently, it is possible that predator effects in my study system were dampened (at least to a certain degree) by myriad weak and reticulated interactions among species.

Other factors may also have driven weak predator effects in this system. For example, in Bahamian wetlands, predation risk has been shown to increase with water depth, suggesting that predation is limited to higher water periods of the tidal cycle (Rypel et al. 2007). During lower tidal levels, predators in shallow Bahamian systems are restricted to deeper refuge areas, i.e., mangrove-lined channels (Hammerschlag-Peyer \& Layman 2010). Most other studies examining predator effects on seagrass faunal communities have been in deeper systems where predators have continuous access to prey (Leber 1985, Gacia et al. 1999, Heck et al. 2000, Hindell et al. 2000, Moore \& 
Hovel 2010). Consequently, in my study, the predation window was limited, perhaps diminishing predator effects on the epifaunal community.

Furthermore, heterogeneity in community structure and composition seemed to be generally high in this study, as suggested by the significant block effects in both experiments (Table 2). The heterogeneity was likely driven by microhabitat features of the selected sites and sub-sites. For instance, macroinvertebrates have been found to use sponges for shelter and sometimes food (Rützler 1976, Klitgaard 1995, Tsurumi \& Reiswig 1997, Magnino \& Gaino 1998, Turon et al. 2000, Saito et al. 2001, Gaino et al. 2004), and their abundance to increase with sponge biomass (Gaino et al. 2004). In this study, sponge biomass potentially may have driven the significant block effects on total densities (Table 2), as total density of epifaunal taxa tended to increase with sponge biomass, and differed mostly among blocks (Fig. 4). Other microhabitat features, such as epiphytes and macroalgae, may also have affected the epifaunal community structure (Sala 1997, Bologna \& Heck 1999, Gacia et al. 1999, Tomas et al. 2005). For example, Bologna and Heck (1999) showed that seagrass epiphytes increased epifaunal richness and density because they augmented the spatial complexity of seagrass beds, and were an important food source for several taxa. Consequently, my findings may suggest that microhabitat features, such as sponge biomass, epiphytes and macroalgae, could play critical roles in shaping faunal community structure.

Within complex food webs that have overall weak community-level predator effects, it is also possible that particular interactions are especially strong, with predators controlling the abundance of a subset of the available prey taxa (Berlow et al. 1999, Neutel et al. 2002, Berlow et al. 2004). Such patterns have been labeled species-level 
cascades (Polis 1999). My experimental results were consistent with this framework, because, in both experiments, the biomass of the decapod mesopredators, Panopeus sp., Pitho sp. and Portunidae, which are common prey of gray and schoolmaster snappers (Starck \& Schroeder 1971, Hammerschlag-Peyer \& Layman In Revision), were higher in the predator exclusions (i.e., either SPE or LPE) than in the control treatments (i.e., either MC or UC; with the exception of Panopeus sp. in the small-scale exclusion; Fig. 3). I also found that species richness was lower in the exclusion treatments than in the controls (Fig. 2), possibly because these decapod mesopredators had strong effects on some of their prey/competitors through competitive exclusion and/or direct predation (Ambrose 1984, Leber 1985). Hence, these findings suggest that species-level top-down controls may exist within my overall community, although my experimental design did not allow me to examine this further.

In contrast to my hypothesis, one of the most consistent patterns in my findings was the lack of differences in the responses to the two treatments, SPE and LPE. It is possible that the predator size range (e.g., schoolmaster snapper: 3-20 cm TL, gray snapper: 3-22 cm TL, Fig.1) might have been too narrow in my study to show significant differences between SPE and LPE treatments. In Bahamian tidal creeks, top predators are rare and the most abundant mesopredators (i.e., Lutjanidae) are typically composed of juvenile and sub-adult individuals (Fig. 1A,B), because larger individuals often move to nearby reefs as they grow (Nagelkerken et al. 2000, Sheridan \& Hays 2003). Furthermore, juvenile schoolmaster $(<12.5 \mathrm{~cm} \mathrm{SL})$ and gray $(<10 \mathrm{~cm} \mathrm{SL})$ snapper seemed to be more abundant than sub-adult individuals (schoolmaster: 12.5-25 cm SL; gray: 10-20 cm SL; Fig. 1). Consequently, because local abundance of predators can 
potentially affect the strength of top-down effects (Hindell et al. 2001), I would expect that higher abundances of sub-adult and adult snappers (or other larger-sized predatory fishes) would have driven significant differences between the different-sized predator exclusions.

According to ecological theory, results of the small-scale experiment would be expected to be mostly driven by behavioral mechanisms of the epifaunal seagrass taxa responding to the presence of predators (i.e., anti-predator behavior), while results of the medium-scale experiment were expected to additionally be driven by some density-based mechanisms as a result of direct predation (Englund 1997, Englund et al. 2001). In general, I did not observe differences in outcome between the small- and medium-scale exclusion. These findings suggest that either (1) there was no overall difference between the indirect (i.e., behavioral mechanisms) and direct (i.e., density-based mechanisms) predator effects on the community, or (2) the medium-scale exclusion was not large enough to display direct predator effects. I suggest the latter is a more likely explanation. For example, a recent empirical experiment demonstrated that effects of a small benthic fish (Cottus gobio) on densities of invertebrates did not differ between instream channels of different lengths in a Swedish stream (Englund 2005), and suggested that even largescale experimental units ( $\sim 8 \mathrm{~m}$ in length) are not sufficient to allow direct predation effects to be manifested (Englund 2005). Consequently, although system specific, it has been suggested that experiments performed in the time period of weeks to months and that use experimental units that are smaller than $10 \mathrm{~m}$ belong to the small-scale domain, and are thus behavior controlled (Englund 2005). My results seem to be consistent with these observations. 
Although much ecological emphasis has been placed on the role of predation on food web structure, the lack of consistency in how food webs respond to predators in seagrass ecosystems, and generally across ecosystem types, encourages further exploration (Borer et al. 2005, Fox 2007). Moreover, in light of the rapid global decline of seagrasses and their associated fauna (Orth et al. 2006, Hughes et al. 2009), a better understanding of predator effects on faunal communities of seagrass beds are critical for conservation efforts. My study contributes to these endeavors and suggests that shallow, species-rich, seagrass communities may have rather weak community-level predator effects. Increased knowledge of predator effects in seagrass ecosystems may help to enhance the understanding of possible consequences of large-scale seagrass declines on community structure and ecosystem function.

\section{Acknowledgments}

This study was funded by NSF OCE \#0746164 and FIU Graduate School Dissertation Year Fellowship. I thanks Friends of the Environment (Abaco), Darlene Haines, and Kaye Rennirt, for their logistical support and all people who helped with field and lab work, data analysis and manuscript editing, especially J. Allgeier, K.

Bernhardt, S. Giery, S. Hurley, M. Ioli, A. Mercado, G. Mineau, M. Seese, Dr. J. Trexler, C. Villegas, L. Yeager and A. Yoc-Kim. Sampling of epifaunal taxa was permitted by the Bahamas Department of Marine Resources and the FIU Institutional Animal Care and Use Committee (IACUC; Permit Numbers: 09-009, 08-008). 
Table 1 Taxa that contributed $\geq 3 \%$ to the overall biomass and density and were included in the community analysis (relative biomass and density for the small-scale and mediumscale exclusion experiment). Taxa are organized in phylogenetic order

\begin{tabular}{|c|c|c|c|c|c|}
\hline \multirow[t]{2}{*}{ Scientific Name } & \multirow[t]{2}{*}{ Common Name } & \multicolumn{2}{|c|}{ Small-s cale } & \multicolumn{2}{|c|}{ Me dium-s cale } \\
\hline & & Biomass & Density & Biomass & Density \\
\hline Cerithium spp. & Sea snail & & $\mathrm{x}$ & $\mathrm{x}$ & $\mathrm{x}$ \\
\hline Gastropoda $^{1}$ & Sea snails other than Cerithium spp. & & $\mathrm{x}$ & $\mathrm{x}$ & $\mathrm{x}$ \\
\hline Codakia spp. & Marine mussel & $\mathrm{x}$ & $\mathrm{x}$ & & $\mathrm{x}$ \\
\hline Lucina spp. & Marine mussel & & & & $\mathrm{x}$ \\
\hline Bivalvia $^{2}$ & $\begin{array}{l}\text { Marine mussels other than Codakia spp. } \\
\text { and Lucina spp. }\end{array}$ & & & $\mathrm{x}$ & $\mathrm{x}$ \\
\hline Phascolion sp. ${ }^{3}$ & Hermit sipunculid & & $\mathrm{x}$ & $\mathrm{x}$ & $\mathrm{x}$ \\
\hline Oligochaeta & Annelids & & & & $\mathrm{x}$ \\
\hline Amphipoda & Amphipods & & $\mathrm{x}$ & & \\
\hline Alpheus sp. & Snapping shrimp & $\mathrm{x}$ & $\mathrm{x}$ & $\mathrm{x}$ & $\mathrm{x}$ \\
\hline Palaemonetes sp. & Grass shrimp & & $\mathrm{x}$ & & $\mathrm{x}$ \\
\hline Squilla sp. & Mantis shrimp & & & $\mathrm{x}$ & \\
\hline Panopeus sp. & Mud crab & $\mathrm{x}$ & $\mathrm{x}$ & $\mathrm{x}$ & $\mathrm{x}$ \\
\hline Xanthidoidae & Mud crabs other than Panopeus sp. & & & $\mathrm{x}$ & $\mathrm{x}$ \\
\hline Portunidae & Swimming crabs & & & $\mathrm{x}$ & \\
\hline Pitho sp. & Urn crab & $\mathrm{x}$ & $\mathrm{x}$ & $\mathrm{x}$ & \\
\hline Dromidia sp. & Decorator crab & & & $\mathrm{x}$ & \\
\hline Majidae $^{4}$ & Spider crabs & & & & $\mathrm{x}$ \\
\hline Ophiurida & Brittle stars & & $\mathrm{x}$ & $\mathrm{x}$ & $\mathrm{x}$ \\
\hline Anguilliformes & Eels & & & $\mathrm{x}$ & \\
\hline Gobiidae/Blenniidae & Gobies and Blennies & $\mathrm{x}$ & $\mathrm{x}$ & $\mathrm{x}$ & $\mathrm{x}$ \\
\hline Pomacentridae & Damselfish & $\mathrm{x}$ & & & \\
\hline
\end{tabular}

${ }^{1}$ Modulus sp., Tegula sp., Bulla sp. and Cerodrillia sp.; ${ }^{2}$ Galeommatidae, Tellinidae, and Glycymeris spp.; ${ }^{3}$ unsegmented worm that inhabits abandoned shells, in this study mostly in Cerithium spp. shells; ${ }^{4}$ Pitho sp., Dromidia sp., and Mithrax sp. 
Table 2 Results of analysis of variance (ANOVA) for the small- and medium-scale exclusion experiment. Treatments consisted of small- and large-predator exclusion, manipulated and unmanipulated control, and in each experiment, four blocks were used. Bold $P$-values indicate statistically significant findings $(P<0.05)$, and italic $P$-values represent marginally significant results $(0.05<P \leq 0.1)$

\begin{tabular}{llcccc}
\hline & & \multicolumn{2}{c}{ Small-s cale } & \multicolumn{2}{c}{ Medium-s cale } \\
& & F & $P$ & F & $P$ \\
\hline Species Richness & Treatment & 4.29 & $\mathbf{0 . 0 4}$ & 2.81 & 0.1 \\
& Block & 3.46 & 0.06 & 3.4 & 0.06 \\
Total Biomass & Treatment & 2.77 & 0.1 & 2.98 & 0.09 \\
& Block & 0.17 & 0.92 & 1.11 & 0.39 \\
Total Density & Treatment & 1.18 & 0.37 & 0.49 & 0.7 \\
& Block & 6.14 & $\mathbf{0 . 0 1 5}$ & 7.45 & $\mathbf{0 . 0 0 8}$ \\
\hline
\end{tabular}



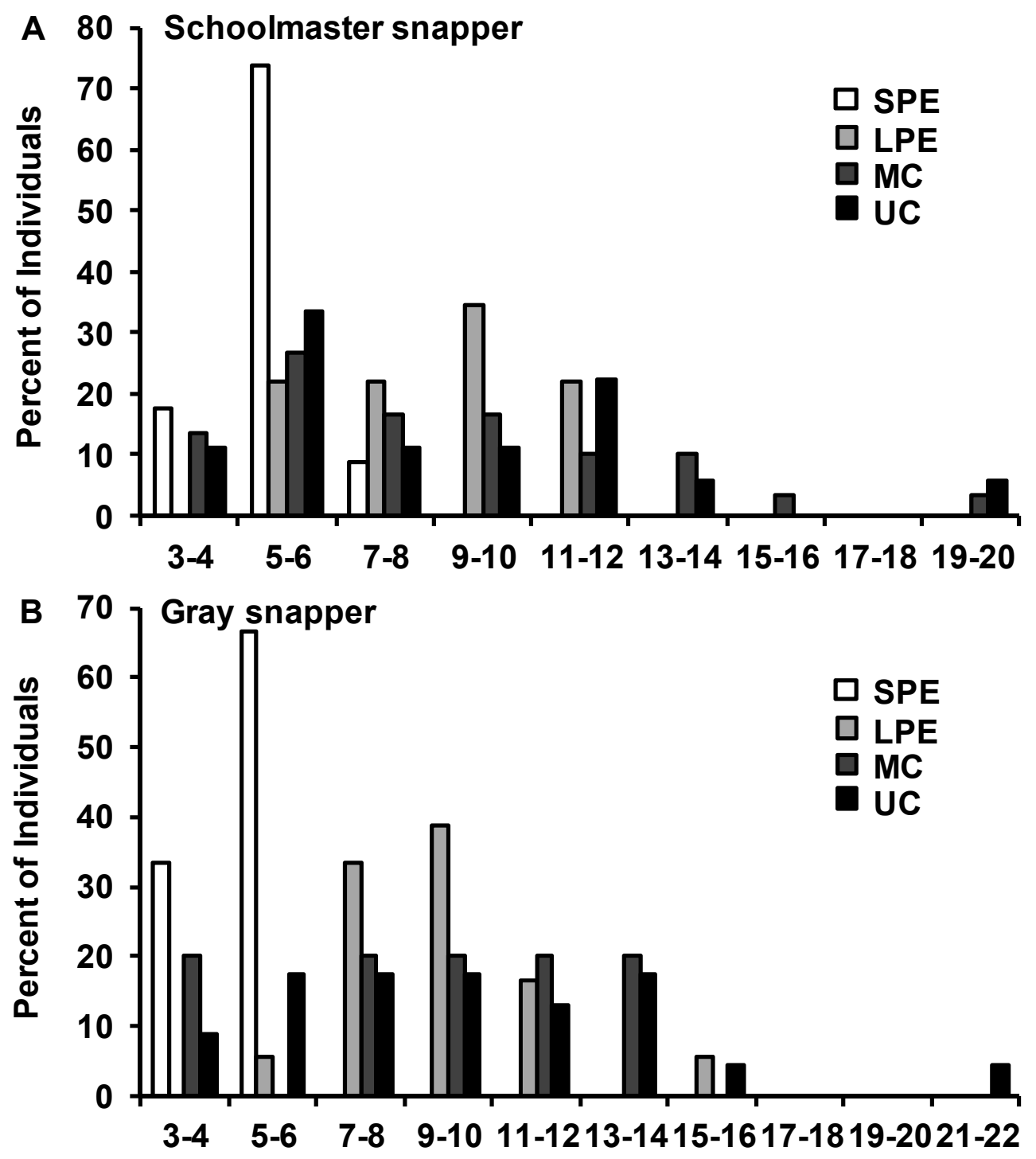

Fig. 1 Size-frequency distribution of A) schoolmaster snapper (Lutjanus apodus) and B) gray snapper (L. griseus) observed in the four different treatments: SPE = small-predator exclusion, $\mathrm{LPE}=$ large-predator exclusion, $\mathrm{MC}=$ manipulated control, and $\mathrm{UC}=$ unmanipulated control. Bins included $2 \mathrm{~cm}$ total length (TL) starting at $3 \mathrm{~cm}$ TL 

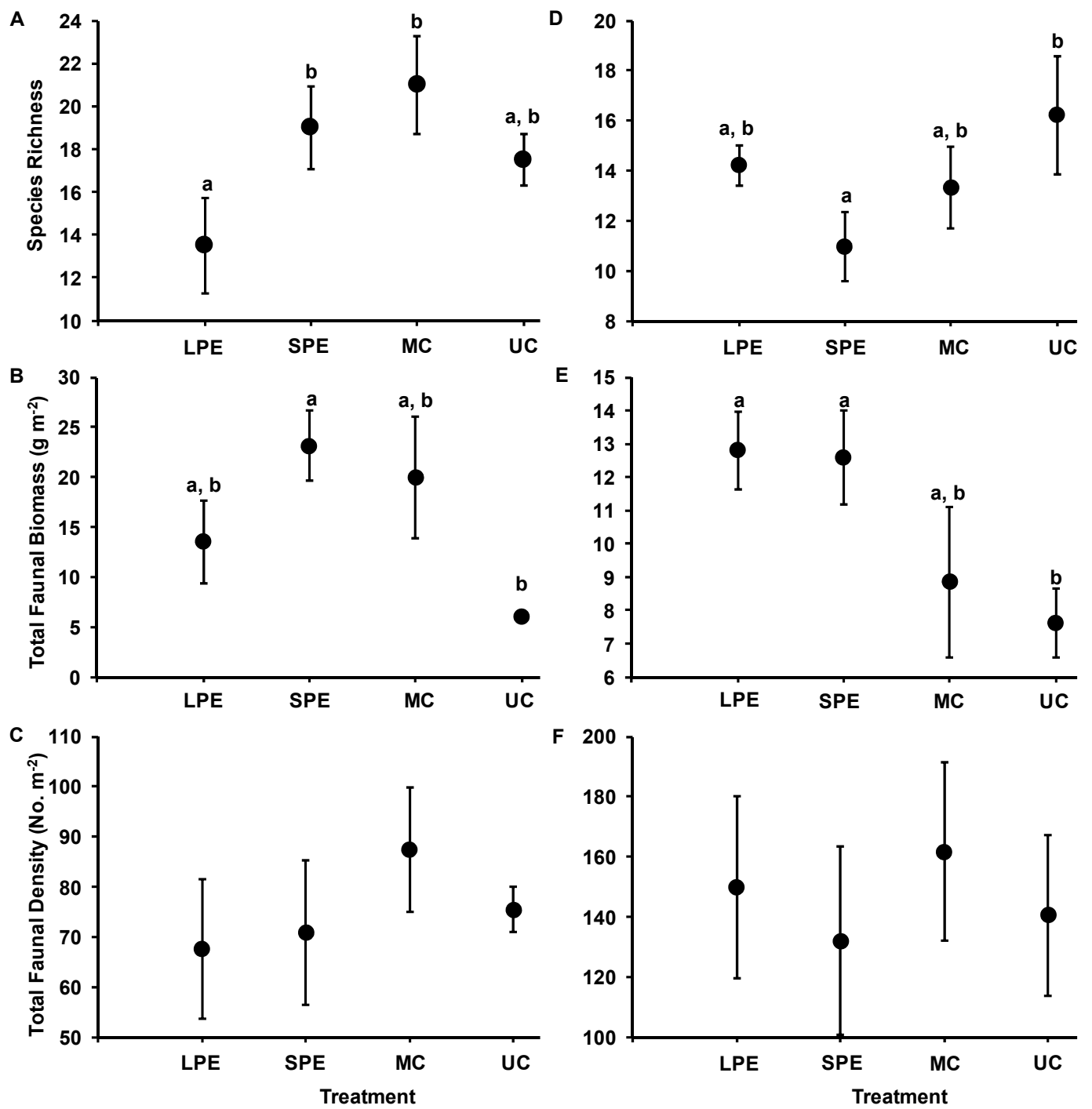

Fig. 2 Species Richness (A and D), Total Biomass (B and E), and Total Density (C and F) of the small-scale (A-C) and medium-scale (D-F) experiments. LPE = large-predator exclusion, $\mathrm{SPE}=$ small-predator exclusion, $\mathrm{MC}=$ manipulated control, $\mathrm{UC}=$ unmanipulated control (see text for more details). Error bars represent standard error. Standard error for total biomass (small-scale exclusion) was low in the unmanipulated control and thus not visible in panel B. $(\mathrm{a}, \mathrm{b})$ indicate statistically significant $(P<0.05)$ differences between treatments (on the basis of Least Significant Difference 
comparisons) and are not present for Total Density ( $\mathrm{C}$ and $\mathrm{F})$ because all pairwise comparisons were $P \geq 0.05$ 

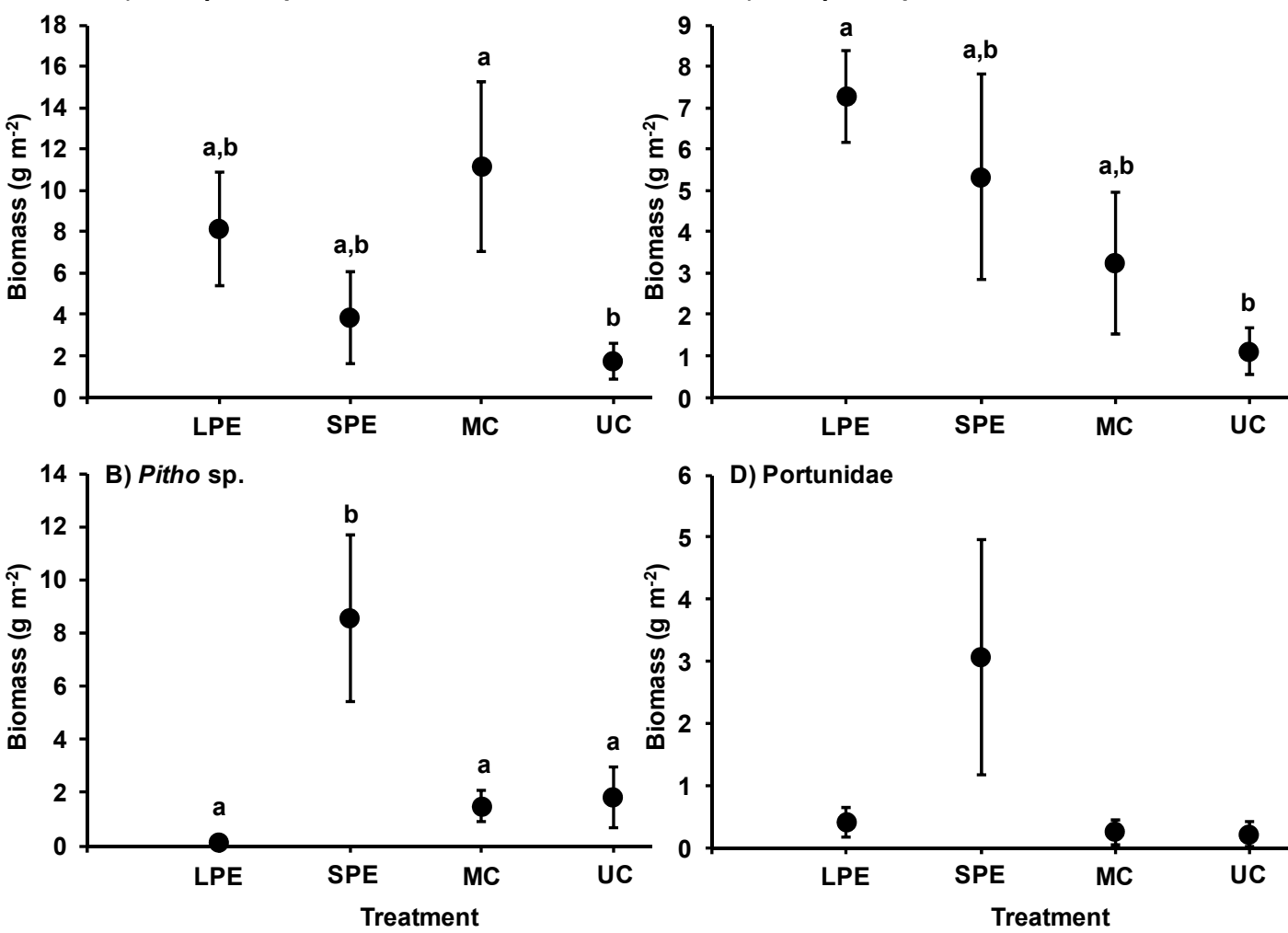

Fig. 3 Total Biomass of A) Panopeus sp. (mud crab), B) Pitho sp. (urn crab), C)

Panopeus sp. and D) Portunidae (family of swimming crabs) in the small-scale (A-B) and medium-scale $(\mathrm{C}-\mathrm{D})$ exclusion. $\mathrm{LPE}=$ large-predator exclusion, $\mathrm{SPE}=$ small-predator exclusion, $\mathrm{MC}=$ manipulated control, $\mathrm{UC}=$ unmanipulated control (see text for more details). Error bars represent standard error. Standard error of Pitho sp. (small-scale exclusion) was low in the large-predator exclusion and thus not visible in panel B. $(\mathrm{a}, \mathrm{b})$ indicate statistically significant $(P<0.05)$ differences between treatments (on the basis of Least Significant Difference comparisons), and are not present for Portunidae (D) because all pairwise comparisons were $P \geq 0.05$ (i.e., SPE-LPE: $P=0.08$, SPE-MC: $P=$ 0.06, SPE-UC: $P=0.06)$ 

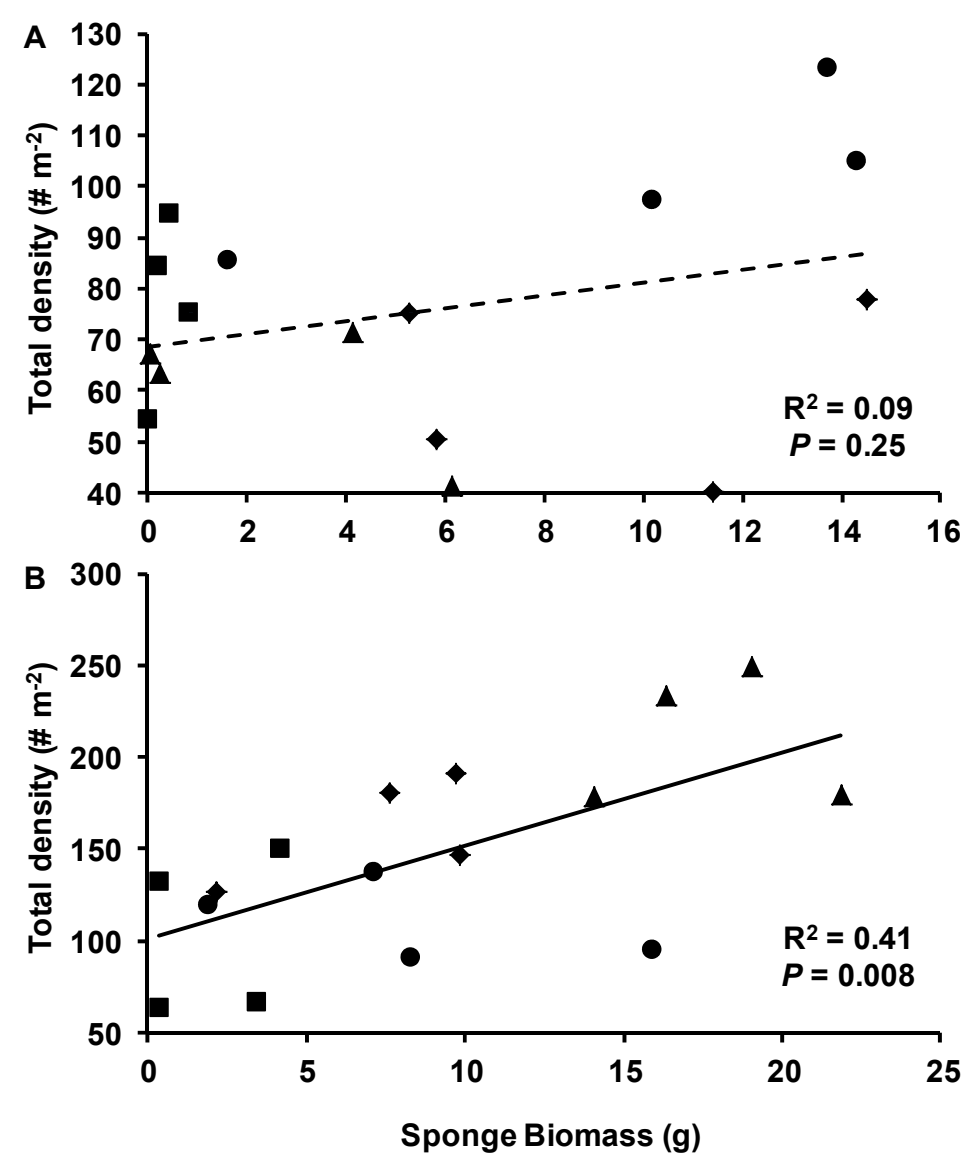

Fig. 4 Linear regression between total density and sponge biomass in the A) small-scale and B) medium-scale exclusion experiment. Block $1=$ squares, block $2=$ triangles, block $3=$ diamonds, block $4=$ circles. Linear regression across the four blocks result in a $\mathrm{R}^{2}=$ 0.09 and $P=0.25$ in the small-scale exclusion (A), and $\mathrm{R}^{2}=0.09$ and $P=0.008$ in the medium-scale exclusion (B). Dashed regression line represents a non-significant trend $(P$ $\geq 0.05)$, and solid line statistically significant relationship $(P<0.05)$ 


\section{LITERATURE CITED}

Ambrose WG (1984) Role of predatory infauna in structuring marine soft-bottom communities. Mar Ecol Prog Ser 17:109-115

Beck MW, Heck KL, Able KW, Childers DL, Eggleston DB, Gillanders BM, Halpern B, Hays CG, Hoshino K, Minello TJ, Orth RJ, Sheridan PF, Weinstein MR (2001) The identification, conservation, and management of estuarine and marine nurseries for fish and invertebrates. Bioscience 51:633-641

Berlow EL, Navarrete SA, Briggs CJ, Power ME, Menge BA (1999) Quantifying variation in the strengths of species interactions. Ecology 80:2206-2224

Berlow EL, Neutel AM, Cohen JE, de Ruiter PC, Ebenman B, Emmerson M, Fox JW, Jansen VAA, Jones JI, Kokkoris GD, Logofet DO, McKane AJ, Montoya JM, Petchey O (2004) Interaction strengths in food webs: issues and opportunities. J Anim Ecol 73:585-598

Bologna PAX, Heck KL (1999) Macrofaunal associations with seagrass epiphytes Relative importance of trophic and structural characteristics. J Exp Mar Biol Ecol 242:21-39

Borer ET, Seabloom EW, Shurin JB, Anderson KE, Blanchette CA, Broitman B, Cooper SD, Halpern BS (2005) What determines the strength of a trophic cascade? Ecology 86:528-537

Bruno JF, O'Connor MI (2005) Cascading effects of predator diversity and omnivory in a marine food web. Ecol Lett 8:1048-1056

Chase JM (2000) Are there real differences among aquatic and terrestrial food webs? Trends Ecol Evol 15:408-412

Clarke KR, Warwick RM (1994) Change in marine communities: an approach to statistical analysis and interpretation, 1st edition, Vol. PRIMER-E, Plymouth

Costa GC (2009) Predator size, prey size, and dietary niche breadth relationships in marine predators. Ecology 90:2014-2019

Englund G (1997) Importance of spatial scale and prey movements in predator caging experiments. Ecology 78:2316-2325 
Englund G (2005) Scale dependent effects of predatory fish on stream benthos. Oikos 111:19-30

Englund G, Cooper SD, Sarnelle O (2001) Application of a model of scale dependence to quantify scale domains in open predation experiments. Oikos 92:501-514

Estes JA, Tinker MT, Williams TM, Doak DF (1998) Killer whale predation on sea otters linking oceanic and nearshore ecosystems. Science 282:473-476

Ferretti F, Worm B, Britten GL, Heithaus MR, Lotze HK (2010) Patterns and ecosystem consequences of shark declines in the ocean. Ecol Lett 13:1055-1071

Finke DL, Denno RF (2005) Predator diversity and the functioning of ecosystems: the role of intraguild predation in dampening trophic cascades. Ecol Lett 8:1299-1306

Fox JW (2007) The dynamics of top-down and bottom-up effects in food webs of varying prey diversity, composition, and productivity. Oikos 116:189-200

Gacia E, Littler MM, Littler DS (1999) An experimental test of the capacity of food web interactions (fish-epiphytes-seagrasses) to offset the negative consequences of eutrophication on seagrass communities. Estuarine Coastal Shelf Sci 48:757-766

Gaino E, Lancioni T, La Porta G, Todini B (2004) The consortium of the sponge Ephydatia fluviatilis (L.) living on the common reed Phragmites australis in Lake Piediluco (central Italy). Hydrobiologia 520:165-178

Hammerschlag-Peyer CM, Layman CA (2010) Intrapopulation variation in habitat use by two abundant coastal fish species. Mar Ecol Prog Ser 415:211-220

Hammerschlag-Peyer CM, Layman CA (In Revision) Factors affecting resource use variation in an abundant coastal fish predator, Lutjanus apodus, in a Bahamian wetland system. Bull Mar Sci

Hammerschlag N, Ovando D, Serafy JE (2010) Seasonal diet and feeding habits of juvenile fishes foraging along a subtropical marine ecotone. Aquat Biol 9:279-290

Heck KL, Pennock JR, Valentine JF, Coen LD, Sklenar SA (2000) Effects of nutrient enrichment and small predator density on seagrass ecosystems: An experimental assessment. Limnol Oceanogr 45:1041-1057

Heck KL, Valentine JF (2007) The primacy of top-down effects in shallow benthic ecosystems. Estuar Coasts 30:371-381 
Hindell JS, Jenkins GP, Keough MJ (2000) Evaluating the impact of predation by fish on the assemblage structure of fishes associated with seagrass (Heterozostera tasmanica) (Martens ex Ascherson) den Hartog, and unvegetated sand habitats. J Exp Mar Biol Ecol 255:153-174

Hindell JS, Jenkins GP, Keough MJ (2001) Spatial and temporal variability in the effects of fish predation on macrofauna in relation to habitat complexity and cage effects. Mar Ecol Prog Ser 224:231-250

Hughes AR, Williams SL, Duarte CM, Heck KL, Waycott M (2009) Associations of concern: declining seagrasses and threatened dependent species. Front Ecol Environ 7:242-246

Jaschinski S, Brepohl DC, Sommer U (2008) Carbon sources and trophic structure in an eelgrass Zostera marina bed, based on stable isotope and fatty acid analyses. Mar Ecol Prog Ser 358:103-114

Klitgaard AB (1995) The fauna associated with outer shelf and upper slope sponges (Porifera, Demospongiae) at the Faroe Islands, Northeastern Atlantic Sarsia 80:122

Langlois TJ, Anderson MJ, Brock M, Murman G (2006) Importance of rock lobster sizestructure for trophic interactions: choice of soft-sediment bivalve prey. Mar Biol 149:447-454

Layman CA, Arrington DA, Langerhans RB, Silliman BR (2004) Degree of fragmentation affects fish assemblage structure in Andros Island (Bahamas) estuaries. Caribb J Sci 40:232-244

Layman CA, Quattrochi JP, Peyer CM, Allgeier JE (2007) Niche width collapse in a resilient top predator following ecosystem fragmentation. Ecol Lett 10:937-944

Layman CA, Silliman BR (2002) Preliminary survey and diet analysis of juvenile fishes of an estuarine creek on Andros Island, Bahamas. Bull Mar Sci 70:199-210

Leber KM (1985) The influence of predatory decapods, refuge, and microhabitat selection on seagrass communities. Ecology 66:1951-1964

Livingston RJ (1982) Trophic organization of fishes in a coastal seagrass system. Mar Ecol Prog Ser 7:1-12 
Magnino G, Gaino E (1998) Haplosyllis spongicola (GRUBE) (Polychaeta, Syllidae) associated with two species of sponges from East Africa (Tanzania, Indian Ocean). Mar Ecol-Pubbl Stn Zool Napoli 19:77-87

Magnusson AK, Williams DD (2009) Top-down control by insect predators in an intermittent pond - a field experiment. Ann Limnol 45:131-143

Marguillier S, vanderVelde G, Dehairs F, Hemminga MA, Rajagopal S (1997) Trophic relationships in an interlinked mangrove-seagrass ecosystem as traced by delta $\mathrm{C}$ 13 and delta N-15. Mar Ecol Prog Ser 151:115-121

McCann K, Hastings A, Huxel GR (1998) Weak trophic interactions and the balance of nature. Nature 395:794-798

Moksnes PO, Gullstrom M, Tryman K, Baden S (2008) Trophic cascades in a temperate seagrass community. Oikos 117:763-777

Moore EC, Hovel KA (2010) Relative influence of habitat complexity and proximity to patch edges on seagrass epifaunal communities. Oikos 119:1299-1311

Myers RA, Baum JK, Shepherd TD, Powers SP, Peterson CH (2007) Cascading effects of the loss of apex predatory sharks from a coastal ocean. Science 315:1846-1850

Nagelkerken I, Dorenbosch M, Verberk W, de la Moriniere EC, van der Velde G (2000) Importance of shallow-water biotopes of a Caribbean bay for juvenile coral reef fishes: patterns in biotope association, community structure and spatial distribution. Mar Ecol Prog Ser 202:175-192

Neutel AM, Heesterbeek JAP, de Ruiter PC (2002) Stability in real food webs: Weak links in long loops. Science 296:1120-1123

Orth RJ, Carruthers TJB, Dennison WC, Duarte CM, Fourqurean JW, Heck KL, Hughes AR, Kendrick GA, Kenworthy WJ, Olyarnik S, Short FT, Waycott M, Williams SL (2006) A global crisis for seagrass ecosystems. Bioscience 56:987-996

Orth RJ, Heck KL, Vanmontfrans J (1984) Faunal communities in seagrass beds - a review of the influence of plant structure and prey characteristics on predator-prey relationships. Estuaries 7:339-350

Paine RT (1966) Food web complexity and species diversity. Am Nat 100:65-75 
Perez KO, Carlson RL, Shulman MJ, Ellis JC (2009) Why are intertidal snails rare in the subtidal? Predation, growth and the vertical distribution of Littorina littorea (L.) in the Gulf of Maine. J Exp Mar Biol Ecol 369:79-86

Polis GA (1999) Why are parts of the world green? Multiple factors control productivity and the distribution of biomass. Oikos 86:3-15

Polis GA, Sears ALW, Huxel GR, Strong DR, Maron J (2000) When is a trophic cascade a trophic cascade? Trends Ecol Evol 15:473-475

Polis GA, Strong DR (1996) Food web complexity and community dynamics. Am Nat $147: 813-846$

Radloff FGT, Du Toit JT (2004) Large predators and their prey in a southern African savanna: a predator's size determines its prey size range. J Anim Ecol 73:410-423

Rudolf VHW (2006) The influence of size-specific indirect interactions in predator-prey systems. Ecology 87:362-371

Rützler K (1976) Ecology of Tunisian commercial sponges. Tethys 7:249-564

Rypel AL, Layman CA, Arrington DA (2007) Water depth modifies relative predation risk for a motile fish taxon in Bahamian tidal creeks. Estuar Coasts 30:518-525

Saito T, Uchida I, Takeda M (2001) Pair formation in Spongicola japonica (Crustacea : Stenopodidea : Spongicolidae), a shrimp associated with deep-sea hexactinellid sponges. J Mar Biol Assoc U K 81:789-797

Sala E (1997) The role of fishes in the organization of a Mediterranean sublittoral community .2. Epifaunal communities. J Exp Mar Biol Ecol 212:45-60

Sheridan P, Hays C (2003) Are mangroves nursery habitat for transient fishes and decapods? Wetlands 23:449-458

Shurin JB, Borer ET, Seabloom EW, Anderson K, Blanchette CA, Broitman B, Cooper SD, Halpern BS (2002) A cross-ecosystem comparison of the strength of trophic cascades. Ecol Lett 5:785-791

Shurin JB, Gruner DS, Hillebrand H (2006) All wet or dried up? Real differences between aquatic and terrestrial food webs. Proc R Soc B-Biol Sci 273:1-9 
Sih A, Crowley P, McPeek M, Petranka J, Strohmeier K (1985) Predation, competition, and prey communities - a review of field experiments. Annu Rev Ecol Syst $16: 269-311$

Silliman BR, Layman CA, Geyer K, Zieman JC (2004) Predation by the black-clawed mud crab, Panopeus herbstii, in Mid-Atlantic salt marshes: Further evidence for top-down control of marsh grass production. Estuaries 27:188-196

Starck WA, Schroeder RE (1971) Investigations on the Gray Snapper, Lutjanus griseus, Vol. University of Miami Press, Coral Gables, Florida

Stoner EW, Layman CA, Yeager LA, Hassett HM (2011) Effects of anthropogenic disturbance on the abundance and size of epibenthic jellyfish Cassiopea spp. Mar Pollut Bull 62:1109-1114

Strong DR (1992) Are trophic cascades all wet - differentiation and donor-control in speciose ecosystems. Ecology 73:747-754

Summerson HC, Peterson CH (1984) Role of predation in organizing benthic communities of a temperate-zone seagrass bed. Mar Ecol Prog Ser 15:63-77

Tomas F, Turon X, Romero J (2005) Effects of herbivores on a Posidonia oceanica seagrass meadow: importance of epiphytes. Mar Ecol Prog Ser 287:115-125

Tsurumi M, Reiswig HM (1997) Sexual versus asexual reproduction in an oviparous rope-form sponge, Aplysina cauliformis (Porifera; Verongida). Invertebr Reprod Dev 32:1-9

Turner MG (1989) Landscape ecology - the effect of pattern on process. Annu Rev Ecol Syst 20:171-197

Turon X, Codina M, Tarjuelo I, Uriz MJ, Becerro MA (2000) Mass recruitment of Ophiothrix fragilis (Ophiuroidea) on sponges: settlement patterns and postsettlement dynamics. Mar Ecol Prog Ser 200:201-212

Valentine-Rose L, Cherry JA, Culp JJ, Perez KE, Pollock JB, Arrington DA, Layman CA (2007) Floral and faunal differences between fragmented and unfragmented Bahamian tidal creeks. Wetlands 27:702-718

Valentine JF, Heck KL, Blackmon D, Goecker ME, Christian J, Kroutil RM, Peterson BJ, Vanderklift MA, Kirsch KD, Beck M (2008) Exploited species impacts on trophic 
linkages along reef-seagrass interfaces in the Florida keys. Ecol Appl 18:15011515

Winkler G, Greve W (2004) Trophodynamics of two interacting species of estuarine mysids, Praunus flexuosus and Neomysis integer, and their predation on the calanoid copepod Eurytemora affinis. J Exp Mar Biol Ecol 308:127-146

Yeager LA, Acevedo CL, Layman CA (In Review) Effects of seascape context on abundance, condition and secondary production of a coral reef fish. Mar Ecol Prog Ser

Yeager LA, Layman CA (2011) Energy flow to two abundant consumers in a sub-tropical oyster reef food web. Aquat Ecol 45:267-277 


\section{CHAPTER VI}

\section{CONCLUSIONS AND FUTURE DIRECTIONS}


Body size is a fundamental characteristic of organisms, determining various important life history and physiological traits (Peters 1983, Werner \& Gilliam 1984, Persson 1988, Brown et al. 2004). Body size also mediates the occurrence and consequences of the interactions among organisms, thus affecting population dynamics, predator-prey interactions, community structure, and ecosystem function (Brooks \& Dodson 1965, Marquet et al. 1990, Brown et al. 1993, Greenwood et al. 1996, Jennings et al. 2002, Cohen et al. 2003, Dalerum \& Angerbjorn 2005, Rudolf 2006, Hildrew et al. 2007, Akin \& Winemiller 2008). My dissertation research focused primarily on the effect of body size on the resource use (i.e., diet and habitat use) of economically and ecologically important coastal fish predators, as well as the influence of body size of these predators on their prey communities. Herein, I summarize the major conclusions of my dissertation, and suggest some future directions that could build on this research.

One major finding of my dissertation research was high variation in resource use among individuals of a population (Chapter II and III). Consistent with other recent reviews, it may be likely that intraspecific variation is more common and pronounced than has previously been acknowledged (Bolnick et al. 2003, Araujo et al. 2011). In the snapper species studied herein, some of this intrapopulation variation in resource use was explained by body size (Chapter III), and some by individual behavior (Chapter II and III), being further influenced by temporal variability (Chapter III). Such intrapopulation variation has important ecological, evolutionary and conservation implications (Bolnick et al. 2003, Bolnick et al. 2011, Araujo et al. 2011). For example, population models that integrate intrapopulation variation can cause extremely different dynamical behavior because of the added capacity for frequency-dependent effects (Bolnick et al. 2003). 
Consequently, such population models can more precisely simulate and predict population and community dynamics and ecosystem function.

Furthermore, intrapopulation variation in resource use has been typically ignored from a fisheries management perspective. Simply focusing on the "average" habitat or prey of a fish population may inherently ignore those individuals that use alternative habitats or food sources, rendering such management efforts ineffective (Durell 2000, Bolnick et al. 2003, Egli \& Babcock 2004). In contrast, fisheries management and conservation measures that take intrapopulation resource variation into account may help preserve species' ecological, phenotypic and genetic diversity, and thus their ability to adapt to environmental change and to respond to human impacts in marine ecosystems (Moritz 1994, Coates 2000, Bolnick et al. 2003).

Another core finding of my research was that effects of these predators were generally weak in a shallow, species-rich, Bahamian seagrass system, with predator size and experimental spatial scale having no major impact on the epifaunal community (Chapter V). These findings were likely the result of high species richness, high incidence of omnivory, and numerous weak and reticulate interactions among species. These findings may be critical for conservation efforts, especially because of drastic declines of seagrasses and their associated fauna worldwide (Orth et al. 2006, Hughes et al. 2009). Decrease in faunal diversity as a result of seagrass die-offs could lead to stronger predator effects in seagrass communities, subsequently driving such seagrass food webs to be less stable (McCann 2000), and to be more prone to effects of predator removal (e.g. because of overfishing) than species-rich seagrass systems. 
I also developed a hypothesis-testing framework (Chapter IV) that extends beyond my focal study systems. This approach can help guide future research focused on categorizing taxonomic or functional classes into specific niche shift scenarios, as well as to help elucidate underlying mechanisms causing particular niche shifts. Future studies should also try to expand the application of this framework to other methods (e.g., stomach content analysis), or make it applicable for the use of combined methodologies (e.g., stable isotope and stomach content analyses), so that the framework can be widely used in the field of ecological studies.

Another future direction building on my research findings would be to attempt to tease apart which mechanisms may drive the high intrapopulation niche variation that I observed. For instance, predation risk may be one major factor affecting habitat use and ontogenetic diet shifts in Lutjanidae (Werner \& Hall 1988). Smaller snappers likely have higher predation risks than larger ones, and thus probably experience a trade-off between feeding opportunities and predation risk. In addition, intraspecific competition has been shown to play an important role in driving intrapopulation resource variation (Svanbäck \& Persson 2004, Svanbäck et al. 2008, Kobler et al. 2009, Svanbäck \& Persson 2009, Frederich et al. 2010). For example, when resources are scarce due to intraspecific competition, some individuals may be driven to forage on less optimal prey items and/or to expand their foraging area (Chapter II). In the shallow systems used for my dissertation research, densities of snappers were especially high because individuals were forced to few deeper areas at low tide (Chapters II, III, and V).

Lastly, future research could examine predator exclusions at even larger spatial scales than employed in my dissertation research. Although the exclusion experiments in 
my medium-scale experiment were relatively large (treatment cages $\sim 20 \mathrm{~m}^{2}$ ) compared to many field experiments, it is still relatively small compared to the spatial scales at which important ecological processes may operate. Although large-scale experiments have obvious limitations in funding and logistical constraints (Carpenter 1990), they may reveal effects that may not be manifested at smaller spatial scales (Werner et al. 2009).

Bahamian wetland systems are increasingly threatened by human activities, such as direct removal through development activities, fragmentation and other forms of habitat alteration and pollution (National Wetlands Committee 2007). Yet, these systems are crucial for coastline protection, recreation and ecotourism, as well as provide critical habitats to numerous ecologically and economically important species (Adams et al. 2006). Consequently, an increased understanding of the ecology of the organisms inhabiting these systems is necessary to properly protect and manage them. My dissertation research contributed to this endeavor by providing insights about dynamics within important fish predator populations, their interactions with prey, as well as their effects on faunal community structure in Bahamian wetland systems. 


\section{LITERATURE CITED}

Adams AJ, Dahlgren CP, Kellison GT, Kendall MS, Layman CA, Ley JA, Nagelkerken I, Serafy JE (2006) Nursery function of tropical back-reef systems. Mar Ecol Prog Ser 318:287-301

Akin S, Winemiller KO (2008) Body size and trophic position in a temperature estuarine food web. Acta Oecol-Int J Ecol 33:144-153

Araujo MS, Bolnick DI, Layman CA (2011) The ecological causes of individual specialization. Ecol Lett 14:948-958

Bolnick DI, Amarasekare P, Araujo MS, Burger R, Levine JM, Novak M, Rudolf VHW, Schreiber SJ, Urban MC, Vasseur DA (2011) Why intraspecific trait variation matters in community ecology. Trends Ecol Evol 26:183-192

Bolnick DI, Svanback R, Fordyce JA, Yang LH, Davis JM, Hulsey CD, Forister ML (2003) The ecology of individuals: Incidence and implications of individual specialization. Am Nat 161:1-28

Brooks JL, Dodson SI (1965) Predation body size and composition of plankton. Science 150:28-35

Brown JH, Gillooly JF, Allen AP, Savage VM, West GB (2004) Toward a metabolic theory of ecology. Ecology 85:1771-1789

Brown JH, Marquet PA, Taper ML (1993) Evolution of body size - Consequences of an energetic definition of fitness. Am Nat 142:573-584

Carpenter SR (1990) Large-scale perturbations - opportunities for innovation. Ecology $71: 2038-2043$

Coates DJ (2000) Defining conservation units in a rich and fragmented flora: implications for the management of genetic resources and evolutionary processes in south-west Australian plants. Aust J Bot 48:329-339

Cohen JE, Jonsson T, Carpenter SR (2003) Ecological community description using the food web, species abundance, and body size. Proc Natl Acad Sci U S A 100:17811786

Dalerum F, Angerbjorn A (2005) Resolving temporal variation in vertebrate diets using naturally occurring stable isotopes. Oecologia 144:647-658 
Durell S (2000) Individual feeding specialisation in shorebirds: population consequences and conservation implications. Biol Rev 75:503-518

Egli DP, Babcock RC (2004) Ultrasonic tracking reveals multiple behavioural modes of snapper (Pagrus auratus) in a temperate no-take marine reserve. ICES J Mar Sci 61:1137-1143

Frederich B, Lehanse O, Vandewalle P, Lepoint G (2010) Trophic Niche Width, Shift, and Specialization of Dascyllus aruanus in Toliara Lagoon, Madagascar. Copeia:218-226

Greenwood JJD, Gregory RD, Harris S, Morris PA, Yalden DW (1996) Relations between abundance, body size and species number in British birds and mammals. Philos Trans R Soc Lond B 351:265-278

Hildrew AG, Raffaeli DG, Edmonds-Brown R (2007) Body Size: The structure and function of aquatic ecosystems, Vol. Cambridge University Press, Cambridge

Hughes AR, Williams SL, Duarte CM, Heck KL, Waycott M (2009) Associations of concern: declining seagrasses and threatened dependent species. Front Ecol Environ 7:242-246

Jennings S, Greenstreet SPR, Hill L, Piet GJ, Pinnegar JK, Warr KJ (2002) Long-term trends in the trophic structure of the North Sea fish community: evidence from stable-isotope analysis, size-spectra and community metrics. Mar Biol 141:10851097

Kobler A, Klefoth T, Mehner T, Arlinghaus R (2009) Coexistence of behavioural types in an aquatic top predator: a response to resource limitation? Oecologia 161:837-847

Marquet PA, Navarrete SA, Castilla JC (1990) Scaling population-density to body size in rocky intertidal communities. Science 250:1125-1127

McCann KS (2000) The diversity-stability debate. Nature 405:228-233

Moritz C (1994) Application of mitochondrial-DNA analysis in conservation - a critical review. Mol Ecol 3:401-411

National-Wetlands-Committee (2007) The Bahamas National Wetlands Policy. In. Bahamas Environment Science and Technology Commission, Nassau 
Orth RJ, Carruthers TJB, Dennison WC, Duarte CM, Fourqurean JW, Heck KL, Hughes AR, Kendrick GA, Kenworthy WJ, Olyarnik S, Short FT, Waycott M, Williams SL (2006) A global crisis for seagrass ecosystems. Bioscience 56:987-996

Persson L (1988) Asymmetries in competitive and predatory interactions in fish populations. In: Ebenman B, Persson L (eds) Size-structured populations: ecology and evolution. Springer-Verlag, Berlin, Germany

Peters RH (1983) The ecological implications of body size, Vol. Cambridge University Press, Cambridge

Rudolf VHW (2006) The influence of size-specific indirect interactions in predator-prey systems. Ecology 87:362-371

Svanbäck R, Eklov P, Fransson R, Holmgren K (2008) Intraspecific competition drives multiple species resource polymorphism in fish communities. Oikos 117:114-124

Svanbäck R, Persson L (2004) Individual diet specialization, niche width and population dynamics: implications for trophic polymorphisms. J Anim Ecol 73:973-982

Svanbäck R, Persson L (2009) Population Density Fluctuations Change the Selection Gradient in Eurasian Perch. Am Nat 173:507-516

Werner EE, Gilliam JF (1984) The ontogenetic niche and species interactions in size structured populations. Annu Rev Ecol Syst 15:393-425

Werner EE, Hall DJ (1988) Ontogenetic habitat shifts in bluegill - the foraging rate predation risk trade-off. Ecology 69:1352-1366

Werner EE, Relyea RA, Yurewicz KL, Skelly DK, Davis CJ (2009) Comparative landscape dynamics of two anuran species: climate-driven interaction of local and regional processes. Ecol Monogr 79:503-521 
VITA

\section{CAROLINE MANYA HAMMERSCHLAG-PEYER}

March 9, 1980

2006
Born, Wolhusen, Switzerland

Diploma in Biology

University of Lausanne,

Lausanne, Switzerland

\section{PUBLICATIONS AND PRESENTATIONS}

Hammerschlag-Peyer, C.M., Allgeier, J.E., and C.A. Layman. In Review. Predator effects on faunal community composition in shallow seagrass beds of The Bahamas. Marine Ecology Progress Series

Hammerschlag-Peyer, C.M., and Layman, C.A. 2010. Intraspecific variation in habitat utilization of two abundant coastal fish species. Biological Research, Florida International University, Graduate Student Symposium

Hammerschlag-Peyer, C.M., and Layman, C.A. 2010. Intraspecific variation in habitat utilization of two abundant coastal fish species. American Society of Ichthyologists and Herpetologists Annual Meeting, Providence, Rhode Island

Hammerschlag-Peyer, C.M. and C.A. Layman. 2010. Intrapopulation variation in habitat use by two abundant coastal fish species. Marine Ecology Progress Series 415: 211-220

Hammerschlag-Peyer, C.M. and C.A. Layman. In Revision. Mechanisms driving resource use variation in an abundant coastal fish predator, Lutjanus apodus, in a Bahamian wetland system predator. Bulletin of Marine Science

Hammerschlag-Peyer, C.M., Yeager, L.A., Araujo, M.S. and C.A. Layman. 2011. A hypothesis-testing framework for studies to investigate ontogenetic niche shifts using stable isotope ratios. PLOS ONE 6: e27104

Layman, C.A., Araujo, M.S., Boucek, R., Hammerschlag-Peyer, C.M, Harrison, Jud, Z.R., Matich, P., Rosenblatt, A., Vaudo, J.J., Yeager, L.A., Post, D.M. and S. Bearhop. In Press. Applying Stable Isotopes to Examine Food Web Structure: An Overview of Analytical Tools. Biological Reviews

Layman, C.A., Quattrochi, J.P., Hammerschlag-Peyer, C.M., and Allgeier, J.E. 2007. Fragmentation Effect on Richness of Gray Snapper Prey. Biological Research, Florida International University, Graduate Student Symposium. 
Layman, C.A., Quattrochi, J. P., Peyer, C.M, and J.E. Allgeier. 2007. Niche width contraction in a dominant species following ecosystem fragmentation. Ecology Letters 10: 937-944.

Layman, C.A., Quattrochi, J.P., Peyer, C.M., and Allgeier, J.E. 2008. Niche width contraction in a dominant species following ecosystem fragmentation. GraduateMeeting of the Specialized Section 'Ecology' of the German Zoological Society, "The ecology of specialized individuals in populations" in Rees-Grietersbach, Germany

Peyer, C.M. 2006. Diploma. Université de Lausanne, Switzerland

Peyer, C.M., and Layman, C.A. 2008. The influence of body size on the ecology of generalist predators in coastal ecosystems. Biological Research, Florida International University, Proposal Defense Seminar 